PAPERS IN PHYSICAL OCEANOGRAPHY AND METEOROLOGY Published by

MASSACHUSETTS INSTITUTE OF TECHNOLOGY

AND

WOODS HOLE OCEANOGRAPHIC INSTITUTION

(In continuation of Massachusetts Institute of Technology Meteorological Papers)

VOL. IV, NO. 4

\title{
A STUDY OF THE CIRCULATION OF THE WESTERN NORTH ATLANTIC
}

\author{
BY \\ C. O'D. ISELIN \\ Contribution No. 108 from the Woods Hole Oceanographic Institution \\ CAMBRIDGE, MASSACHUSETTS \\ August, I936
}





\section{CONTENTS}

InTRODUCTION

Preliminary considerations . $4 . .4 .45$

Equipment and methods

Distribution of stations

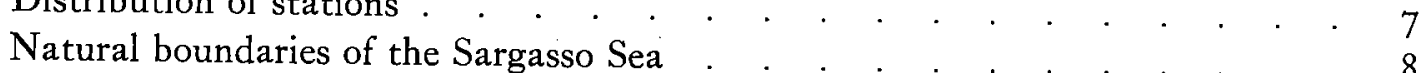

The Bermuda Triangle . . . . . . . . . . . . . .

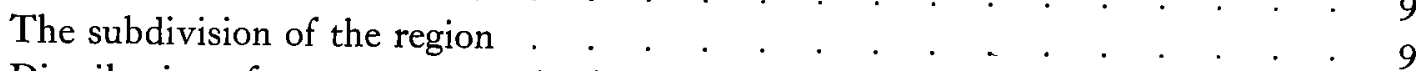

Distribution of temperature and salinity by the method of sections . . . . . . i3

Chesapeake Bay-Bermuda . . . . . . . . . . . . . . . . . . . . 13

Nova Scotia-Bermuda . . . . . . . . . . . . . . . . . . . . . . .

Variations of temperature and salinity with depth . . . . . . . . . . . . 26

Method . . . . . . . . . . . . . . . . . . . . . 26

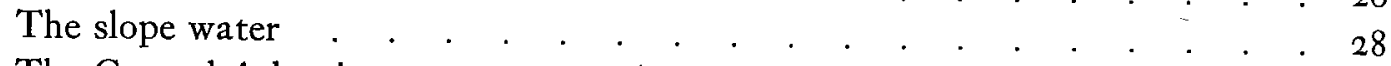

The Central Atlantic water . . . . . . . . . . . . . . . . . . . . .

Seasonal temperature cycle near the surface . . . . . . . . . . 34

Correlation between temperature and salinity . . . . . . . . . . . 34

Method

The slope water . . . . . . . . . . . . . 34

The Central Atlantic water

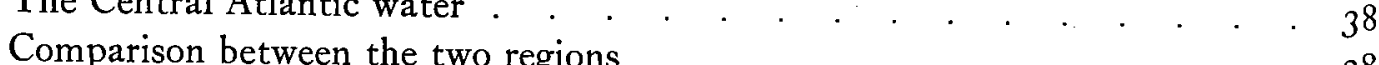

The deep water

Temperature

Salinity .

Density . . . . . . . . . . . 4 II

Other Athantis Sections

The location of the sections.

Mid-Atlantic sections

The North Atlantic Current

The Northern Equatorial Current

Antilles Current sections

Haiti-Bermuda.

Bermuda-Elbo Cay

Florida Current sections

Cape Canaveral

Jacksonville.

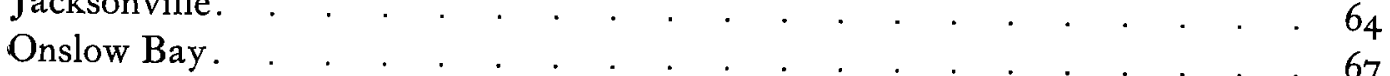

67 
The Depth of the $10^{\circ}$ Isotherm in the Western North Atlantic . . . . 69

The Gulf Stream System • . . . . . . . . . . . . . . . 72

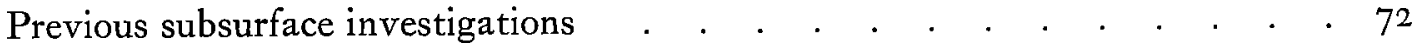

The three subdivisions of the Gulf Stream System . . . . . . . . . 73

The sources and character of the Gulf Stream System . . . . . . . . 75

The Sargasso Sea. . . . . . . . . . . . . . . . . . . $8 \mathrm{r}$

Its boundary . . . . . . . . . . . . . . . . . . . . . . $8 \mathrm{I}$

The surface movements in relation to the wind . . . . . . . . . . 82

The lateral movements at mid-depths . . . . . . . . . . . . .88

The internal mixing .

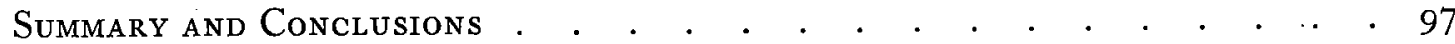

BibliographY . . . . . . . . . . . . . . . . . . . . 99 


\section{INTRODUCTION}

\section{Preliminary Considerations}

With the opening of the Woods Hole Oceanographic Institution in July I93I, there was inaugurated a program of investigations in the deep waters of the western North Atlantic for which there had long been a great need. In contrast to most deep-sea investigations, which have had to be planned as single expeditions, the Institution was able to initiate a general program which could be carried out gradually in order to take advantage of knowledge gained during the course of the work. Sufficient funds having been provided for the continuous operation of its research vessel "Atlantis," work could be planned for all seasons of the year.

Although these investigations have not been in progress for long and new data are continually being brought in by the "Atlantis," there are several reasons that make it seem desirable at this time to publish a preliminary report based on the completed temperature and salinity observations. In the first place, the problem of oceanic circulation is such that we cannot hope for a satisfactory solution for a long time to come. Moreover, it would be unwise to allow too much data to accumulate, because several years may pass before we can arrive at more important conclusions. Secondly, both the chemical and biological programs undertaken at the same time, require as a background the general scheme of circulation in the western North Atlantic as well as the distribution of temperature and salinity. It is, in fact, the necessity of taking into consideration the movements of the sea water which ties together the whole subject of oceanography. Therefore, it is the duty of those interested in ocean circulation to make available their findings as soon as possible for investigators of other problems in the same area.

The "Atlantis" temperature and salinity observations discussed in these pages were planned with two main purposes in view. The first objective was an intensive study of seasonal changes along sections running from the southwestern corner of Nova Scotia to Bermuda and from Bermuda to the mouth of Chesapeake Bay. ${ }^{1}$ This, of course, included an examination of fluctuations in the Gulf Stream, as well as of the variations in the water masses on each side of it. Second, there has been planned and partly carried out, a more general survey of the western North Atlantic, where accurate, deep stations have been sadly lacking.

\section{Equipment and Methods}

A detailed description of the "Atlantis" has not yet been published. Minor changes are still being made to render the hydrographic equipment more serviceable. At the same time, methods are being worked out whereby the technique of some of the work has been much improved. It will perhaps suffice to say now that the ship is equipped with an electric winch capable of easily handling 10,000 meters of 5/32 inch diameter wire. The cable in use goes under the trade description of "Roebling $7 \times 7$ Wire Center Galvanized Aircraft Cord," and has a breaking strain of 2600 pounds. The winch is fitted with an automatic device for guiding the wire on the drum, while a special boom and a system of strong springs enable those on board to judge how much strain is being placed on the wire and to regulate the hauling speed accordingly. The meter-wheel sheave is made of

${ }^{1}$ For convenience the area inclosed by these two sections is here referred to as the "Bermuda Triangle." 
special non-scoring metal, thus minimizing this usual source of error. The equipment has given great satisfaction and can be strongly recommended.

The Nansen type water-bottles have likewise caused very little trouble. Because, in general not more than eight of them have been sent down at one time, the majority of the stations here reported required two or more successive lowerings. Since a rack for the water-bottles stands in the deck laboratory, conveniently near the hydrographic winch, the temperatures can be recorded and the water-samples drawn off under cover.

The deep-sea thermometers in use on the "Atlantis" were made by Richter and Wiese, and a sufficient assortment with various temperature ranges has been on hand to secure reliable readings at all depths. Usually the water-bottles have held either one low range $\left(-3^{\circ}\right.$ to $8^{\circ}$ or $3^{\circ}$ to $\left.13^{\circ}\right)$ and one high range $\left(-2^{\circ}\right.$ to $25^{\circ}$ or $10^{\circ}$ to $\left.3^{\circ}\right)$ thermometer, or a protected thermometer has been paired with an unprotected. As a result, there are comparatively few cases where the corrected readings of two similar instruments can be compared. We have listed below the number of cases on five of the cruises when such a comparison is possible. Unfortunately these are mostly cases in which two long range $\left(-2^{\circ}\right.$ to $\left.25^{\circ}\right)$ instruments have been used in the same frame and since with these, even when a lens is used, the hundredth place has to be estimated, we can feel sure that the "Atlantis" corrected temperatures seldom have an error greater than $.03^{\circ}$, while the average error is undoubtedly considerably less.

\begin{tabular}{|c|c|c|c|c|c|c|}
\hline Cruise & $\# 6$ & \#10 & \#I I & $\# x_{4}$ & $\# 15$ & Total \\
\hline $\begin{array}{c}\text { Dif. in Reading } \\
0 \\
.01 \\
.02 \\
.03 \\
.04\end{array}$ & $\begin{array}{l}2 \\
6 \\
3 \\
1 \\
0\end{array}$ & $\begin{array}{l}7 \\
6 \\
\text { I } \\
\text { I } \\
0\end{array}$ & $\begin{array}{r}11 \\
22 \\
14 \\
4 \\
0\end{array}$ & $\begin{array}{r}\mathrm{I} 2 \\
4 \mathrm{I} \\
\mathrm{I} 8 \\
\mathrm{IO} \\
0\end{array}$ & $\begin{array}{r}25 \\
51 \\
13 \\
4 \\
1\end{array}$ & $\begin{array}{r}57 \\
\mathrm{I} 26 \\
49 \\
20 \\
\mathrm{I}\end{array}$ \\
\hline & & & & & & 253 \\
\hline
\end{tabular}

The salinity determinations have mainly been carried out in the laboratory at Woods Hole by the usual method of chlorine titrations, ${ }^{2}$ the readings being frequently checked against "standard water." Although every reasonable care has been taken, occasionally such a large number of samples have had to be analyzed in a rather short time, that, especially for the surface layers a third determination was not always made when the results of the first two titrations agreed within .02 parts per thousand in chlorinity. From this and other reasons, it is probable that the maximum error for the salinity determinations should be put at \pm .02 parts per thousand. ${ }^{3}$ This accuracy, although adequate for observations in the surface layers, was thought perhaps not good enough for a close examination of the North Atlantic deep water. Therefore, special care was taken with the deep samples from the more recent cruises. Apparently these results are not essentially different from the earlier observations (see page $4 \mathrm{r}$ ). In short, the salinity determinations of the "Atlantis" water samples are satisfactory for the present purposes.

\footnotetext{
2 The salinity values on Cruise I (stations I0OI-1053) were determined on shipboard by Dr. Franz Zorrell of the Deutsche Seewarte. We are extremely indebted to him for this and other most accurate work, as well as for his co-operation in securing instruments and giving helpful advice on the "Atlantis" " first voyage.

3 Unfortunately, occasional samples when titrated give results that are clearly in error by a large amount when comparison is made with neighboring observations. Usually it is possible to decide what caused such a mistake and the observation can be disregarded. There remain, however, always a few cases that are difficult to deal with, because the samples seem only slightly out of line. In all probability these result from carelessness at the time when the citrate bottles were being filled.
} 
The depths of the observations have been corrected through the use of unprotected thermometers. This method was introduced by Ruppin (I906) and Perlewitz (I 908), but has only recently become general practice. Usually there have been five such readings at each deep "Atlantis" station. For many of the stations the depths were worked out by the usual method (Wüst I932). ${ }^{4}$ Recently, however, a quicker and sufficiently accurate system was used for the stations of the Bermuda sections. Curves were constructed for each of the "Atlantis" unprotected thermometers, depth being plotted against $\Delta t$, the difference in reading between the protected and unprotected thermometers. These curves give the depth for any given value of $\Delta t$ at a glance and with the same accuracy as the usual method, provided the latitude range of the stations is not too great. Even the change in density experienced in crossing the Gulf Stream only causes an error in the calculated depth of approximately one meter in 3000 .

As has been shown repeatedly by Schumacher (1923) and others, the depths calculated from unprotected thermometer readings are extraordinarily accurate. The most important avoidable error lies in the factor of the individual thermometers. These are given on the certificates to the fifth decimal place but are perhaps apt to change after a few years. Several trials at sea under favorable conditions of calm weather and no current have shown that at the end of three years there was no appreciable change in the factors of the "Atlantis" unprotected thermometers.

The importance of the use of unprotected thermometers cannot be overemphasized. Until this method was perfected, the depths of all observations were liable to error. A number of cases have been noticed among the deeper "Atlantis" stations where the depths corrected only for the wire angle at the surface give values which the unprotected thermometers show to be in error by as much as 300 meters.

\section{Distribution of Stations}

Although to date the "Atlantis" has completed 54 cruises, much of the work has been in the shallow water areas between Nova Scotia and Cape Hatteras. Discussions of some of these coastal temperature and salinity observations have already appeared (Bigelow I933; Bigelow and Sears 1935; Rakestraw 1933) and the more extensive investigations from the Gulf of Maine are now in the process of being worked up. Since the present report is largely confined to deep-sea observations, the accompanying charts (Figs. I, 28, and 40 ) show the location of only about 200 stations from 6 "Atlantis" cruises. The observational data from the great majority of these stations have already been published (Cons. Perm. Int. I933a, I933b, I934), while the more recent work will shortly appear in succeeding volumes of the same publication.

In general, where the depth of the water allowed, at least 3000 meters of wire and 16 water-bottles have been lowered, but because of the wire angle, the corrected depths often fall far short of this. Occasionally the stations have extended deeper, for the aim has been to take enough deep readings to give an adequate picture of the bottom layers without unduly prolonging the stations. During cloudy weather, when running a section of closely spaced stations across a strong current, it is usually better to continue the observations no deeper than necessary, for with the delay of repeated lowerings the vessel may drift so badly out of position that the station becomes of doubtful value for the particular profile.

${ }^{4}$ In this recent paper Wüst gives a general review of the literature on this subject as well as an analysis of the accuracy of the method as used by the "Meteor" expedition. 
We might mention here also that at the time most of these "Atlantis" sections were run, the ship was not equipped with sonic sounding equipment, so that the deepest stations could not be extended with safety to as near the bottom as is desirable.

All observations from the eastern North Atlantic previous to I923 were summarized by Helland-Hansen and Nansen (I 926) and this report was later amplified with the publication of the "Michael Sars" data (Helland-Hansen I930). Therefore, the present discussion is in general confined to the deep-sea temperature and salinity conditions west of longitude $30^{\circ} \mathrm{W}$ and between latitude $50^{\circ} \mathrm{N}$ and the equator (excluding the region around the Grand Banks covered by the International Ice Patrol Service). Since the northwestern corner of the ocean has been well surveyed by recent expeditions (International Ice Observation I913-), and since the Gulf of Mexico and the Caribbean are now being examined under the joint auspices of the Woods Hole Oceanographic Institution and the Bingham Oceanographic Foundation, it should not be long before we have a relatively complete knowledge of the temperature and salinity distribution in the whole western North Atlantic ocean as well as in the neighboring seas and gulfs.

A very complete reference list of the available subsurface temperature and salinity observations from the North Atlantic has recently been published by Wüst (1935). Since, except in the case of the most modern work, unprotected thermometers were not used, the depths given for many of the early observations cannot be relied on and, therefore, for some purposes they are unsuitable for combining with the "Atlantis" surveys. However, in discussing the temperature-salinity correlation (p. 92), nearly all former observations become useful.

\section{Natural Boundaries of the Sargasso Sea}

The majority of the observations discussed in the succeeding pages lie in the central region of the North Atlantic. They fall, for the most part, in the relatively warm, saline, waters of the Sargasso Sea..$^{5}$ This term is a useful one in the oceanography of the North Atlantic, for the distribution of weed (Krümmel I89I) roughly maps a region which forms one unit in the makeup of the ocean. From both the biological and the physical points of view, within this large oval area, centering somewhere east of Bermuda, only small horizontal variations occur. Even the climatic conditions are monotonous, for the position of the Sargasso Sea roughly corresponds to that of the mid-Atlantic high pressure belt, or horse-latitudes. Above the depth of about 2000 meters the comparatively slow moving waters of this region form a huge oval core around the edge of which the swifter, warm water, surface circulation of the North Atlantic takes place. Evidence presented in this paper permits a more exact definition of the hydrographic limits of this area than has hitherto been possible.

The current system marks the boundaries of the Sargasso Sea even better than the distribution of the weed. ${ }^{6}$ Especially on the west and north, the Gulf Stream and its continuation as the Atlantic Current form a deep barrier across which little transfer seems to take place except near the surface. On the south and east the boundaries are not so sharp. Moreover, the Canaries Current and Northern Equatorial Current do not protect the mid-depths of the Sargasso Sea from outside influence. For, as we shall see later, these wind currents are probably not deep and some water from the Mediterranean

5 The terms "Central Atlantic water" and "Sargasso Sea water" will be used interchangeably.

${ }^{6} \mathrm{~A}$ recent paper Winge (I923) points out that the observed distribution of Sargassum is not quite as regular as Krümmel's chart would indicate. However, from a hydrographic standpoint it seems unnecessary to abandon the term Sargasso Sea in its generally accepted meaning. 
and from the South Atlantic is able to penetrate at mid-depths (800-1200 meters), to lose its identity slowly through turbulence in the central part of the Sargasso Sea.

A full understanding of the factors involved in the circulation of the waters of this Central Atlantic region will aid considerably in the solution of the general problem of oceanic circulation. Above all, it is the region where typical warm water conditions are continually manufactured near the surface, thus producing and maintaining a contrast in density with the colder, heavier northern seas.

The "Atlantis" observations from the northwestern Sargasso Sea will next be presented as the first step in this study.

\section{THE BERMUDA TRIANGLE}

\section{The Subdivision of the Region}

The months chosen for the "Atlantis" quarterly sections on the triangle, Nova Scotia-Bermuda-Chesapeake Bay, were February, May, August and November. To date, in accordance with this plan, only four sections have been completed on the line between Chesapeake Bay and Bermuda and two sections on the line between Nova Scotia and Bermuda (Fig. I). There are available also an incomplete line of stations (I I 25 to I I 30 ) on the southern profile, started in December I93I but broken off by the failure of the hydrographic winch drum, and two stations from February I933. The dates and station numbers of the various "Atlantis" cruises on these two sections are as follows:

CHESAPEAKE BAY-BERMUDA

Dec. 5-7, I93I-Stations I I 25-II30

Feb. I I-I 8, I932-Stations I I 3I-I I 45

Apr. 17-23, 1932-Stations 1220-1235

Aug. 28-Sept. 3, I932-Stations I360, I361, I363, I365-1377

Nov. 30-Dec. 5, I 932-Stations I4I7-I 43 I

Feb. 7-8, 1933-Stations $1_{4} 62$ and $1_{4} 63$

NOVA SCOTIA-BERMUDA

Nov. 2I-26, I 93 I-Stations I IO7-I I 20 and I I 22-II 24

Aug. I4-20, I932-Stations $1339-1345$ and $1347^{-1} 355$

For a modern comparison with the "Atlantis" Bermuda to Chesapeake Bay observations, we have the "Dana" profile (Jacobsen I929), from May I4-I6, I922. Also, there exists a shallower section (Iselin 1930) by the schooner "Chance" July I4-22, I927 consisting of $2 \mathrm{I}$ stations along the same track as those of the "Atlantis."

As far as the salinity conditions near the surface are concerned, both the northern and the southern profiles constructed from the "Atlantis" observations cross four distinctive bands of water. Proceeding from the land outward, there is first the relatively fresh $(<35 \%)$ coastal water covering the continental shelf, and extending often near the surface to a point somewhat beyond the two hundred meter curve. Then, between the continental slope and the Gulf Stream lies a band of water having intermediate values in salinity $(35-36 \%$ in the surface layers and relatively low temperature at middepths, while beyond the Gulf Stream true Central Atlantic water of higher salinity $(>36 \%)$ is found. To aid in the discussion, the area of the Bermuda triangle can, therefore, conveniently be broken up both horizontally and vertically into smaller divi- 


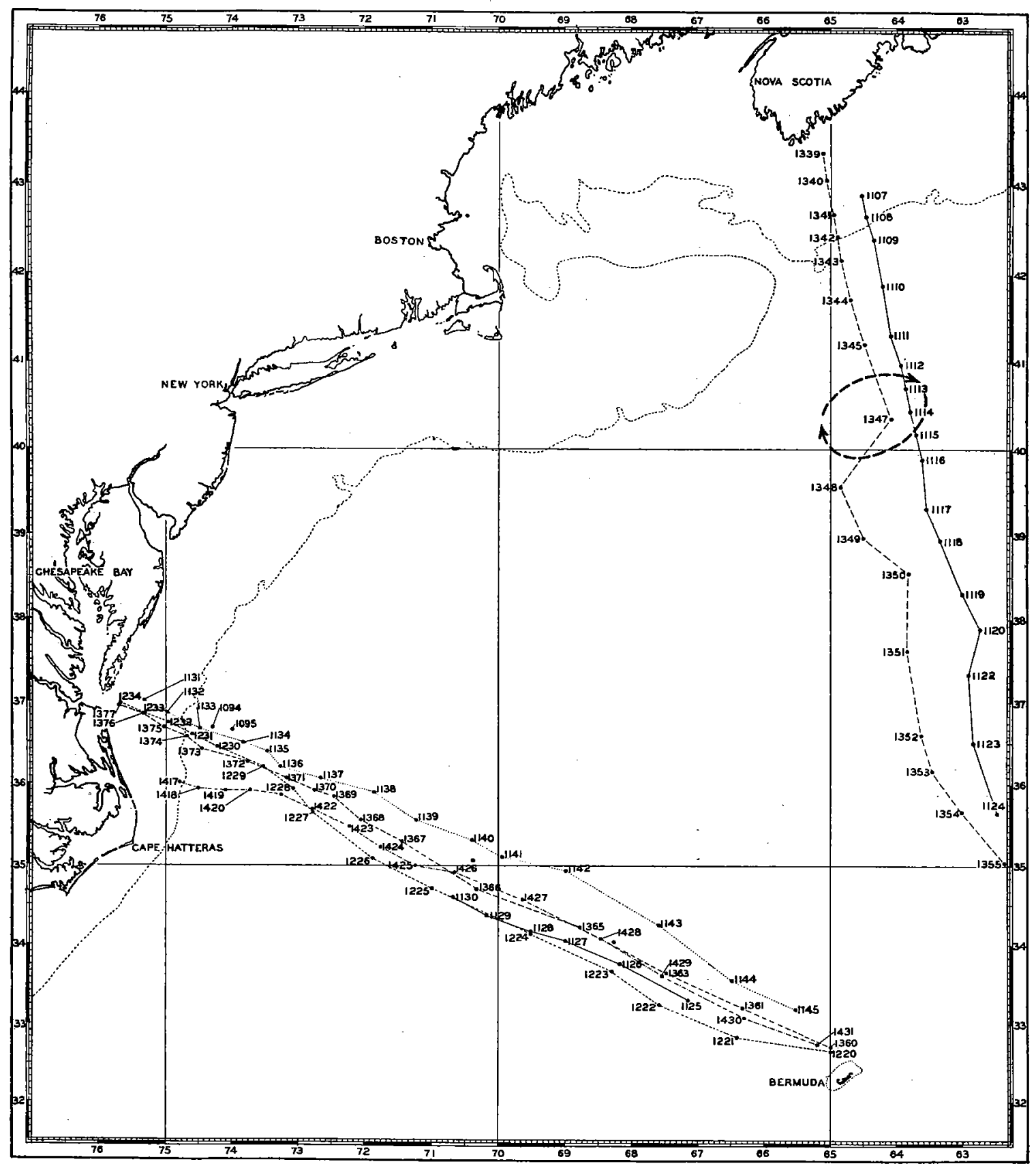

Fig. r.-Locations of stations constituting the "Atlantis" sections, Chesapeake Bay-Bermuda and Nova Scotia-Bermuda. The eddy (shown by arrows) just south of the Nova Scotian continental shelf is discussed on page 24 . 
sions which are shown diagrammatically in Fig. 2. In this paper any discussion of the coastal water is omitted, because this area has been recently treated in detail (Bigelow 1915, 1917, I922, 1927, I933; Bigelow and Sears 1935; Sandström I919; Parr 1933).

The band of water between the edge of the continental shelf and the Gulf Stream averages about 60 miles wide on the Chesapeake Bay section (where the stations cross it somewhat obliquely) and about I70 miles wide off Nova Scotia. It is characterized by being the mixing zone, in the upper layers (down to 200 meters), for coastal water, which has escaped from over the continental shelf, and Gulf Stream water, which has been carried west of the current's path. At mid-depths, the relatively cold waters of this inter-

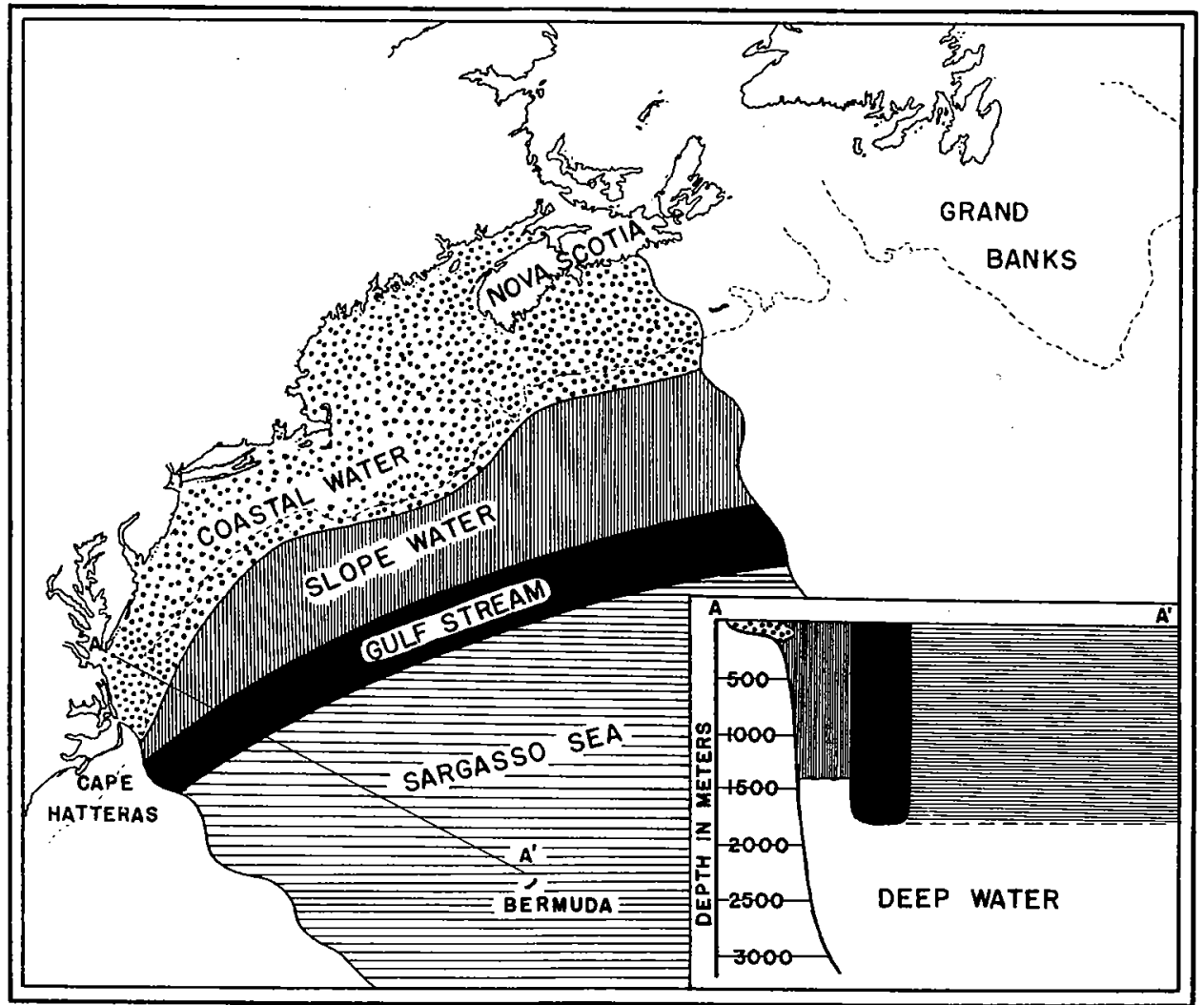

FIG. 2.-Diagrammatic representation of the subdivisions of the triangular area, Nova ScotiaBermuda-Chesapeake Bay.

mediate belt are very consistent in character but do not quite resemble the Central Atlantic water in temperature-salinity ratio (page 38 ).

This zone of water, with easily recognized characteristics, appears to be continuous from Cape Hatteras to the Grand Banks. A detailed study of this band of water between the swift current and the edge of the continental shelf will undoubtedly yield illuminating clues concerning the hydrodynamics of the Gulf Stream's flow. It is clearly one of the key bodies of water in the North Atlantic and, therefore, worthy of a name. Huntsman (I924) while writing of the waters just beyond the Ioo fathom curve off the coast of Nova Scotia has used the term "slope water." Bigelow (1927, pages $84^{2-845}$ ) has also 
used the same designation for the waters just outside Georges Bank. From the "Atlantis" sections it is apparent that the temperature and salinity conditions along the continental slope are continued almost unchanged off shore to the inner edge of the swift flowing part of Gulf Stream and along shore for a great distance. Therefore, the expression "slope water" may be expanded to include the whole mass of water northeastward from Cape Hatteras, between the coastal band and the Gulf Stream, and down to the depth (about $900 \mathrm{~m}$.) where it becomes indistinguishable from North Atlantic deep water.

The usefulness of the term "slope water" is not lessened by the fact that the distribution of temperature and salinity in this region is extremely variable in the superficial layers. Nor are the water layers at mid-depths free from gradient for at several points strong eddies frequently develop. In fact, because of the horizontal mixing which must always occur along the edge of a swift current such as the Gulf Stream, and also because of the variable winds of these latitudes, it is surprising that the slope water band remains as distinct as it now appears to be. Though future work off the eastern part of the Nova Scotian continental shelf may show that this sector of the slope water is somewhat different from the part between Cape Hatteras and Cape Sable, and for which we now have adequate data, it is probable that some general term will always be needed to designate the whole band of deep, relatively still water northwest of the Gulf Stream from Cape Hatteras northeastward to the Grand Banks.

The transition belt between the slope water and the Central Atlantic water along this sector is occupied by the northeasterly flowing Gulf Stream. ${ }^{7}$ To avoid any confusion we must state here that our use of this term is not restricted to the surface aspect of the current. The name "Gulf Stream" will designate the whole of the northeasterly flowing current between Cape Hatteras and the Grand Banks. In other words, the relatively cold deep layers of the current are included as well as the warm surface film.

The average width of the band of swift current (having velocities at the surface greater than $10 \mathrm{~cm}$. per sec.) off Chesapeake Bay is shown by the "Atlantis" sections to be about I30 miles. As thus defined the available observations indicate that the Gulf Stream averages only slightly wider off Nova Scotia. Not only is this band of current narrower than is generally supposed, but as we shall see, its effect can be traced to very great depths (I 800 meters). Since the Gulf Stream is the transition between the relatively cold slope water and the warmer Central Atlantic water, it follows, as has been brought out by Wüst (1930), that in general no part of the current will be warmer than the water at the same depth in the Sargasso Sea. Only at the surface is this rule broken, where a shallow band shows temperatures slightly higher than at corresponding depths in the much less swiftly moving waters on either side. These warmest temperatures near the surface over the current are always found wherever the movement has a northerly component. They represent warm surface water brought from lower latitudes. It is this belt of warmest water, to be seen in all sections where the Gulf Stream is flowing northward, which is the only apparent justification for the incorrect popular belief that the current resembles a warm river flowing through colder seas. The fact is, that by far the greatest part of the northeasterly moving water is relatively cold, while even the southeastern side of the current (except at the surface) is not quite as warm as the water at corresponding depths in the Sargasso Sea.

Running off shore from the Gulf Stream, the sections penetrate one edge of the great

\footnotetext{
${ }^{7}$ For a full definition of this term see page 73 .
} 
core of Central Atlantic water (Sargasso Sea). They can be used to study the seasonal variation, not only between the Gulf Stream and Bermuda, but over a much wider field, because of the uniformity of the waters and of the climatic conditions over much of the great area of the Sargasso Sea.

\section{Distribution of Temperature and Salinity by the Method of Sections}

CHESAPEAKE BAY-BERMUDA

The reader is referred to the temperature and salinity profiles given on the succeeding pages, because it is difficult to describe briefly in writing data which can be clearly represented on cross-section paper. These diagrams are constructed on such a scale that

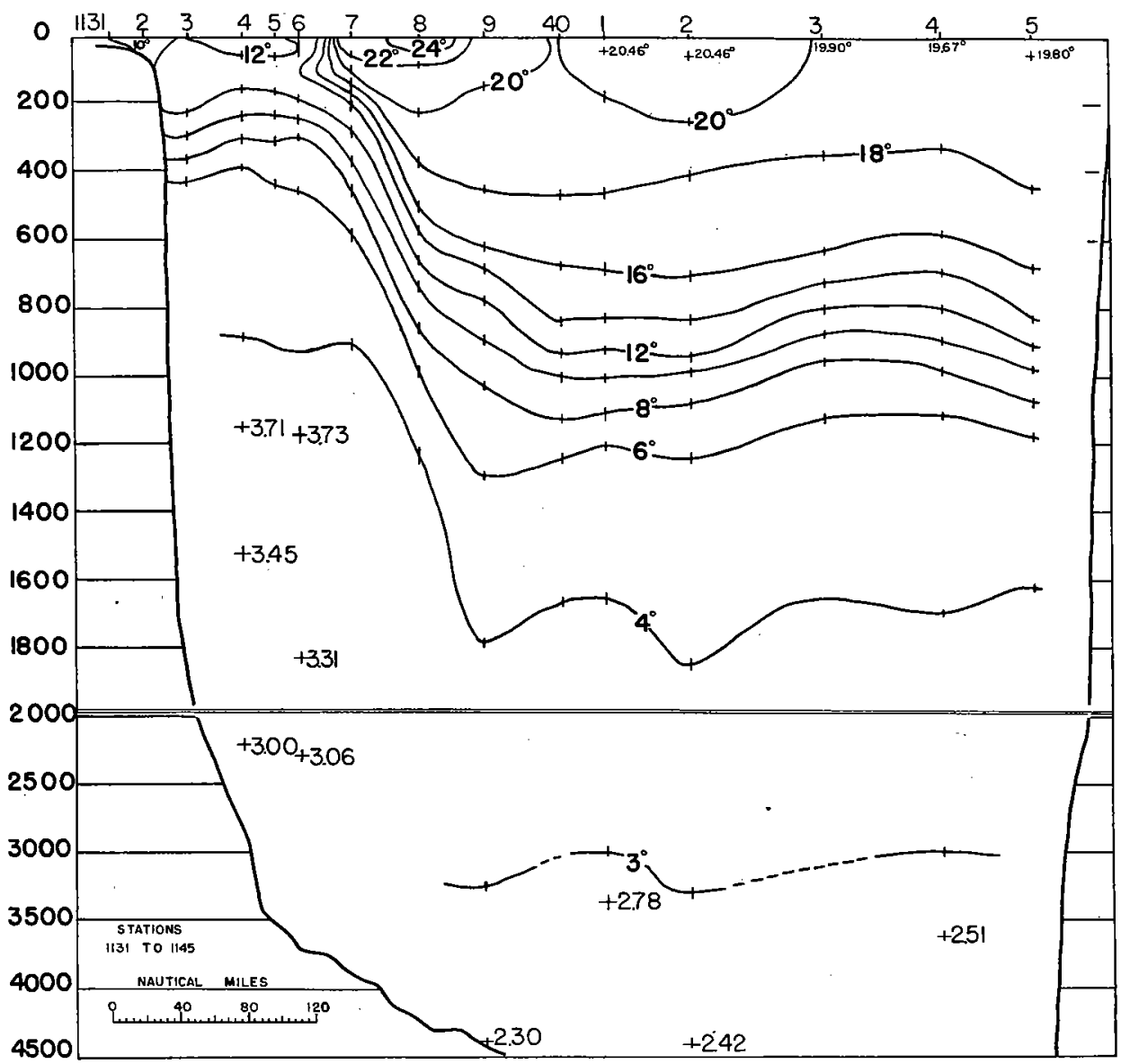

Fig. 3.-Temperature section, Chesapeake Bay-Bermuda, Feb. I I-I8, I932.

between the depths of 0 and 2000 meters, a distance of I nautical mile in a lateral direction is equal to 5 meters vertically (a distortion of $\mathrm{I}: 370$ ). In order to represent the conditions near the surface clearly, and still not exaggerate the profile beyond all recognition, the depth scale has been broken at 2000 meters. A double horizontal line across each profile draws attention to this change, and below it I nautical mile horizontally equals $\mathrm{I} 2.5$ meters in depth, so that the distortion is there reduced to $I: 148$. 
The profiles make no allowance for the fact that owing to stress of weather and currents, the stations did not fall always along a straight line. The actual distances between' stations have been used in constructing the sections and can be found from the scale given on each profile. The values for enough of the deeper observations are shown to indicate the general conditions in the depth zones where vertical changes are so small that no isolines appear. Small vertical dashes mark the points where the stations cut the isolines.

The first complete "Atlantis" section on the line between Chesapeake Bay and Bermuda was made February I I-I 8, I932. Although this profile is representative of the winter months, the surface waters were probably still in the process of being chilled, for the coldest period does not come until about a month later (see page 35 ).

Considering first the distribution of temperature (Fig. 3) near the surface, the most noticeable feature is the characteristic triple banding of the profile, the relatively cold $\left(\mathrm{I} 2^{\circ}\right)$ slope water being more sharply set off from the warm $\left(>22^{\circ}\right)$, superficial Gulf Stream waters than the latter are from the deeper (down to 400 meters), well stirred mass of Central Atlantic water to the eastward. As stated above, relatively warm water is always found over the swift part of the Gulf Stream ${ }^{8}$ wherever the current has a northerly component.

This threefold thermal diversion of the surface layer is also clearly mirrored in the salinity section (Fig. 4), but the isohalines of the slope water band (above 200 meters) show that the conditions there are more complex than could have been learned from temperature observations alone. Since the surface layer west of the Gulf Stream is a mixing zone for coastal and tropical waters, some such intermingling of fresh and saline masses is usually observed, but in this example the layer occupied by coastal water $(<35.0 \%)$ is somewhat deeper than on other "Atlantis" profiles. This can probably be accounted for by the westerly gales which in winter must often blow coastal water offshore, ${ }^{9}$ thus diluting to a greater depth than at other seasons the surface layer of the slope water, the vertical stability of which is at this time much reduced by winter cooling. However, such conditions are not necessarily persistent, for at any time, as has been shown by Church (I932a), warm tropical water from the Gulf Stream may also invade the surface of the slope water band to cause a sharp increase in salinity.

The fact that the superficial salinities of the Gulf Stream, though much higher than in the slope water zone, are somewhat lower than those found in the Sargasso water will be shown later to result from contributions to the stream received from the Caribbean and the Antilles Current. Also resulting from the same cause are the relatively high readings between the depths of 80 and 400 meters, which along the axis of the current show slightly higher values than at the same depths to the eastward. Both the fresh superficial waters and the very saline wedge-shaped layer just beneath are characteristic features of the Florida Current (see page 6I).

Eastward of the current, the salinity profile shows a thick superficial layer (down to

${ }^{8}$ It will be shown later that the position of the current corresponds almost exactly to the band occupied by the slanting isolines at mid-depths while the swiftest flow occurs in the narrow zone of greatest slope (page 43). Although the changes of temperature and salinity with depth exert opposite influences on the distribution of density, and therefore might seem to counteract each other, this is not the case, for it is the former which is much the most important in the open ocean. In other words, the colder waters will always be heavier in spite of the fact that they are less saline.

${ }^{9}$ The coastal current, which ordinarily is found following the edge of the continental shelf southward, does not pass Cape Hatteras (Bigelow 1934). Therefore, the conditions off Chesapeake Bay are especially favorable for the offshore movement of coastal water. 
400 meters) where the salinity varies only slightly $(36.50-36.65 \%)$. Such a deep well stirred surface layer is only found in the Sargasso Sea during the winter months.

Below the wind stirred surface zone, the same threefold division of the water (slope water, Gulf Stream and Sargasso Sea) can be traced tovery great depths. The temperature profile demonstrates that west of the Gulf Stream the main thermocline ${ }^{10}$ occupied the

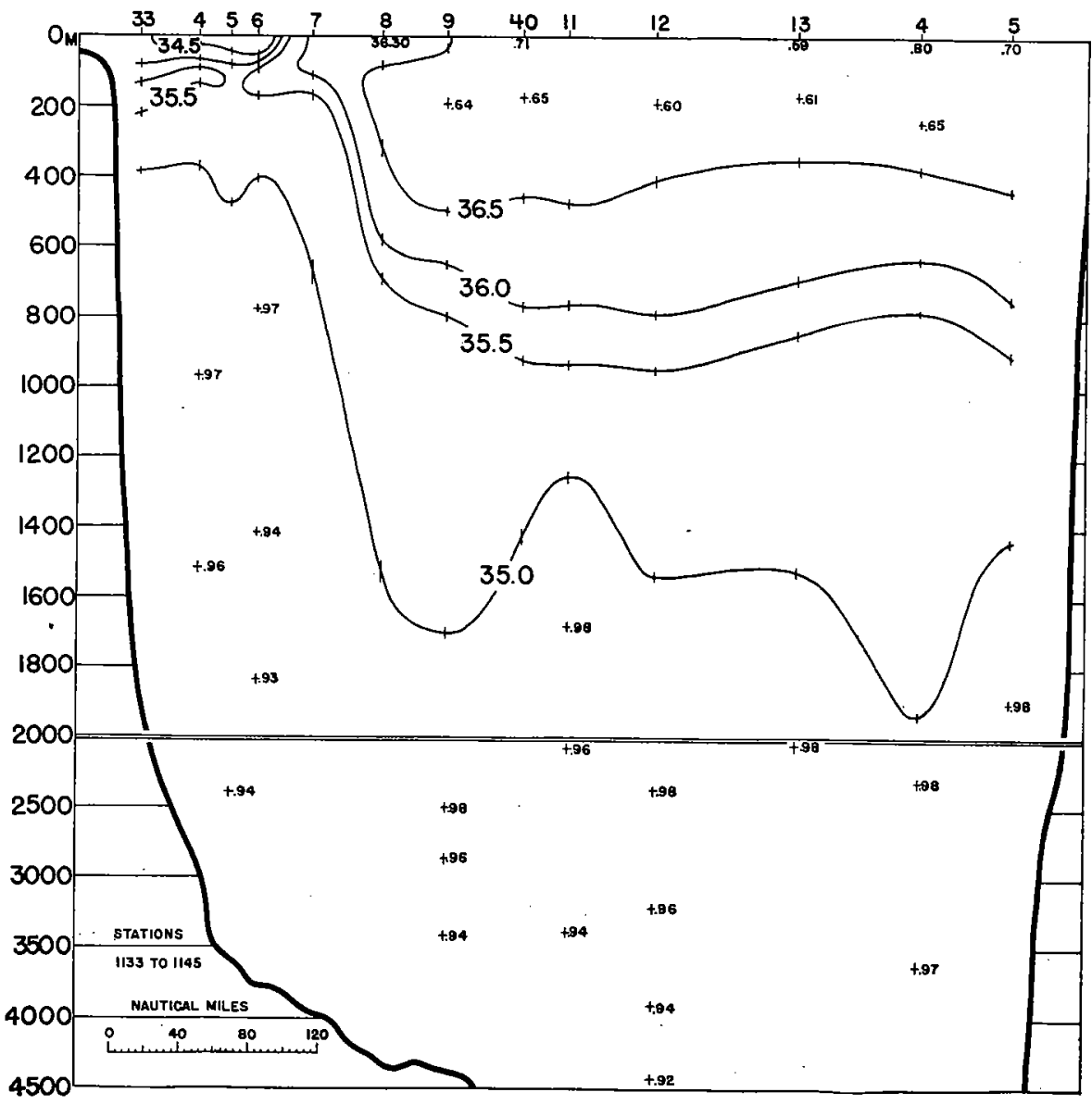

FIg. 4.-Salinity section, Chesapeake Bay-Bermuda, Feb. I1 1 -18, 1932.

layer between 200 and 400 meters. On the other hand, in the Sargasso Sea the corresponding isotherms were found considerably deeper (between 600 and I 200 meters) and also more widely spaced, showing that the thermocline was less abrupt there.

The distribution of salinity at mid-depths on this profile closely parallels the thermal trends; indeed this is always the case in both the slope water and in the western Sargasso Sea. Especially notable is the correspondence in depth between the $6^{\circ}$ isotherm and the isohaline of $35 \%$ which roughly mark the lower limit of the thermocline layer across the profile. It can be seen, however, that $6^{\circ}$ water in the Sargasso Sea has a slightly higher salinity than in the slope water band. East of the Gulf Stream, the more or less wavelike trends of the deeper isotherms can be largely attributed to the fact that below the

${ }^{10}$ The layer having the most rapid temperature change with depth. For a fuller discussion of this zone see page $3 \mathrm{I}$. 
thermocline the changes with depth become so slight that it is difficult to be sure of the exact depth of a scaled value of temperature. The depth of the $35 \%$ isohaline is even more subject to inaccuracy, because the probable error in the determinations $( \pm .02)$ is enough to make a large depth discrepancy along this particular part of the station curves. But, even after allowance has been made for these sources of inaccuracy, there are

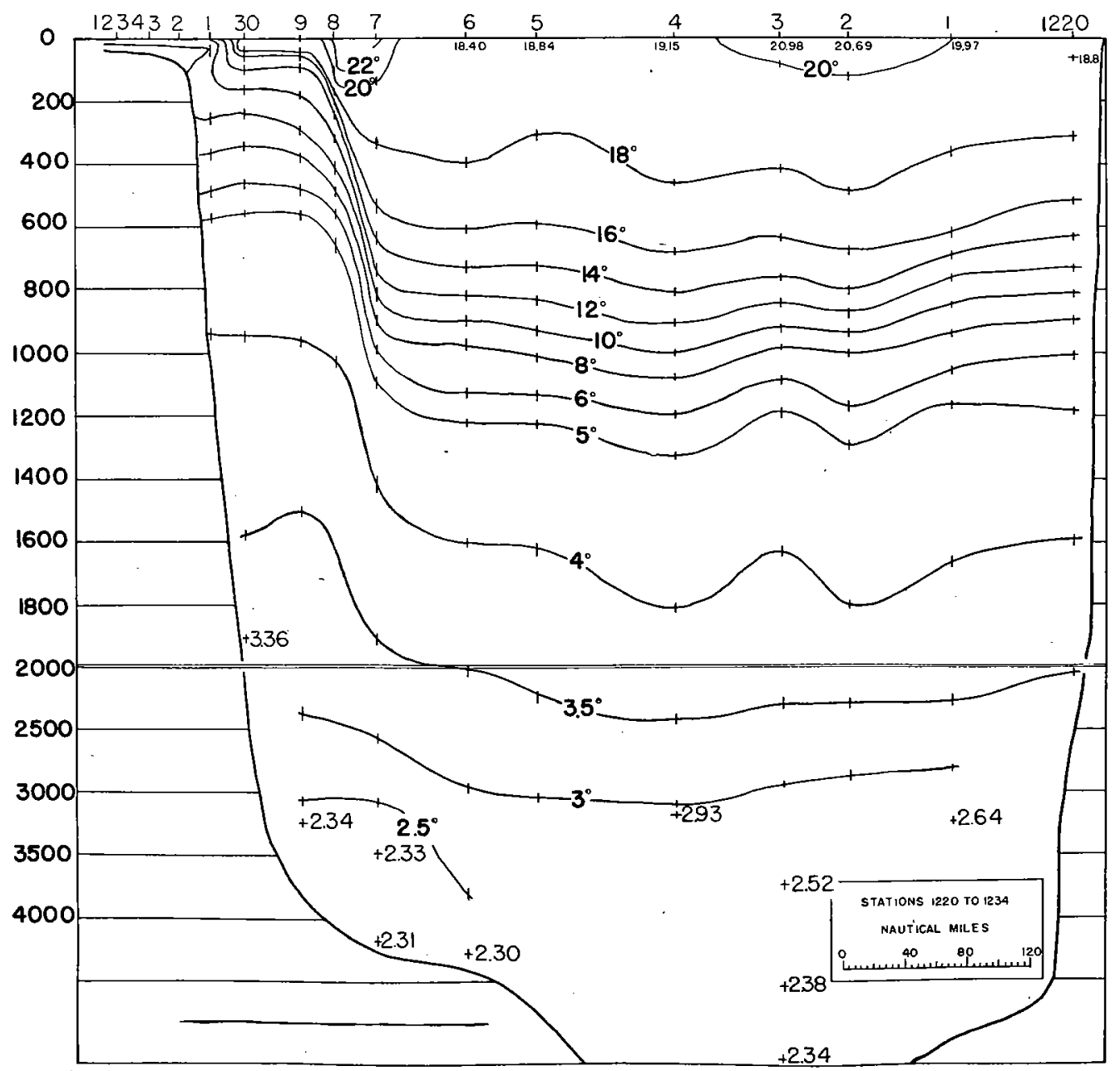

Fig. 5.-Temperature section, Chesapeake Bay-Bermuda, April I7-23, 1932.

still other factors which occasionally disturb the normal, nearly horizontal arrangement of the water layers at mid-depths in the Sargasso Sea (page 38 ).

In connection with the distribution of temperature and salinity at mid-depths, we should note also that about Ioo miles west of Bermuda the thermocline layer is slightly higher than in the region roughly half way between the island and the Gulf Stream. Some such upward slope of the isolines at mid-depths in the neighbourhood of Bermuda is always found and will be discussed in more detail later (page 70 ).

Below the isotherm of $4^{\circ}$ the temperature decreases only very gradually with depth, 
but even in the deepest layers there can be found some differences in the depth of the isolines on the two sides of the Gulf Stream.

Slightly more than two months later (April I7-23) when this section was repeated, the axis of the Gulf Stream, as shown by the slope of the isolines (Figs. 5 and 6), had moved about 36 miles inshore and the swift part of the current (where the slope was

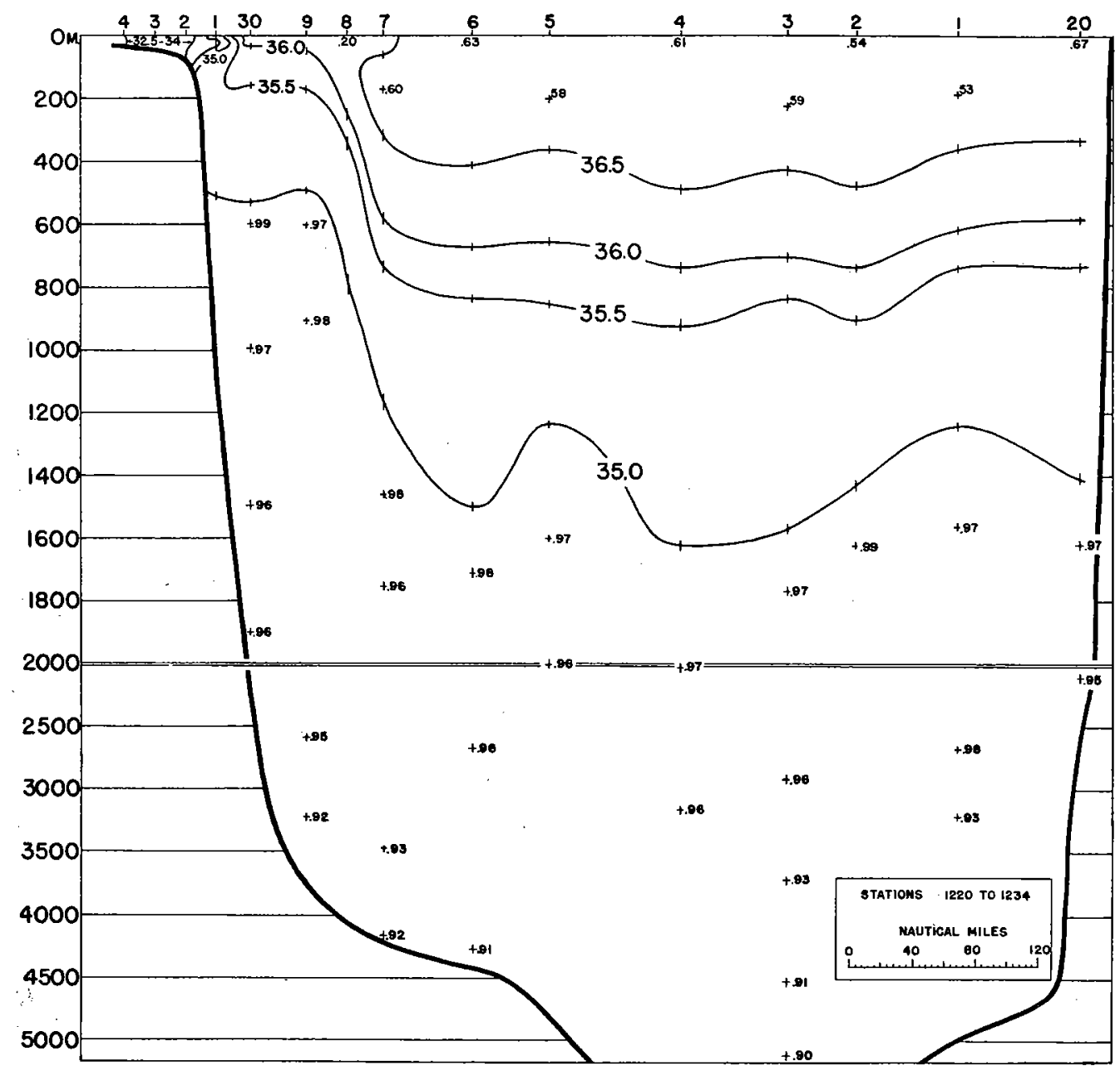

FIG. 6.-Salinity section, Chesapeake Bay-Bermuda, April I7-23, $193^{2}$.

most abrupt) was apparently narrower than it had been in February. As a result, the band of warmest water at the surface of the current, which reflects more southerly temperatures, was also much narrower in April.

In the slope water band the only important change in temperature and salinity values occurred near the surface where the readings had risen from $12^{\circ}$ in February to $18^{\circ}$ in April, and the layer of low salinity had so contracted that it extended at the surface only a few miles beyond the edge of the continental shelf. On the other hand, no significant change had yet taken place in the deep nearly homogeneous surface layer of the western 
Sargasso Sea. In other words, the seasonal thermal advance, though well started in the slope water band, had not yet progressed off shore to warm the surface of the Sargasso Sea ared.

Furthermore, the sections show that no significant change had taken place from February to April in the depths of the isolines constituting the thermocline layer. A more delicate method of studying this matter is discussed later (pages 26-34).

The third section on the line between Chesapeake Bay and Bermuda was run late in August of the same year, by which time surface warming had probably reached a maxi-

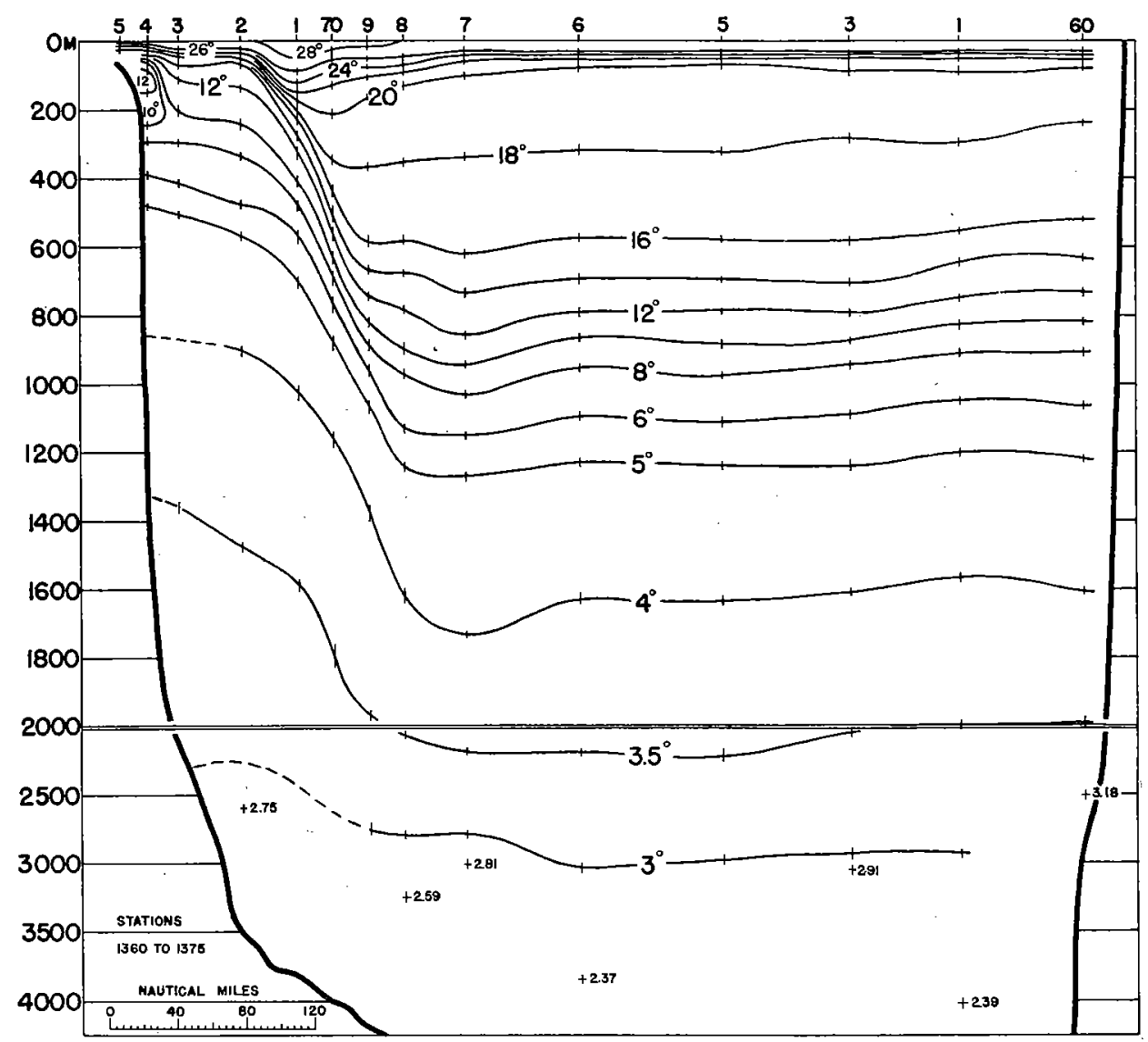

FIG. 7.-Temperature section, Chesapeake Bay-Bermuda, Aug. 28-Sept. 3, I932.

mum. Owing to the fact that no heavy weather was experienced during this cruise, and also owing to the increased accuracy of the navigation due to less cloudy weather, these "Atlantis" observations present a particularly reliable picture of the normal mid-summer distribution of temperature and salinity.

The profiles (Figs. 7 and 8) show at first glance that the axis of the Gulf Stream was still at about the same distance from the continental shelf, but that the band of swift current had once more expanded in breadth, as made evident by the more gradual slope of the isolines across its path.

More striking is the strong secondary thermocline which had developed between the 
depths of 20 and 80 meters in both the slope water and in the Central Atlantic water. In the former the stability thus produced was great enough to prevent the coastal water $(34-33.6 \%$ ) seen at the surface (Fig. 7) from mixing downward to as great a depth as in the February profile (Fig. 3). Passing under the warmest water carried northward by the Gulf Stream, this secondary thermocline became less abrupt, probably as a result of the greater turbulence in the band of current. But east of this, the closely packed, nearly horizontal isotherms just beneath the surface show that the penetration of solar warming was constant across the western sector of the Sargasso Sea.

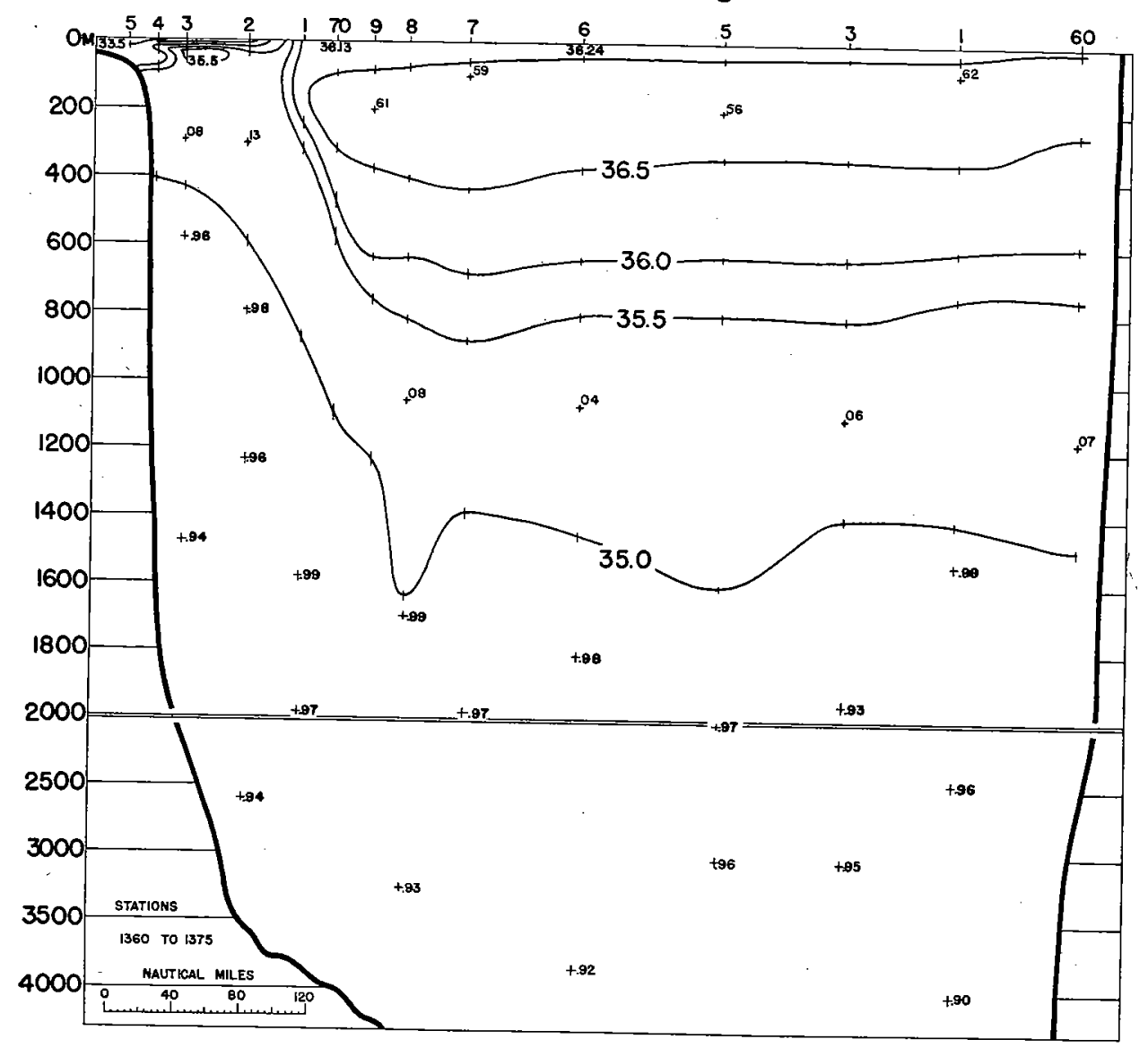

FIg. 8.-Salinity section, Chesapeake Bay-Bermuda, Aug. 28-Sept. 3, I932.

For comparison with "Atlantis" station 1366 (about half way between the Gulf Stream and Bermuda), we have from July I8, I927 in the same locality a station made by the schooner "Chance." The close agreement of these stations (Fig. 9), as far as temperature is concerned, is evidence that the "Atlantis" profile is probably a reliable picture of mid-summer conditions in the superficial layers of the western Sargasso Sea. The agreement in salinity though not as close, suggests that during the summer months as a rule the precipitation is probably greater than the evaporation, 11 for in both 1927

${ }^{11}$ The rainfall for Bermuda shows no significant increase during the summer months. However, it is probable that the evaporation in summer, because of the saturated and relatively stagnant conditions of the atmosphere just above the sea
surface, is much less effective than in winter. 
and 1933 the surface salinity was somewhat lower than that observed at other seasons or at depths between 50 and 400 meters in summer.

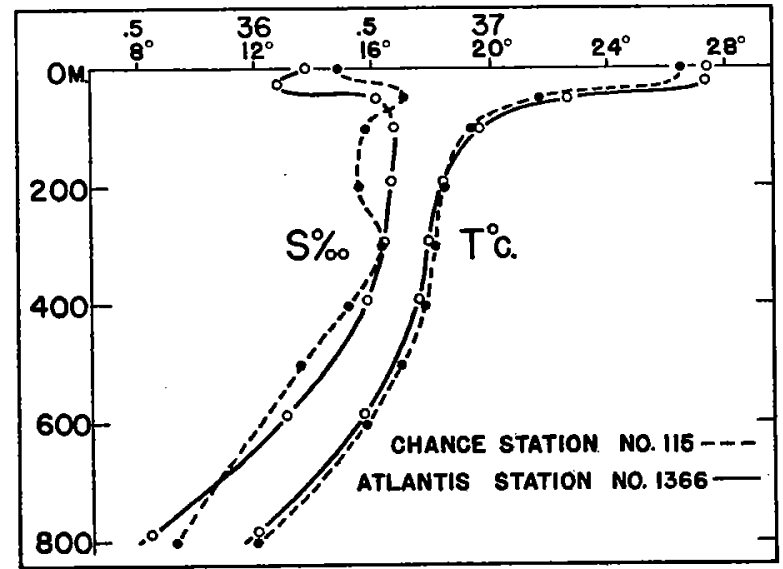

Fig. 9.-Comparison between "Chance" Station I I 5 ( $35^{\circ} 36^{\prime}$

N., $71^{\circ} 14^{\prime}$ W., July 18, 1927 ) and "Atlantis" Station I 366

$\left(34^{\circ} 42^{\prime}\right.$ N., $70^{\circ} 20^{\prime}$ W., Aug. 31,1932$)$ in the western Sargasso Sea.

East of the Gulf Stream the flatness of the water layers at mid-depths is particularly striking, but the same slight upward trend of both the isotherms and isohalines.on ap-

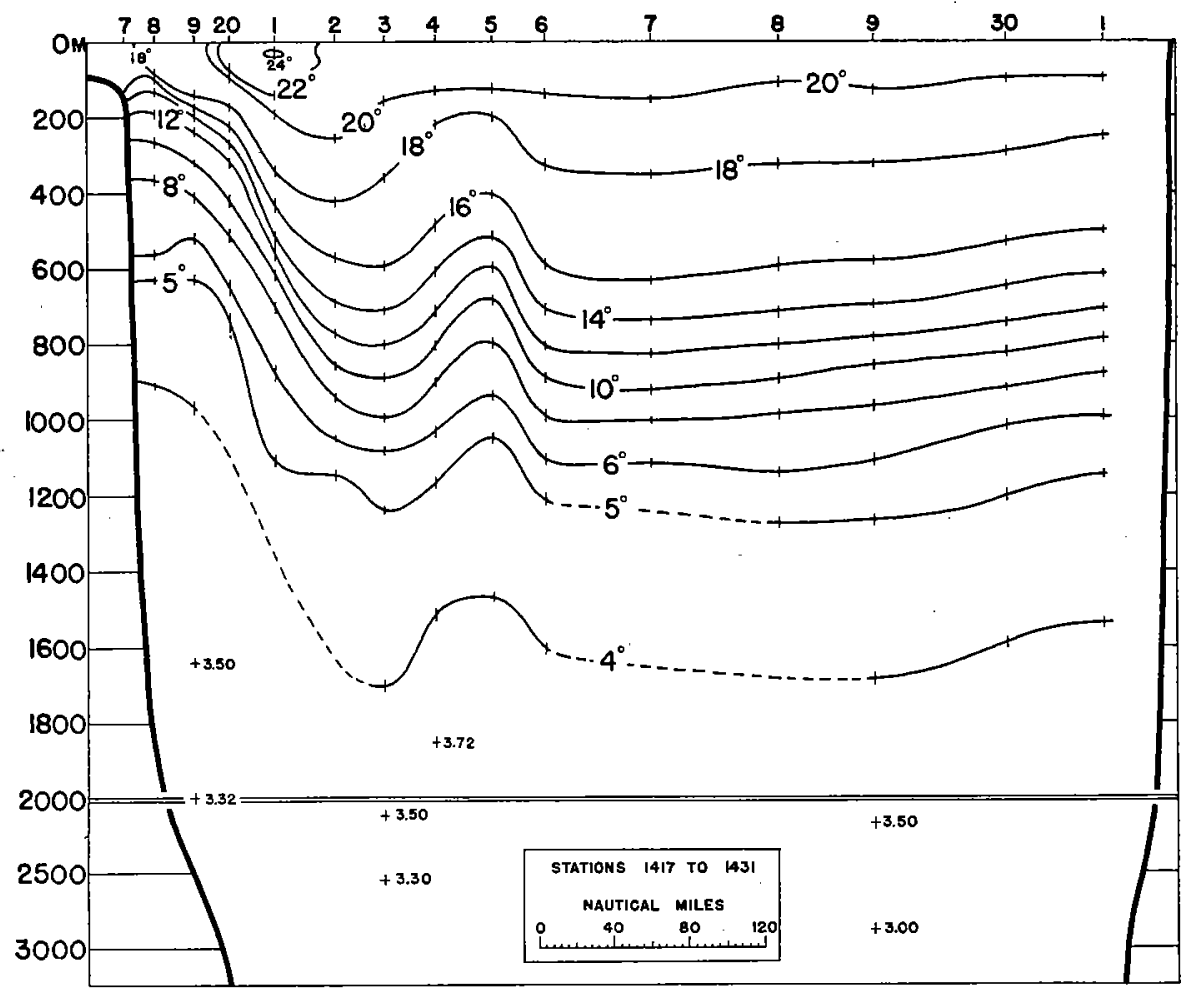

Fig. 10.-Temperature section, Chesapeake Bay-Bermuda, Nov. 30-Dec. 5, 1932. 
proaching Bermuda was again present, though to a less extent than in the February and April sections.

For an autumn profile we have the observations (Figs. IO and I I) from cruise $\mathrm{I}_{4}$ (Nov. 30-Dec. 6, 1932). The start of this section was delayed by a very severe northeast storm which lasted three days. As soon as the wind moderated, a station ( $\mathrm{r}_{4} \mathrm{I} 7$ ) was made at the edge of the continental shelf and the "Atlantis" then proceeded towards Bermuda much handicapped by a heavy and persistent swell. This storm is mentioned because it seems probable that to it we can attribute both the exceptional width of the Gulf Stream and the upswing of the isolines (stations $\mathrm{I}_{42} \mathrm{H}^{-\mathrm{I}} 426$ ) just east of it. A violent disturbance of this type, especially when its force is contrary to the flow of the current, may be expected to cause fluctuations in the velocity of the latter and thus to send out such a submarine

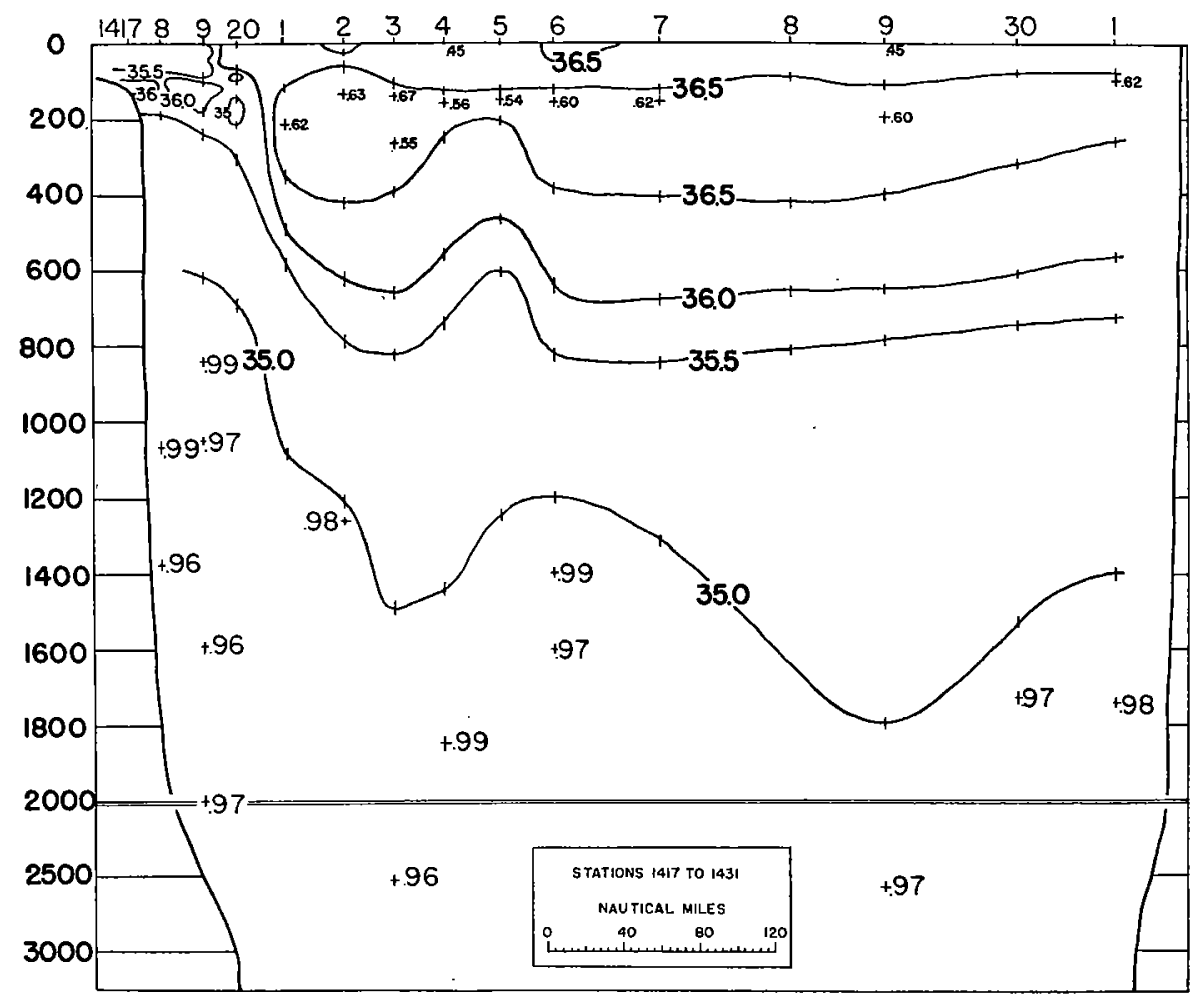

FIG. I I.-Salinity section, Chesapeake Bay-Bermuda, Nov. 30-Dec. 5, 1932.

wave $^{12}$ into the normally nearly horizontal water layers of the Sargasso Sea. It will be noticed also that on this profile the band of slope water was much narrower than on the three previous profiles. A glance at Fig. I will show the reason for this to be that the westtern stations lay considerably further south than on previous sections and approached closely the Cape Hatteras area where the Gulf Stream flows along the continental slope.

East of the Gulf Stream, except for the upswing of the isolines just mentioned, the distribution of temperature and salinity at mid-depths for the autumn closely followed that found at other seasons. As has each time been the case with sections crossing this corner of the Sargasso Sea, the water at nearly all depths gradually became slightly

12 $I_{t}$ is also possible that the section crossed a deep anticlockwise eddy produced through the same cause. 
colder and somewhat less saline approaching Bermuda, but the central stations (I426I428) again showed nearly horizontal conditions.

We have seen that in August there was little difference in surface temperature between the slope water and the Central Atlantic water. By December, on the other hand, the autumn chilling had lowered the temperature west of the current about $2^{\circ}$ below that of the Sargasso Sea. However, $6^{\circ}$ of additional cooling was still required in the slope

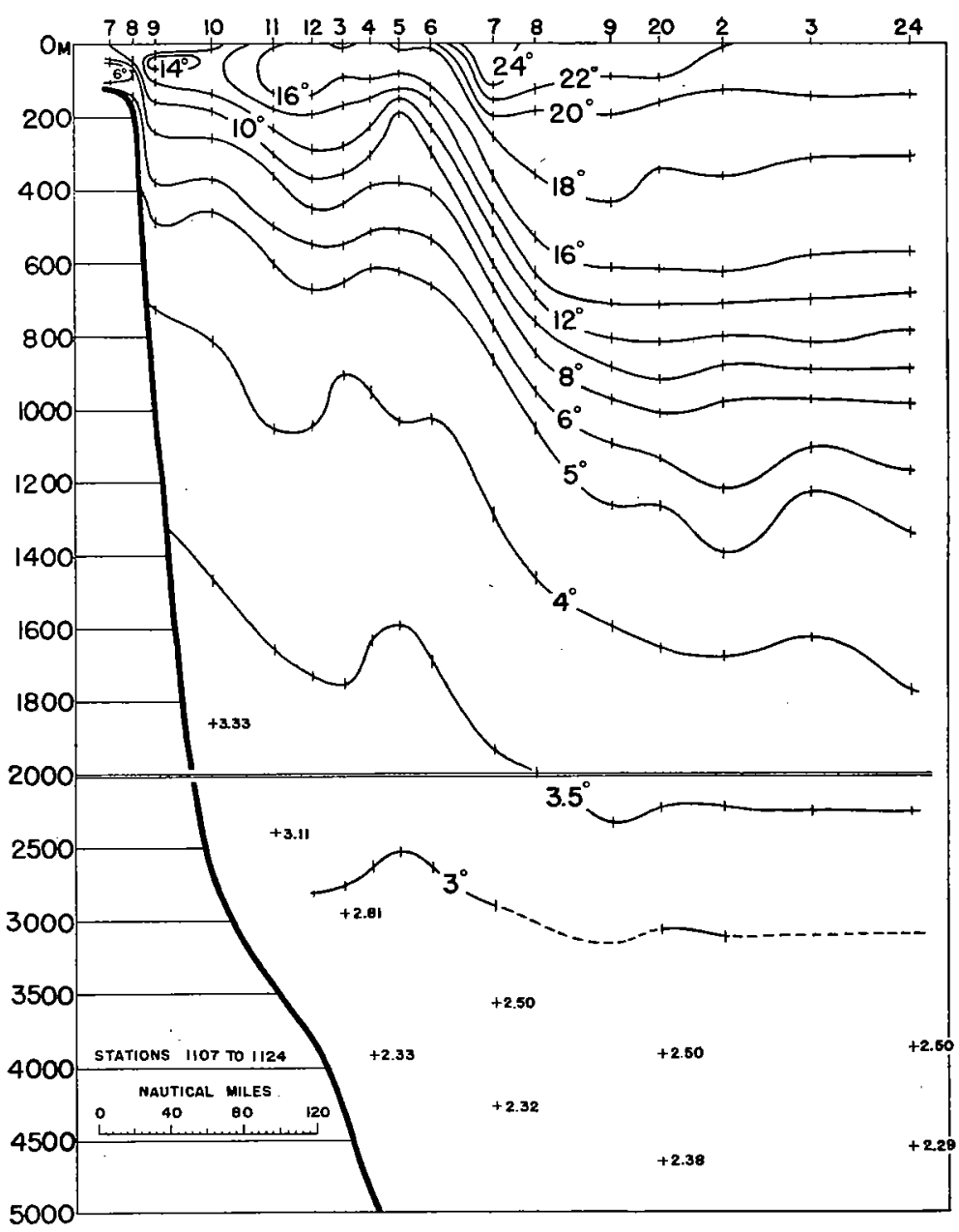

Fig. 12.-Temperature section, Nova Scotia-Bermuda, Nov. 21-26, I931.

water and only I ${ }^{\circ}$ east of the Gulf Stream to bring the surface temperatures down to the February values.

NOVA SCOTIA-BERMUDA

Although the original program called for quarterly observations on the Nova ScotiaBermuda line, only two sections have been completed, partly because the winter conditions on the northern half of this section are very severe, and partly because it did not at first seem as if the results would be as valuable as from the more southerly line of stations just discussed. 
It is to be expected that the conditions. in the slope water off the Nova Scotian coast are more variable than off Chesapeake Bay. In the first place, the Gulf Stream lies further offshore, so that greater fluctuations in the path of the current are probable; and in the second place, the variations in climate near the Nova Scotian coast are more extreme and violent.

The observations from November 2I-26, I93I (Figs. I2 and I3) show that the band of slope water at the time was about 55 miles wide, with a shallow layer of coastal water

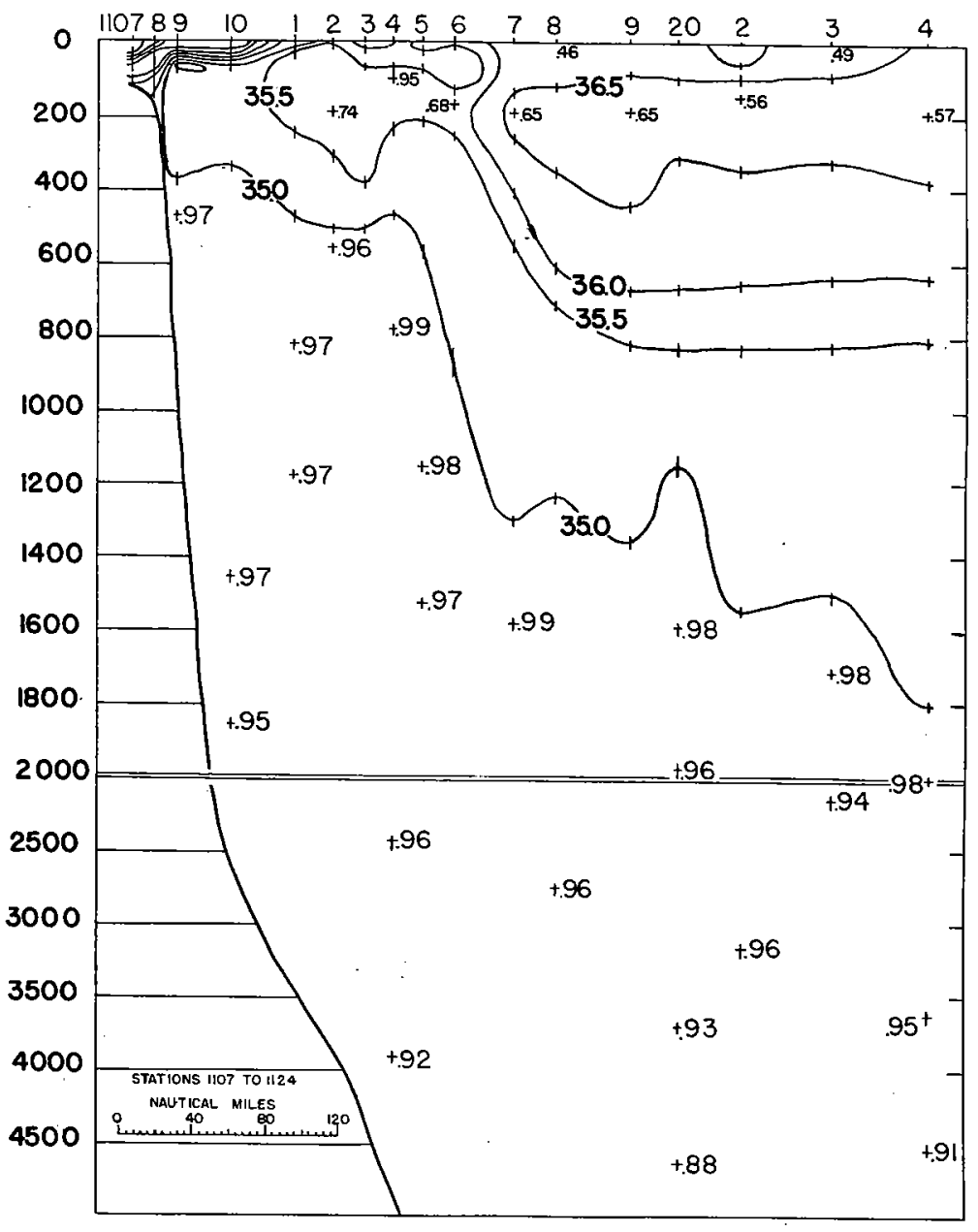

FIG. 13.- Salinity section, Nova Scotia-Bermuda, Nov. 21-26, I931.

(less than $34 \%$ in salinity) extending offshore at the surface for about 56 miles beyond the 200 meter curve. The tongue of much more saline $(35.7 \%)$ and warmer water lying slightly deeper (at about I90 meters) had apparently come from the Gulf Stream. This is a good example of how, in the surface layers of the slope water, the process of mixing continually produces values intermediate in salinity, and to a lesser extent in temperature. The depression of the isotherms at the central stations (I I I I-III 4 ) suggests the existence of a clockwise eddy in this region. But on the whole, the vertical distribution of 
temperature and salinity in the mid-depths of the slope water seems much the same as off Chesapeake Bay.

Because the Gulf Stream is considerably further offshore on these sections than off Chesapeake Bay, only 4 stations (I I 20, I I 22-I I 24) show true Sargasso Sea conditions, but there is apparently little difference in the vertical distribution of temperature and salinity between this region north of Bermuda and the Central Atlantic water farther west. However, the more gradual slope of the isotherms across the Gulf Stream off Nova

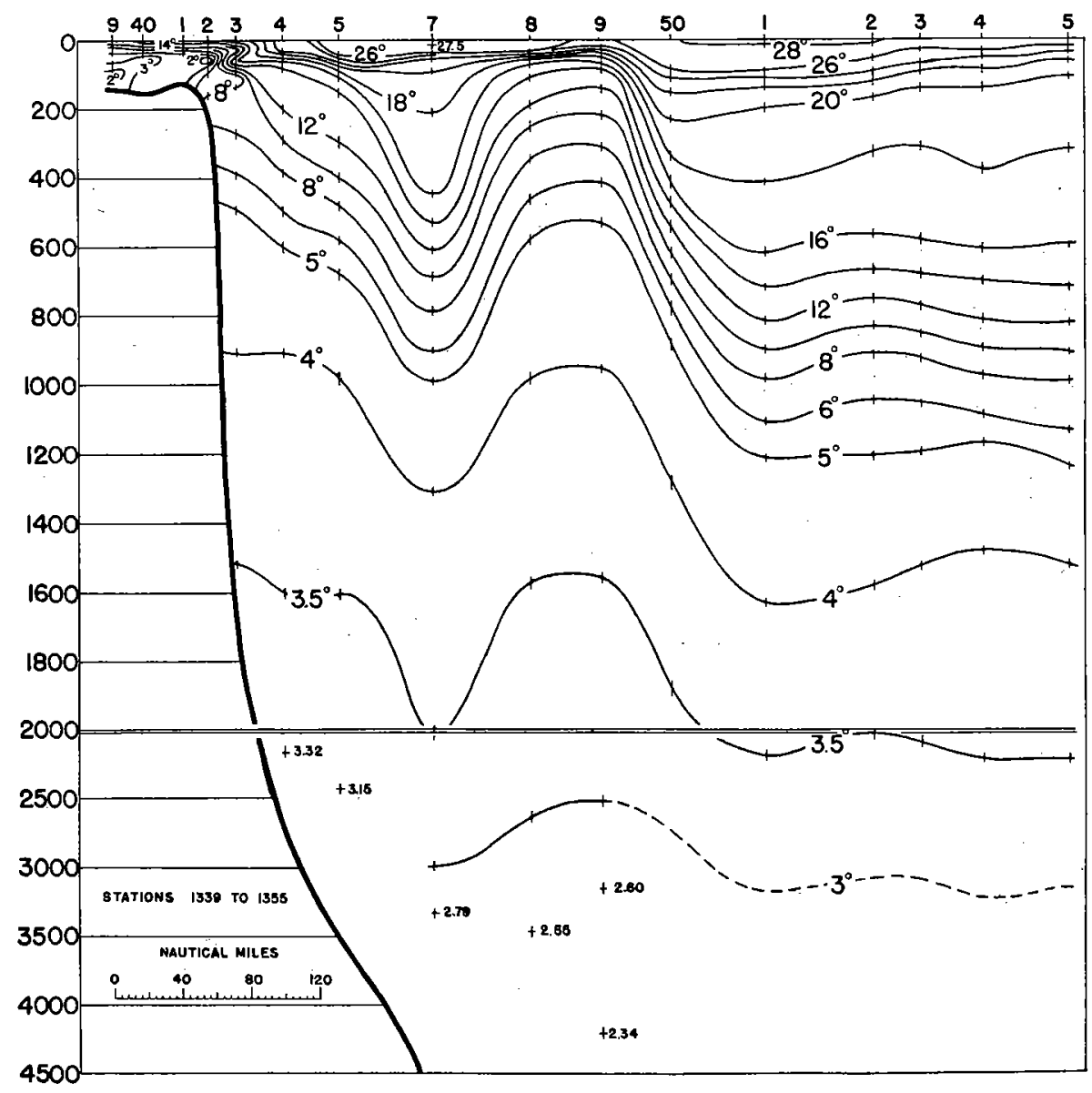

FIg. 14.-Temperature section, Nova Scotia-Bermuda, Aug. I4-20, 1932.

Scotia shows that at the time of this "Atlantis" profile the current there was broader and weaker than we have sometimes observed it off Chesapeake Bay.

The isolines on the other Nova Scotia-Bermuda section (stations I339-I355, Figs. I 4 and I 5), made August I4-20, I932, show a well developed depression in the central part of the band of slope water at about the same position as the similar but less pronounced disturbance, observed in November I93 I (Figs. I 2 and I3). There is a possibility, suggested diagrammatically in Fig. $I$, that the November stations crossed the eastern edge of a permanent eddy, while the August observations crossed its center. At any rate, 
the August temperature profile bears out the navigational record of this cruise in showing that the "Atlantis," after leaving the continental shelf, passed through a strong northeast set and then experienced an equally strong current towards the southwest before meeting the Gulf Stream. Near the surface (chiefly between 50 and 200 meters) and in the center of this whirl (station 1347), or perhaps for want of conclusive evidence we should say "between the two opposite currents," was found a large "pool" of tropical water (I $9.8^{\circ}$ and $36.64 \%$ ).

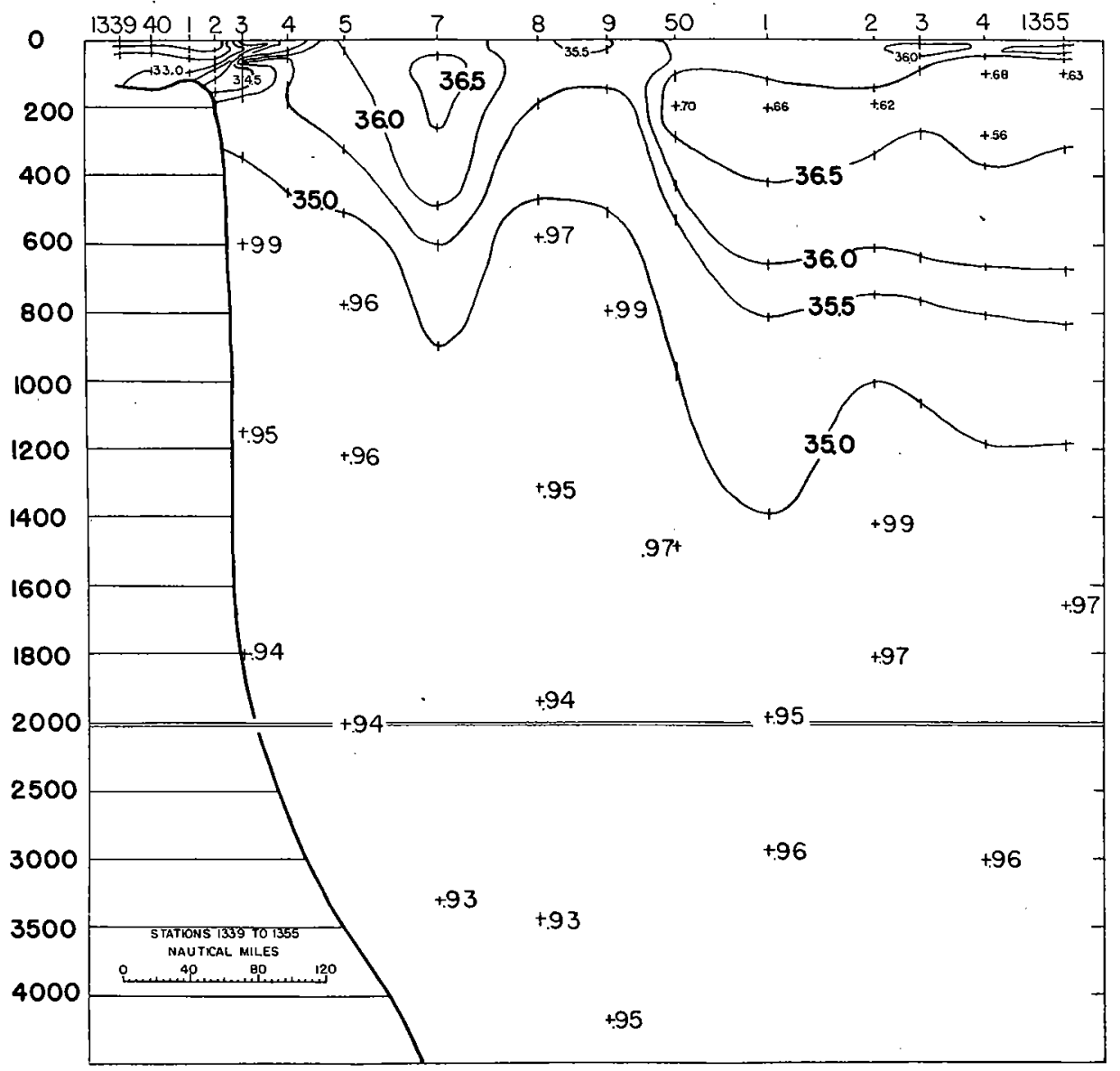

FIG. I 5.- Salinity section, Nova Scotia-Bermuda, Aug. I4-20, I932.

In this case the trend of the isotherms indicates that the Gulf Stream was not much broader off Nova Scotia than it usually was off Chesapeake Bay, while the distribution of temperature and salinity in the Central Atlantic water (stations I35I-55) again was much the same as is characteristic west of Bermuda. That surface temperatures are not always a reliable indication of the position of the deep current is well demonstrated in this section, for the warmest surface water $\left(28.4^{\circ}\right)$ lay just south of the axis of the Gulf Stream, probably having been displaced by wind. The usual drop in surface temperature (Church 1932b) just inshore from (in this case north of) the current can also be clearly seen in the profile on this section in the vicinity of station I349. 
From this cursory survey of the "Atlantis" observations on the Chesapeake BayBermuda and the Nova Scotia-Bermuda lines, the broad features, common to all sections across this sector of the Gulf Stream, can be summarized as follows:

(a) There is a general correspondence between the trend of the isotherms and of the isohalines across the profiles.

(b) Near the surface in the band of slope water the temperature and salinity varies widely from season to season ( $12{ }^{\circ}$ and $34.5 \%$ in February, $26^{\circ}$ and $33.6 \%$ in August), but in the Sargasso Sea the much more moderate climate produces orly small changes $\left(20^{\circ}\right.$ and $36.6 \%$ in February and $26^{\circ}$ and $36.2 \%$ in August).

(c) Except near the surface (o-200 meters), where the seasonal changes in solar radiation and rainfall play an important part, the various isotherms and isohalines are at about the same depths both in the slope water and in the Central Atlantic water throughout the year. However, the main thermocline in the slope water is more abrupt and occupies much shallower depths than in the Sargasso Sea.

(d) Since the depths of the isolines in the thermocline layer remain nearly unchanged in the slope water and in the Central Atlantic water from season to season, the obliquity of the water-layers at mid-depths within the current will depend largely on the width of the latter.

(e) The position of the axis of the Gulf Stream varied little during the time covered by the four "Atlantis" profiles, but the width of the band of swift current changed considerably from section to section.

(f) The rather flat arrangement of the isotherms in the Central Atlantic water suggests that this is a region of relatively weak currents.

(g) Although the isotherms in the band of slope water usually slope somewhat downward in an off-shore direction the movements in this region are in general also probably slight. ${ }^{13}$

\section{Variations of Temperature and Salinity with Depth}

\section{METHOD}

It is obvious that plotting the temperature and salinity observations in the form of sections, such as we have just examined, does not bring out clearly either the seasonal variations near the surface due to the climatic cycle, or the mean variations in the deeper layers from profile to profile. The "Atlantis" observations between Chesapeake Bay and Bermuda should provide excellent material for the examination of both these questions, although we can perhaps expect less satisfactory results in the slope water region than in the Sargasso Sea, partly because these particular sections cross this band so near its southern limit, and partly because the available data are less extensive.

Since we are here dealing with two bodies of water, separated by the Gulf Stream and each having relatively horizontal water layers, a logical method is to average all the slope water stations and likewise all the Central Atlantic stations for each cruise. By so doing, the individual peculiarities of the stations near the surface are partly eliminated, as well as the distortion of the deeper isotherms and isohalines due to submarine waves. We can then compare from season to season the mean changes in the distribution of temperature and salinity on the two sides of the Gulf Stream.

${ }^{13}$ An obvious exception to this statement is the well developed eddy south of Cape Sable crossed by the Aug. I932 section (Fig. $\mathrm{I}_{4}$ ). Such deep whirls may be a more general characteristic of the waters bordering the northern edge of the Gulf Stream than is now realized. 
This method is perhaps the best now available for studying the variations in the slope water, but in the Central Atlantic water, where more stations can be used, a somewhat different approach proves more productive. It has been pointed out above that in general the water near Bermuda is slightly colder and less saline at mid-depths than in the region roughly half way between the Gulf Stream and the islands, and that it is only in this central region that the water layers are strictly free from obliquity. Therefore, if all of the Sargasso stations are averaged for each section, the mean values will be influenced by the number of stations falling each cruise within this colder region. ${ }^{14}$

In Fig. I 6 we have plotted the changes in depth of the isotherms (solid lines) between 500 and I 100 meters at the warmest Sargasso station on each section. Since these changes

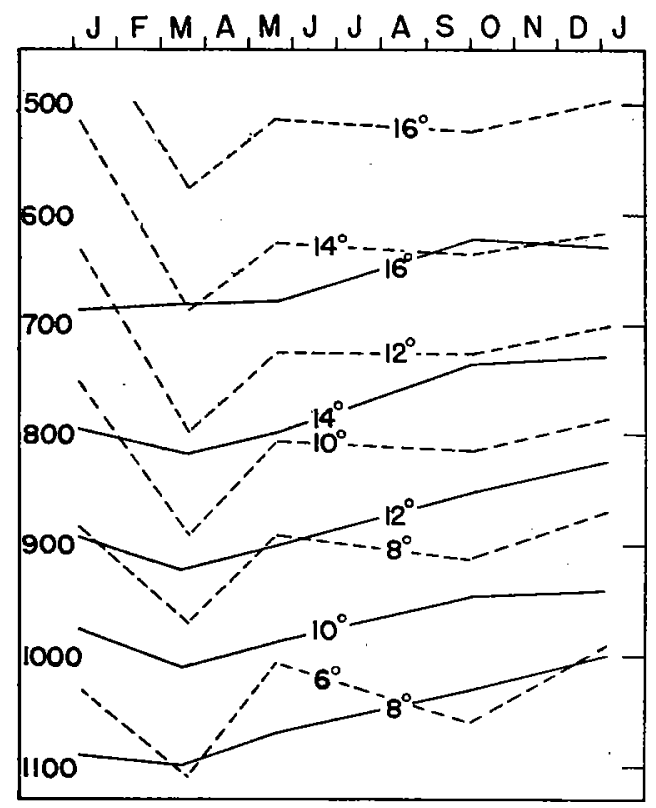

FIG. 16.-Comparison between the temperature changes in the Central Atlantic water during $193^{2}$ at the warmest (solid lines) and coldest (broken lines) "Atlantis" station from the Chesapeake BayBermuda sections.

are below the depth of solar influence, no seasonal periodicity need be expected. The isotherms lay deepest in February I932, their trend showing increasingly colder conditions at all depths on subsequent cruises. In the same way, the broken lines in Fig. I6 show the changes at the coldest Sargasso station on each cruise.

The results from Figure I6 can be summarized as follows:

I. In the region between the Gulf Stream and Bermuda there is a general correspondence between the changes occurring at the warmest and coldest stations on each section.

2. The coldest stations (near Bermuda) show wider variations than the warmest stations (from the central region).

${ }^{14}$ The significance of this rise of the thermocline layer near Bermuda will be discussed later (page 70) but it should be mentioned here that it is partly a local phenomenon, resulting from the obstruction which the island cone must offer to the free movement of the deeper waters. 
3. Both types of stations were colder in February I 932 than on later cruises, and especially for the central stations, the rise in temperature seems to have been gradual between the depths of 500 and I 100 meters until the end of the period (Dec. I933) covered by these observations.

We can conclude that since the region near Bermuda is subject to more extreme variations, it may be influenced by some fluctuating current. Indeed, variable currents have frequently been reported from near the island. On the other hand, the three central (warmest) stations do not appear to be as much affected by local currents and, therefore, are better adapted for a detailed study of changes in temperature and salinity at middepth.

The objection might be raised that the depths of the isotherms at these central stations perhaps depend on the velocity of the Gulf Stream during the period each section was run. Such a question cannot be settled at the present stage of oceanography because it is not known yet to what extent the distribution of temperature and salinity in the sea is the cause or the result of the permanent current system. However, since it appears from Fig. I 6 that the variations in this central region were much smaller than at more easterly stations, any other choice of data would produce greater average fluctuations from cruise to cruise, and the significance of the results would be more uncertain because of local currents.

The stations finally selected for a closer study of the variations in temperature and salinity on the Chesapeake Bay-Bermuda line can be tabulated as follows:

\begin{tabular}{|c|c|}
\hline \multicolumn{2}{|c|}{ Slope Water } \\
\hline Feb. I2, I9.32 & Stations I 134, I I35, I I 36 \\
\hline Apr. $\quad 22,1932$ & Stations 1229,1230 \\
\hline Sept. $2-3,1932$ & Stations 1372, 1373 \\
\hline Dec. $\quad$ I, I932 & Stations $\mathrm{I}_{4} \mathrm{I}_{8}, \mathrm{I}_{4} \mathrm{I} 9$ \\
\hline \multicolumn{2}{|c|}{ Central Atlantic Water } \\
\hline Dec. $\quad 6-7, \quad$ I93I & Stations I I 27, I I 28, I I 29 \\
\hline Feb. $I_{4}-\mathrm{I} 5, \mathrm{I}_{932}$ & Stations I I $40, \mathrm{II}_{4} \mathrm{I}, \mathrm{I} \mathrm{I}_{42}$ \\
\hline Apr. I9-20, I932 & Stations I $223, \mathrm{I} 224, \mathrm{I} 225$ \\
\hline Aug. $29-31,1932$ & Stations $1363,1365,1366$ \\
\hline Dec. $2-3$, I 932 & Stations $\mathrm{I}_{4} 26, \mathrm{I}_{42} 2, \mathrm{I}_{4} 28$ \\
\hline
\end{tabular}

For each of the above stations a temperature depth curve and a salinity depth curve was constructed. Scaled values at even depths (I00 meter intervals) were then averaged for each group of stations. The curves shown in Figs. I7 and I9 were drawn through these points. The result is a series of curves giving the average variations of temperature and salinity with depth in the two types of water. The symbols for the individual readings show the amount of scattering of the observations from which these average curves were constructed. The diagrams include no data from below I 600 meters, for in the deeper layers the changes from section to section seem not to be greater than the observational errors.

THE SLOPE WATER

Since the surface layer of the band of slope water is exposed to large climatic changes and in addition serves as a mixing zone for coastal and Gulf Stream waters, the variations in temperature and salinity above 200 meters in Fig. 17 are large $\left(26.8^{\circ}\right.$ to II. $9^{\circ}$ 


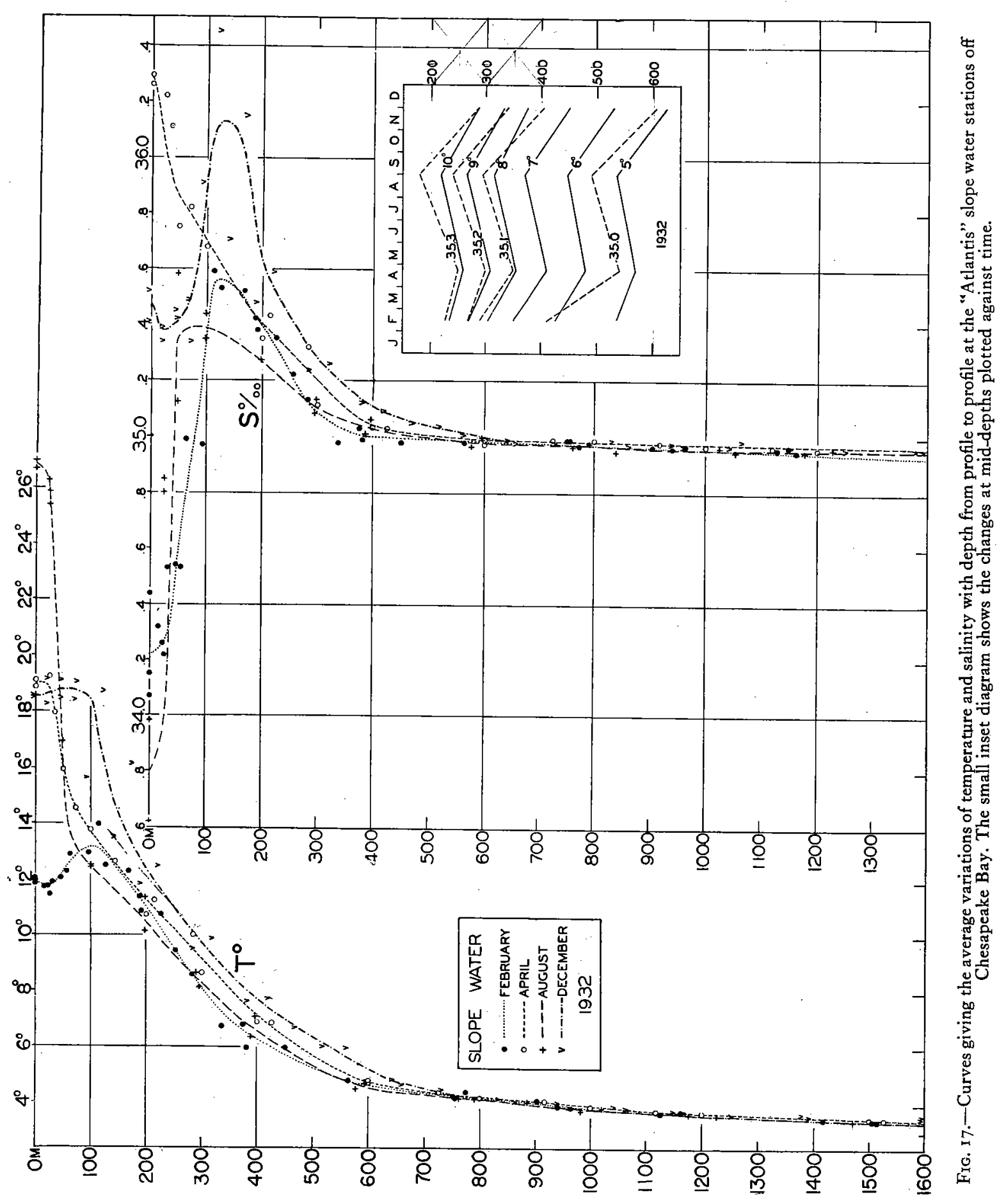


and $33.8 \%$ to $36.3 \%$ ). It is evident from the course of the mean temperature curves that the effect of the local climate can be traced downward to at least 150 meters. The fact that in February (Fig. 4) and in August (Fig. 8) the surface layer contained a considerable admixture of relatively fresh coastal water accounts for the wide divergence between the mean salinity curves near the surface for these months (Fig. 17). The effect of the "pool" of tropical water in December (Fig. I I) can also be made out in the course (at about 150 meters) of the mean salinity curve for that cruise.

But these influences do not explain the wide variations in the mean curves, or the scattering of the observations between the depths of 200 and 600 meters. These depths closely mark the limits of the main thermocline west of the Gulf Stream, where in a vertical distance of 400 meters the water cools by about $6^{\circ}$. A transition zone of this sort between the wind stirred surface layer and the relatively homogeneous mass of deep water is present nearly everywhere in the sea.

In discussing the various layers of oceanic water, a difficulty clearly brought out in Fig. I 7 sometimes arises. The zone of most rapid salinity change does not always coincide with the depths occupied by the thermocline. In this example the break in the slope of the mean temperature curves falls at about 600 meters while the corresponding change in salinity comes at about $35^{\circ}$ meters. Thus the variations in depth of $5^{\circ}$ water are not reflected by corresponding fluctuations of the mean salinity curves.

In order to stress the similarity between the thermal arrangement of the ocean and of the atmosphere, Defant (1928) suggested the meteorological term "troposphere" for the warm water layer of the ocean (from the surface down to the lower limit of the main thermocline). The turbulent surface layer, mixed by the wind, forms part of the troposphere. The remaining deeper, cold layer (below the bottom of the thermocline) he named the "ocean stratosphere." Wüst (I929) in his studies of north and south movements at mid-depths came to the conclusion that the boundary between the troposphere and stratosphere of the ocean should be put somewhat higher (at the center of the thermocline). This Defant accepted (1929) in view of the fact that in the South Atlantic and Pacific the layer having temperatures between $10^{\circ}$ and $6^{\circ}$ (the lower half of the thermocline) clearly has its origin in high southern latitudes and therefore should not be classified with tropical water. More recently these authors have settled on the $8^{\circ}$ isotherm as most representative in the Atlantic ocean for the boundary between troposphere and stratosphere.

While it is true that the thermal arrangement of the ocean closely resembles that of an inverted atmosphere, the comparison must not be carried too far. In the ocean the horizontal circulation is most vigorous at the surface and decreases with depth, while in the atmosphere no marked lessening of the movements with height is found until the stratosphere is reached. Again in contrast to the troposphere of the air, in the surface layers of the ocean convectional forces are probably less important than in the atmosphere, while frictional forces tend to increase rather than decrease the currents set up by the wind.

If we consider the matter further, we can find other reasons that make it seem unwise to stress a division of the ocean into a tropospheric and a stratospheric layer. In the atmosphere the boundary between the two zones is rather sharp, while above the boundary the stability is relatively great. In the ocean, the thermocline (except near the equator) occupies a layer several hundred meters thick and below it the stability is only slight. 
The divisions of the ocean used in this paper are shown diagrammatically in Fig. I8. They are not entirely satisfactory, as mentioned above, because the halocline often does not exactly correspond in depth to the thermocline. But since, on the whole, the distribution of density in the sea so nearly corresponds to the thermal trends, it seems better to base the divisions on temperature rather than on salinity. The $5^{\circ}$ isotherm has been chosen arbitrarily as marking the often uncertain lower limit of the thermocline layer, because in the central North Atlantic the movements of the water colder than $5^{\circ}$ are relatively slight. In summer (see Fig. 2I) a sharp secondary thermocline may be expected to develop just beneath the turbulent surface layer.

Returning to Fig. 17 with these points in mind, the fact that the secular variations in temperature and salinity within the thermocline layer show a general correspondence, that is, the water when warmer than the mean was also slightly more saline and vice

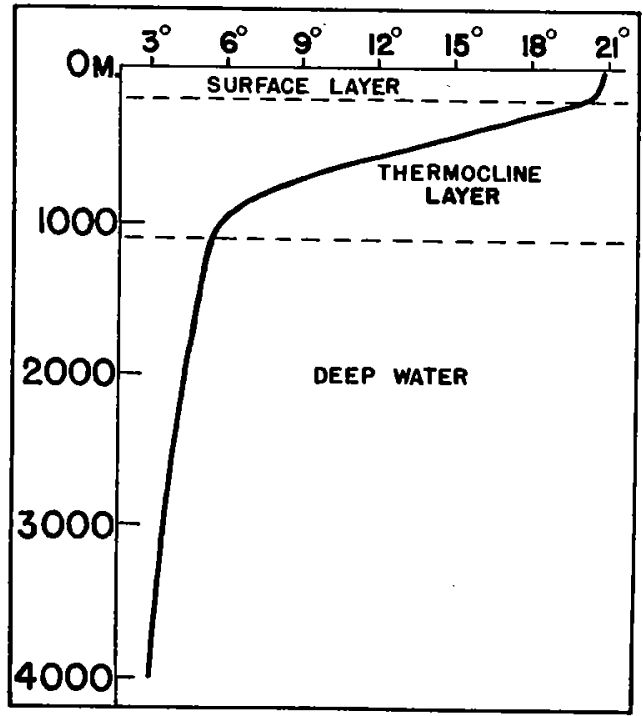

FIG. 18.-The vertical subdivisions of the ocean.

versa, suggests that the whole thermocline layer is subject to slow oscillations in depth. Such changes of temperature and salinity with depth could not have been produced by the local climatic cycle because the layer involved is too deep. The sequence of the changes, between the depths of 200 and 600 meters (inset Fig. 17), shows the water on the whole coldest and least saline in February 1932, and warmest and most saline in the following December. Since only four sets of observations demonstrate this trend, it is impossible to know whether or not the warmer conditions found in April developed further during the spring.

Similarly, it seems probable that the scattering of the observations within the thermocline layer was caused by short period oscillations, possibly tidal in origin. If this is so, it can be argued that by averaging only two stations for each cruise, mean curves may have been produced which are incorrect by the full amplitude of the short period changes. In other words, the short period oscillations might have been at the same phase at both stations. But as Fig. I7 shows, the error from this cause could only account for about $\frac{1}{4}$ of the extreme changes in depth of the isolines within the thermocline, for none of the 
observations depart from the average curves by more than 25 meters, while the total shift in depth during the period February-December 1932 amounted to about 100 meters.

Similar curves are given for the Central Atlantic water in Fig. I9. In this case we are fortunate in having suitable observations from five consecutive "Atlantis" cruises covering the period December I931-December 1932. At once it is evident that here the variations in temperature and salinity extend to a much greater depth than in the slope water (Fig. I7) and that, especially between 600 and I 100 meters, the divergence of the curves is much greater. On the other hand, the changes at the surface are much smaller, reflecting the more moderate climatic conditions over the Sargasso Sea.

A more careful examination of the curves down to 350 meters discloses that precipitation is probably greater here in summer than evaporation. But on the whole, the salinity of the surface layer is much more constant than in the slope water region and the divergence of the temperature curves at these depths must be due largely to the seasonal interchange of heat with the atmosphere and to variations in solar radiation. In contrast to the surface layers of the slope water, it is very doubtful whether any important part of the thermal changes near the surface exhibited by these mean curves for the Sargasso Sea can have been caused by the inflow of water from hydrographically different regions.

Although there is again a close correspondence between the variations of the average temperature and salinity curves at mid-depths, so thick a layer is involved that it might be expected that some other factor in addition to an oscillation in depth of the thermocline layer may play a part in these changes.

The magnitudes of the changes at intermediate depths plotted in Fig. I 9 are indeed very great. For example, at 900 meters the mean temperature of the Central Atlantic water varied between $9.3^{\circ}$ in August and $12.7^{\circ}$ in February and at 800 meters the average salinity changed from $35.5 \mathrm{I}$ to $35.90 \%$. Individual observations varied even more widely. Such disagreement is to be expected between single stations taken at the same spot but at different seasons, and even at the same season of different years, as can be seen by comparing the observations of December I931 with those of December 1932. Similar examples have been published by Helland-Hansen (1930) from the eastern North Atlantic and there is little reason to doubt that such depth oscillations in the thermocline layer are a widespread phenomenon. Therefore, a single station is never strictly representative of the average conditions for a given region. Only by combining the observations from several neighboring stations can the short period changes be averaged out. The long period, slow oscillations of the type disclosed by these "Atlantis"' sections are a matter for future study. Such investigations as have been attempted (Le Danois I934) point to a number of superimposed cycles.

The changes in depth of the mid-layer isotherms and isohalines, when plotted against time (Fig. 19) show a trend of decreasing temperature and salinity in the Central Atlantic water during the period covered by the observations. Since this is the reverse of the situation found in the slope water, we can only conclude that during the year 1932 the contrast in temperature and salinity between the regions separated by the Gulf Stream was diminishing. For example, in the slope water the average location of the $8^{\circ}$ isotherm sank from a depth of 305 meters to 375 meters, while in the central Atlantic water it pose during the same period from I 100 meters to 985 meters, and changes of the same 


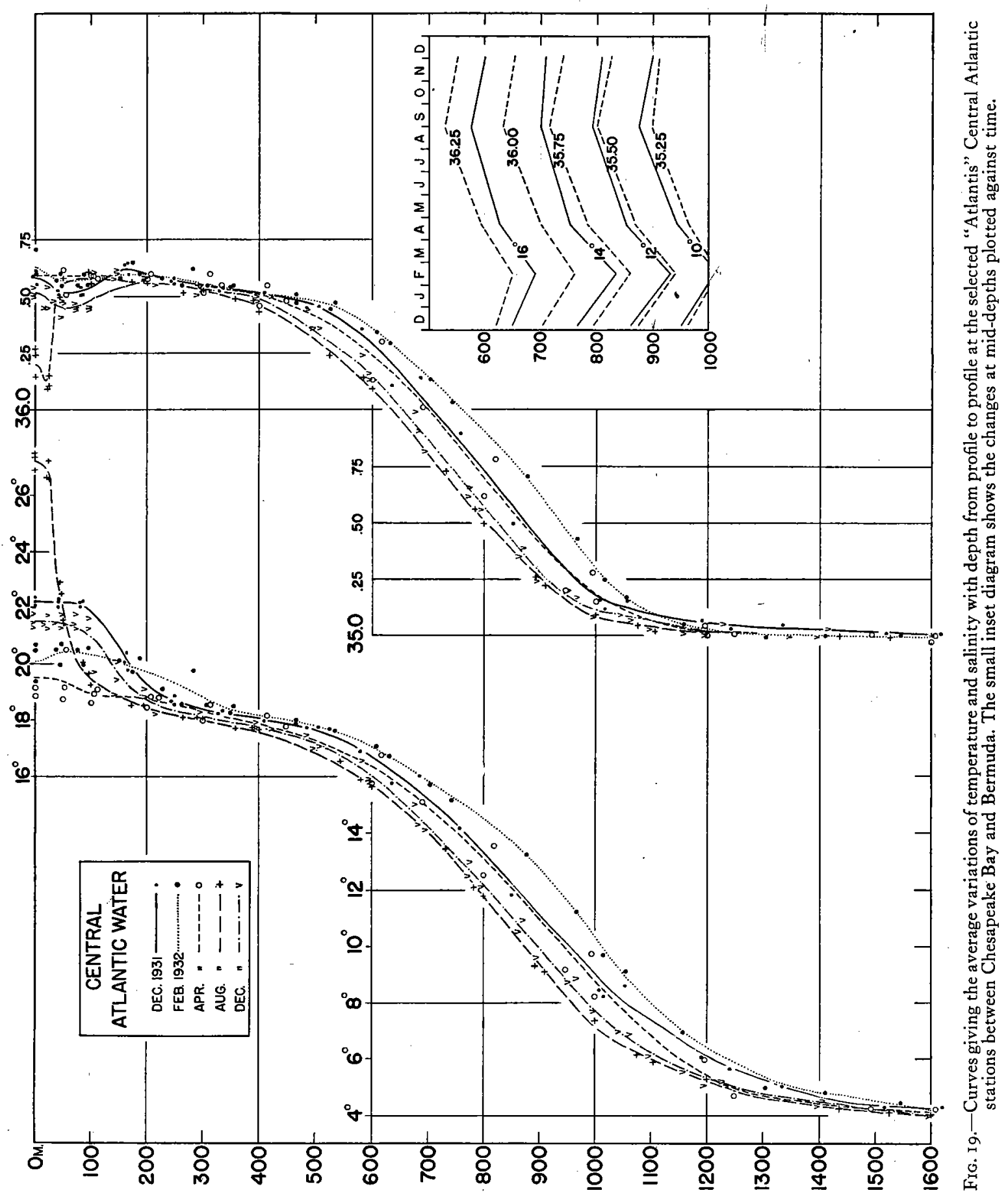


order of magnitude occurred at all depths occupied by the thermocline in each region. The effect of these changes on the Gulf Stream must have been considerable. Since the total slope of the water layers across the current's path was less in December 1932 than at the beginning of the year, the transport of water by the Gulf Stream must have gradually decreased during the same period.

\section{SEASONAL TEMPERATURE CYCLE NEAR THE SURFACE}

We have seen from Fig. Ig that in the Central Atlantic water, near the surface, the temperature curves for each season have a characteristic shape. The two groups of December observations also show that considerable annual differences may be expected, for in December 1932 the water was about $0.8^{\circ}$ colder between $\circ$ and $15 \circ$ meters than in the same month of the previous year. Two stations ( $I_{4} 62$ and $I_{4} 63$ ) made in this region in February 1933, when averaged, show these colder conditions as still persisting. Thus the data from all the cruises (6 in number) covering the period December I93I-February I 933 can be used to study the process of warming and cooling which goes on in the surface layer in the western Sargasso Sea.

In constructing the curves shown in Fig. 20 the same method of averaging was used as for Figs. I7 and I9, but in this case no selection of the data was necessary because of the nearly uniform climatic conditions along this part of the profiles and because the wind stirred surface layer is not disturbed by deeper, local currents. Also included, but only used as a guide in drawing the curves, are the average temperature values calculated in the same manner from the "Chance" (I927) and "Dana" (I922) stations in the same area. These fill the long gap which would otherwise have existed between the "Atlantis" observations from April and those for August. Because of annual variations, these data cannot be expected to fall exactly on the "Atlantis" curves.

Fig. 20 indicates that in I932, the mean minimum surface temperature (19.75 ) probably occurred about March I 5 th, and the summer maximum (28.0 ) about August 20 oth but the curve for 50 meters shows that the temperature was not at its lowest at that depth until April, nor highest until late in November. The curves for Ioo and 200 meters demonstrate that this lag of the seasonal schedule is progressive with depth, but at 300 meters the annual variations are apparently sometimes greater than the seasonal change, the expected maximum for February 1933 not appearing at all.

The reversal of the seasons between the surface and the 300 meter level shown by these "Atlantis" curves results largely from the fact that the summer warming produces such a shallow, stable film that wind stirring is only able to transfer this heat downward very gradually, so that it is not until the autumn that any considerable deeper mixing takes place. This question has been more fully discussed by Helland-Hansen (1930), who has published similar diagrams from stations in the eastern North Atlantic.

One further point is worthy of notice here, because it illustrates the important rôle of stability and wind stirring in the surface layers. From Fig. 20 we find that while it took about four months for the winter surface minimum to penetrate down to 300 meters, the summer maximum did not reach the same depth until after six months.

\section{Correlation between Temperature and Salinity}

METHOD

It has been noted already that in both the slope water and the Central Atlantic water the fluctuations at mid-depths disclosed in Figs. I7 and 19 were probably caused by 
changes in depth of the thermocline, because such a close correlation existed between the variations of mean temperature and salinity. The temperature-salinity diagram method, first introduced by Helland-Hansen (I9I8), and later extensively used in the North Atlantic by Jacobsen (I 929 ), is adapted for a closer examination of this correlation. At the same time, we will be able to find out whether or not some of the variations found at mid-depths in the "Atlantis" Chesapeake Bay-Bermuda sections could have been caused by the inflow of water from hydrographically different regions.

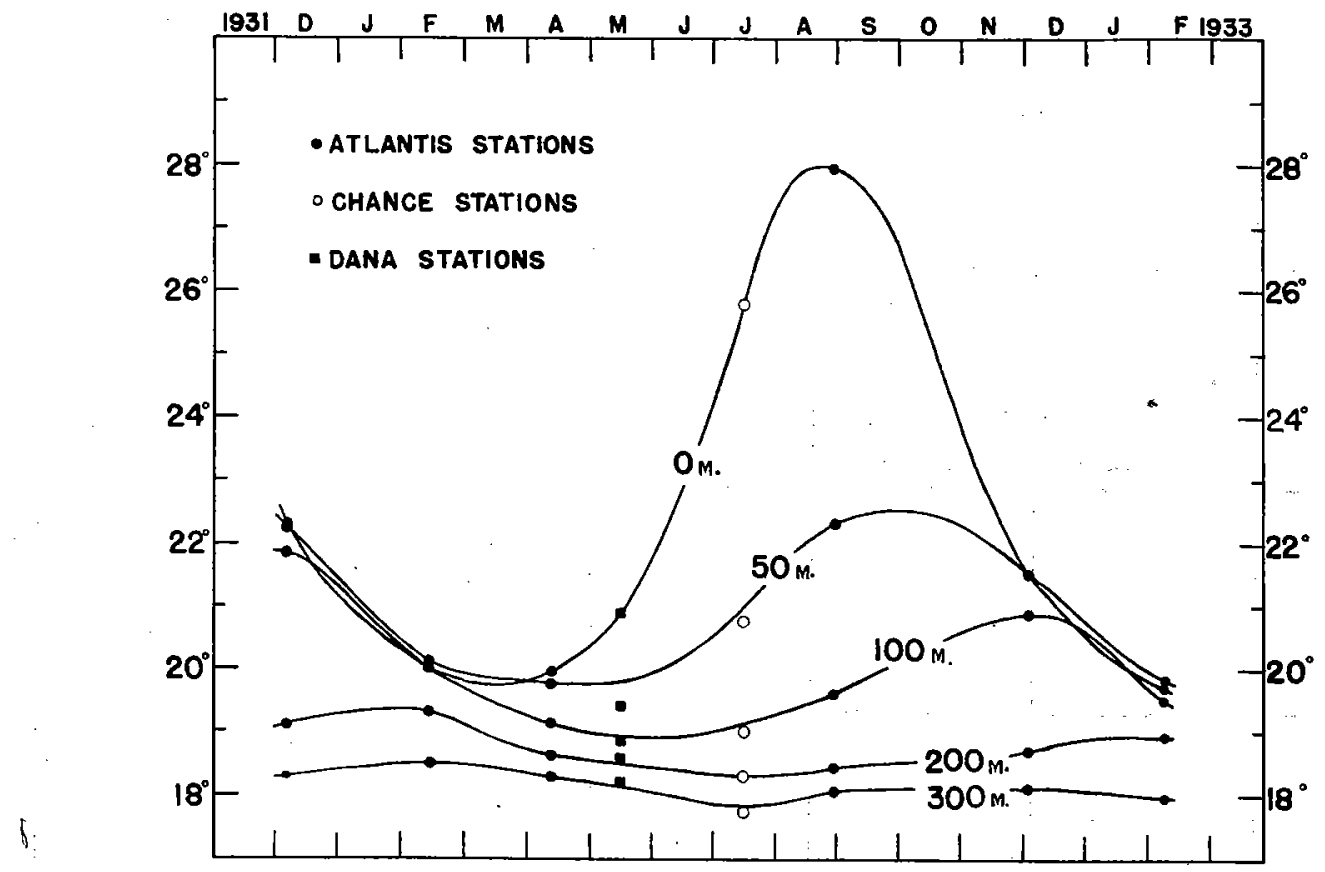

FIG. 20.-Seasonal temperature changes near the surface in the western Sargasso Sea.

The observations from a single station are often unsuitable for constructing a T-S diagram. For example, if too few readings are secured in the thermocline layer (frequently readings between $10^{\circ}$ and $6^{\circ}$ are lacking), the curve giving the temperature-salinity ratio of the station will probably be flattened between the too widely spaced points. But if the observations from several neighboring stations are combined, the exact course of the T-S curve will not often be in doubt. For our present purposes there is no objection to combining thus the observations from the slope water or from the Central Atlantic water used in Figs. I 7 and I9 to disclose any change in temperature-salinity ratio from season to season. Also it can be shown that the regions separated by the Gulf Stream do not have the exactly same mean T-S curves.

The T-S diagram method is again taken up in more detail on page 94. For the present, we will merely be considering whether or not there exist variations of the T-S ratio not caused by the transfer of heat or moisture in the wind stirred surface layer.

THE SLOPE WATER

The observations from the slope water stations used to construct the mean temperature and salinity curves of Fig. I7 have been replotted in Fig. 2I. The same symbols 
again distinguish the four sets of data listed on page 28. An approximate depth scale has been indicated along this composite T-S diagram.

The seasonal changes in temperature and the presence or absence of coastal water produce for the surface layer (warmer than $10^{\circ}$ ) considerable scattering of the points on

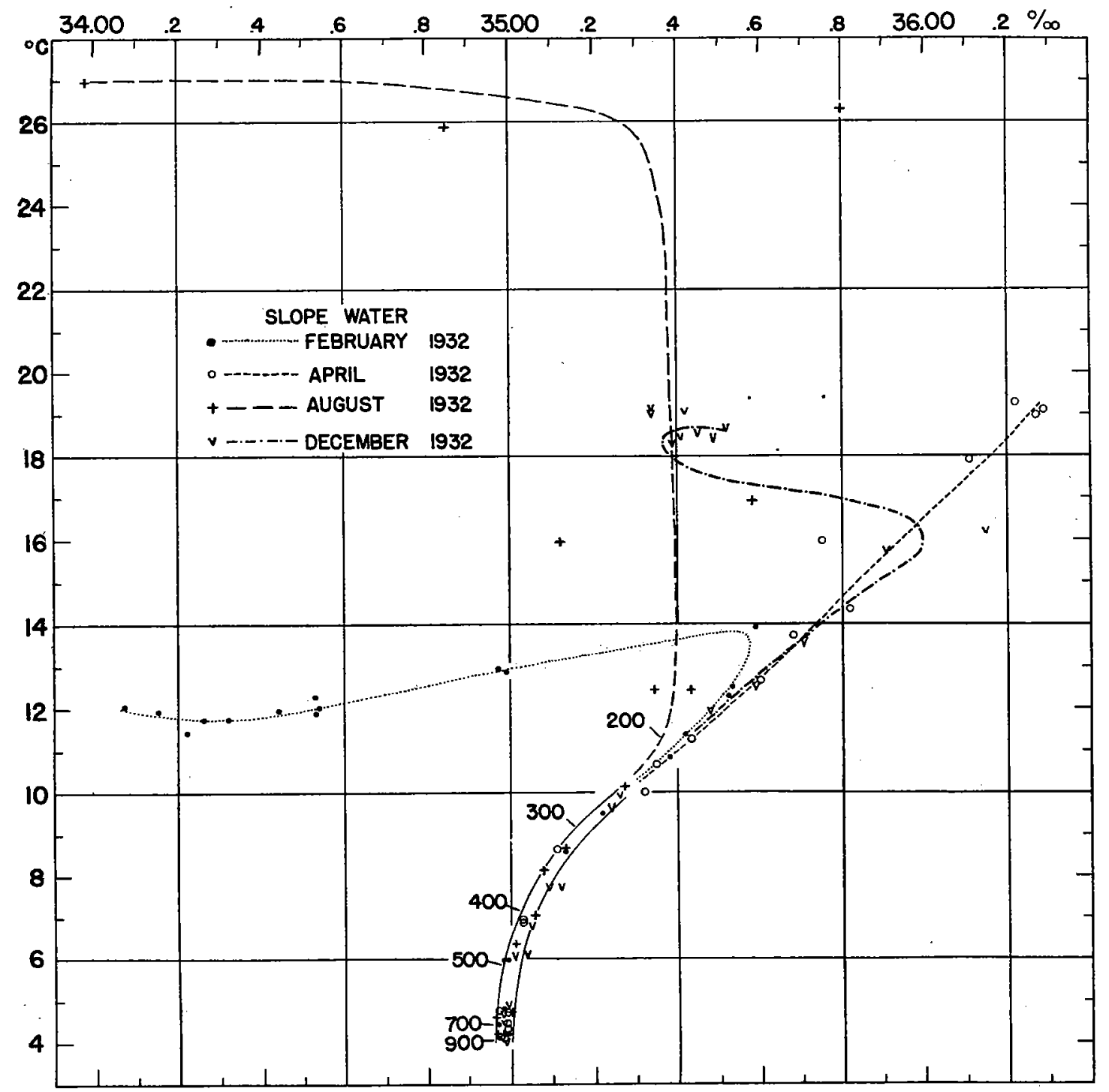

FJG. 21.-Temperature-salinity correlation in the slope water off Chesapeake Bay for each of the available "Atlantis" ștations.

this diagram and a wide divergence of the four mean T-S curves. The fact that the scattering diminishes and the curves come together at about 240 meters indicates that this is the lowest limit of both of these influences. Below this depth, the majority of the observations fall along a path marked on the diagram by two nearly parallel, solid, curving lines. These are so drawn that in a horizontal direction they are separated by a distance 
VOL. IV, NO. 4. A STUDY OF THE CIRCULATION OF THE WESTERN NORTH ATLANTIC

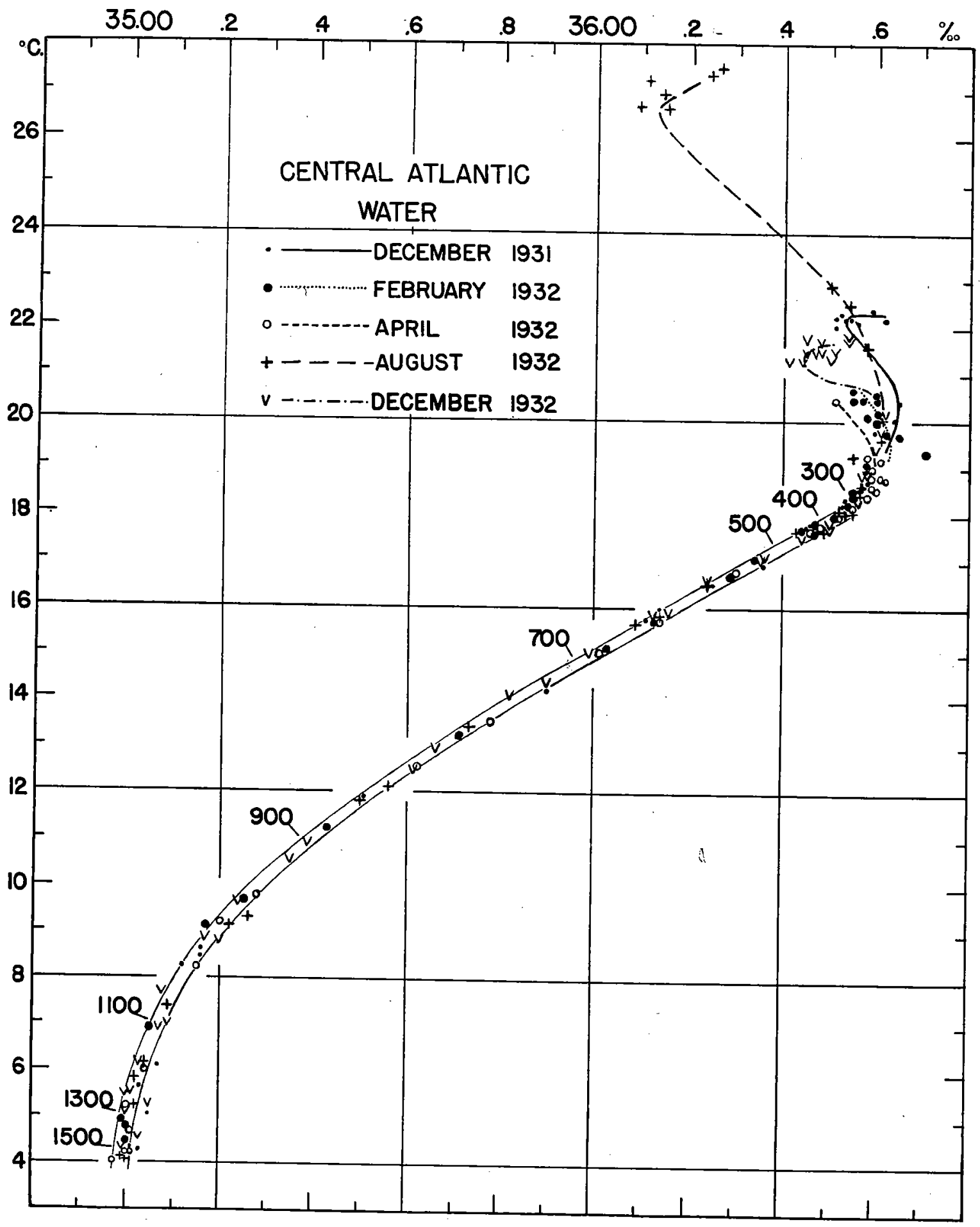

FIG. 22.- Temperature-salinity correlation at the selected Central Atlantic stations from each of the Chesapeake Bay-Bermuda sections. 
equal to $0.04 \%$ on the salinity scale, the probable maximum error of the determinations. The two exceptions come from the December 1932 profile. We have seen from Fig. I that on this cruise the western stations lay somewhat further south than on the others and that the sloping isotherms and isohalines marking the Gulf Stream's path were closer to the continental shelf than usual. It is not surprising then that these two observations should have a higher salinity, characteristic of the Gulf Stream for these temperatures.

We can conclude that if the salinity determinations had had no error (and if the two December observations be excepted), all of the slope water observations between the depths of 240 and 900 meters would have fallen along the same curve when plotted as a T-S diagram. Thus the variations of the mean temperature and salinity depth curves in Fig. I 7 must have been due largely to oscillations in the depth of the thermocline layer and not to the inflow of any water having a different T-S ratio.

THE CENTRAL ATLANTIC WATER

The observations from the Central Atlantic water (from the stations listed on page 28) are also plotted in the same manner in Fig. 22. Since here the seasonal changes in temperature and salinity near the surface are much smaller, the mean T-S curves for each group of stations are strikingly less divergent than west of the Gulf Stream. Then below a depth of about 320 meters, the great majority of the points fall again along a curved path, the horizontal thickness of which is equal to .04 parts per thousand on the salinity scale. Thus we can imagine that, had there been no error in the salinity determinations, most of these stations would have had identical T-S diagrams between the range of $18^{\circ}$ and $4^{\circ}$ in temperature and 36.52 to $34.99 \%$ in salinity.

The 8 exceptional observations came from 7 different stations and occur from all cruises except that of April 1932. These divergences cannot be disregarded because the stations used in this diagram were all well separated from the Gulf Stream's path. When we examine the temperature-salinity ratio over the whole western North Atlantic (page 90), the reason for these slight variations in the 900-1600 meter layer immediately appears, as they can be traced back to the Mediterranean outflow. We can conclude that in the western Sargasso Sea there are occasionally found at mid-depths small changes in the normal T-S ratio. However, on the whole we can again feel sure that most of the variations found in Fig. Ig were caused by fluctuations in the depth of the thermocline layer.

\section{COMPARISON BETWEEN THE TWO REGIONS}

If there had been no error in the salinity values plotted in Figs. 2I and 22, the T-S relationship in each case at mid-depths could probably have been represented by a single curved line. It seems logical that this would fall along the middle of the path of the observations. Fig. 23 shows such a mean T-S curve for the slope water (broken line) and for the Central Atlantic water (solid line). The diagram demonstrates that between the range of $10^{\circ}$ and $4^{\circ}$, the slope water is slightly fresher for a given temperature than the Central Atlantic water. This difference varies between $0.04 \%$ for $7.5^{\circ}$ water and 0.02 $\%$ for $4^{\circ}$ and $10^{\circ}$ water. The slope water curve is for depths between 240 and 900 meters, while the corresponding sector of the Central Atlantic curve is from the 900-1600 meter layer. The average difference in T-S correlation between the two regions, though small, suggests that at mid-depths little transfer takes place across the Gulf Stream's path. 
Unfortunately, because of the difficulty of taking observations in the swiftest part of the current, data from stations in the middle of the Gulf Stream are too scanty to show with certainty whether or not the water from mid-depths in the heart of the current gives intermediate values. The evidence, though too inconclusive to reproduce here, seems to point to a T-S ratio at nearly all depths in the Gulf Stream off Chesapeake Bay not unlike that of Central Atlantic water. This seems logical when we consider (as will be shown later) that south of Cape Hatteras no band of slope water exists. This question will again be brought up when the "Atlantis" observations from the Florida Current are discussed (page 60).

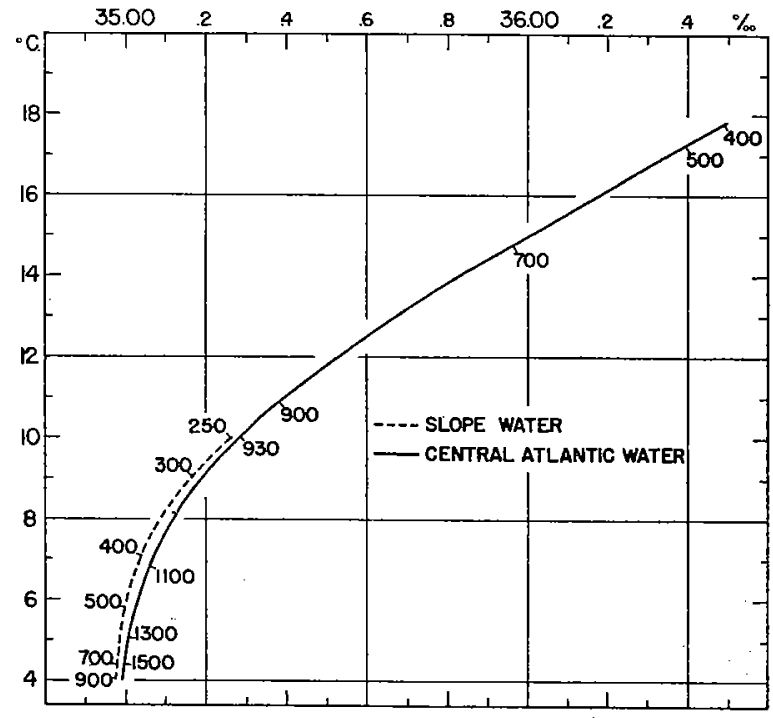

FIG. 23.-Comparison between the mean temperature-salinity correlation of the slope water and of the Sargasso water on the

"Atlantis" sections from Chesapeake Bay to Bermuda.

The Deep Water

TEMPERATURE

Below 2000 meters the number of "Atlantis" observations from a single cruise has usually been too small to warrant drawing in detail the deeper isotherms. In an attempt to show more clearly the probable distribution of temperature in the deep water on the Chesapeake Bay-Bermuda line, we have combined into a single section (Fig. 24) all the observations from water colder than $4^{\circ}$. In this way, it is possible to draw with some certainty the isotherms for each tenth of a degree. The small dots give the locations of the observations on this composite profile. The slope exhibited by the isotherms of from $4^{\circ}$ to $3.5^{\circ}$ on this diagram is considerably less than that shown on the individual profiles (Figs. $3^{-\mathrm{II}}$ ), because in this case the distortion has not been increased in depths shallower than 2000 meters.

The procedure adopted in Fig. 24 would have been misleading if any considerable changes had occurred in the deep water during the period of the "Atlantis" investigations. Especially below a depth of 2500 meters. the changes in temperature from cruise to cruise must have been extremely small, because in drawing the deeper isotherms none of 
the observations from water colder than $3.2^{\circ}$ were inconsistent. In the layer bounded by the isotherms of $3.2^{\circ}$ and $3.5^{\circ}$, six observations seemed to depart from the average trend by slightly more than the observational error. Above this, between $3.5^{\circ}$ and $4^{\circ}$, the uncertainty of the exact trend of each isotherm was somewhat greater. This layer appears to be influenced slightly by oscillations in the depth of the main thermocline. However, in no layer deeper than the $4^{\circ}$ isotherm was there a sufficient departure from the average temperature to obscure the general course of each isotherm.

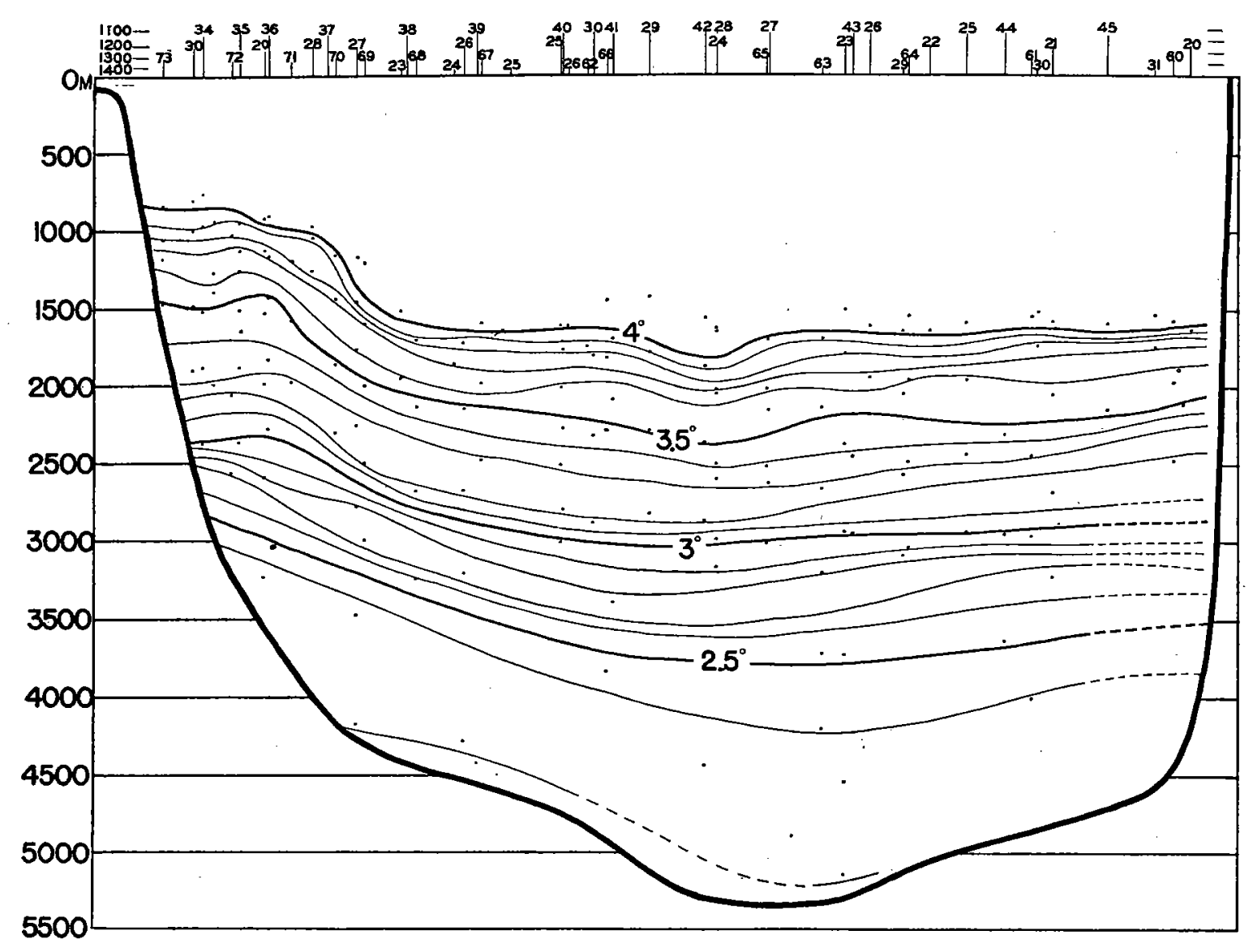

FIG. 24.-Composite temperature section for the waters colder than $4^{\circ}$ constructed from all available "Atlantis" observations of the Chesapeake Bay-Bermuda sections.

In spite of the poverty of readings from below 3000 meters, it seems certain that the rather flat arrangement of the isotherms just below the main thermocline on each side of the Gulf Stream gradually disappears with depth, until in the deepest parts of the section the thermal trends roughly parallel the contour of the bottom. The decrease in temperature with depth apparently remains nearly constant until the $2.5^{\circ}$ isotherm is reached. Below this depth the vertical temperature gradient is very small, but nowhere is thermal stability entirely lacking. As has been pointed out by Wüst (1933) in his discussion of the Atlantic bottom temperatures, the bottom water in this part of the North Atlantic contains only a small percentage of water from the far south. 


\section{SALINITY}

As shown above (Fig. 23) the average depth of the isohaline of $35 \%$ was about 450 meters in the slope water and I 400 meters in the Central Atlantic water. The "Atlantis" observations on this section from below 4000 meters show salinities of between 34.90 and $34.93 \%$. Therefore, a combination of all the deep "Atlantis" salinity observations into one section is not allowable, because the error in the determinations is about half as great as the average total decrease in salinity found between mid-depths and the bottom.

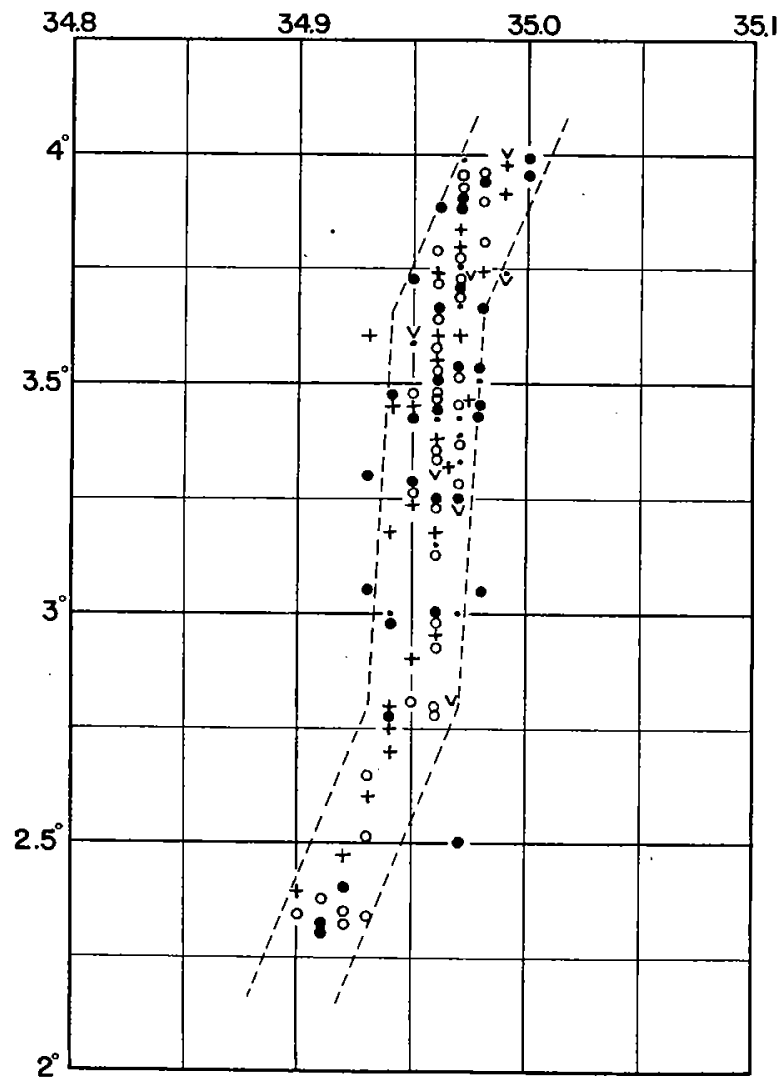

FIG. 25.-Temperature-salinity correlation for the waters colder than $4^{\circ}$ on the Chesapeake Bay-Bermuda sections.

A plotting of the observations in the form of a T-S diagram provides a suitable method of examining closely the distribution of salinity in the deeper parts of the "Atlantis" sections between Chesapeake Bay and Bermuda. This has been done in Fig. 25, using the customary symbols to distinguish between the observations from each of the five cruises. It can be seen that the great majority of the points again fall between two parallel lines separated by a distance equal to $0.04 \%$ on the salinity scale. The mean of these two lines gives the average relationship between temperature and salinity for the temperature observations plotted in section in Fig. 24. The distribution of the points on the diagram suggests that there is very little decrease in salinity with depth in the layer bounded by the isotherms of $3.7^{\circ}$ and $2.8^{\circ}$. This is the layer which Wüst (I935) has named the "mid- 
dle North Atlantic deep water" (Tm). It is characterized by maximum oxygen readings which clearly indicate that it has a southward component through these "Atlantis" sections. ${ }^{14 a}$

\section{Density}

No attempt will be made here to present a full discussion of the distribution of density on the "Atlantis" sections, because it would then be necessary to enter more deeply in to the complex question of oceanic circulation and the causes of the Gulf Stream's flow.

Awaiting more suitable data for a dynamic study in the western North Atlantic, it is enough in the present connection to point out the close parallelism between temperature

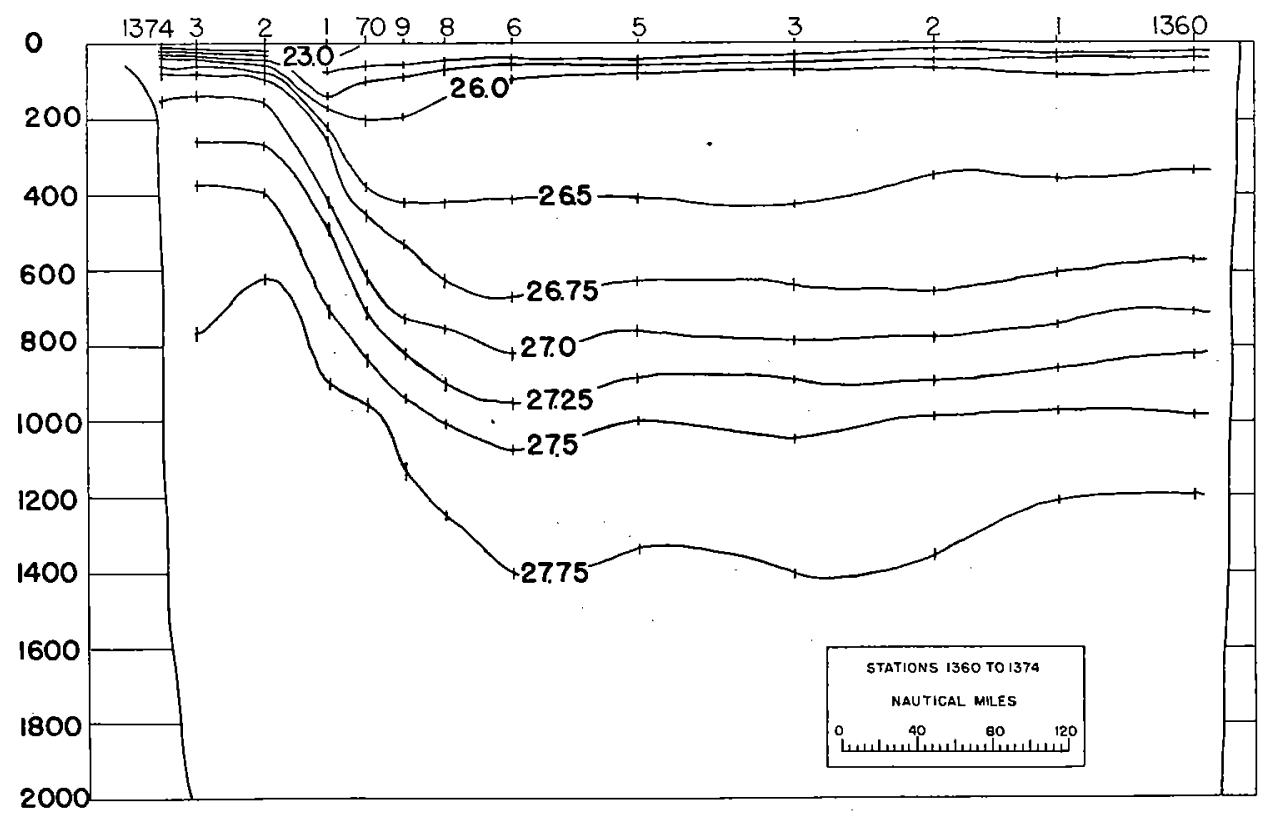

FIg. 26.-Density $\left(\sigma_{t}\right)$ values of the "Atlantis" section between Chesapeake Bay and Bermuda, Aug. 28-Sept. 3, 1932.

and density $\left(\sigma_{t}\right)$ in this region. This can be examined by comparing the distribution of density on the August section between Chesapeake Bay and Bermuda (Fig. 26) with the corresponding temperature profile (Fig. 7). Their almost complete agreement proves that in this region the effect of salinity is secondary and that the isopicnals follow closely the thermal trends.

Through the kindness of Lt. Hoyle of the U. S. Coast Guard, who carried through the necessary calculations, a velocity profile (Fig. 27) based on the April section can be presented here. The 2000 decibar level has been used as the reference plane. ${ }^{15}$ This dia-

${ }_{14 a}$ However, if the circulation theorem is to be relied on in the deeper layers, it is evident from Fig. 24 that in the western half of this section the deeper waters are moving northward. Only in the eastern half, at depths greater than 2000 meters, does the slant of the isotherms call for a southward flow.

15 A velocity profile based on the same "Atlantis" section has recently been published by Dietrich (1936). Since his calculations are referred only to the $8^{\circ}$ isothermal level, the velocities are considerably lower than given here. We do not hold with his argument that the oxygen minimum, which coincides with the $8^{\circ}$ isotherm, is indicative of a lack of current. On the contrary, the evidence is strong that the flow is by no means negligible in the 800-1000 meter level. The low oxygen readings in the heart of the current at these depths result from the influence of Sub-Antarctic intermediate water transported well north of its usual limits by the Florida Current (Fig. 59). For a further discussion of this important question, see Rossby (I936). 
gram confirms the general belief that the western margin of the current is extremely abrupt, while on the eastern side the velocity decreases gradually. The total transport of the current is found to equal $82.25 \times 10^{6}$ cubic meters per second. The sources of the moving water will be considered later (page 75). Meanwhile, the close agreement between the distribution of velocity and the slope of the isotherms (compare with Fig. 5) is important evidence that in this region the temperature sections can readily be interpreted in terms of currents and even to some extent of velocity.

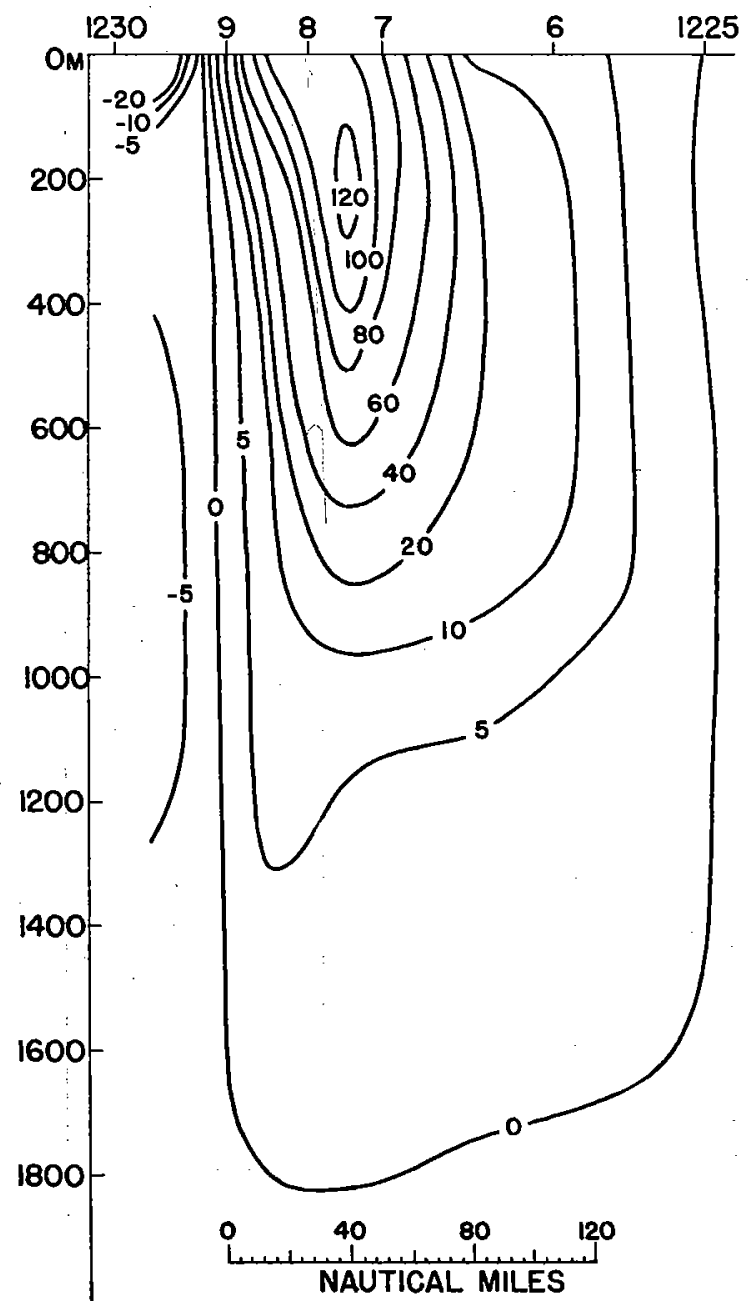

FIG. 27. - Velocity profile, expressed in cm. per sec., across the Gulf Stream off Chesapeake Bay, April 20-22, 1932.

\section{OTHER “ATLANTIS” SECTIONS}

\section{The Location of the Sections}

In accordance with the plan of gradually carrying out a general survey of the western North Atlantic, several times during the past five years the "Atlantis" has been sent on longer cruises to gather temperature and salinity data outside the region just examined. 


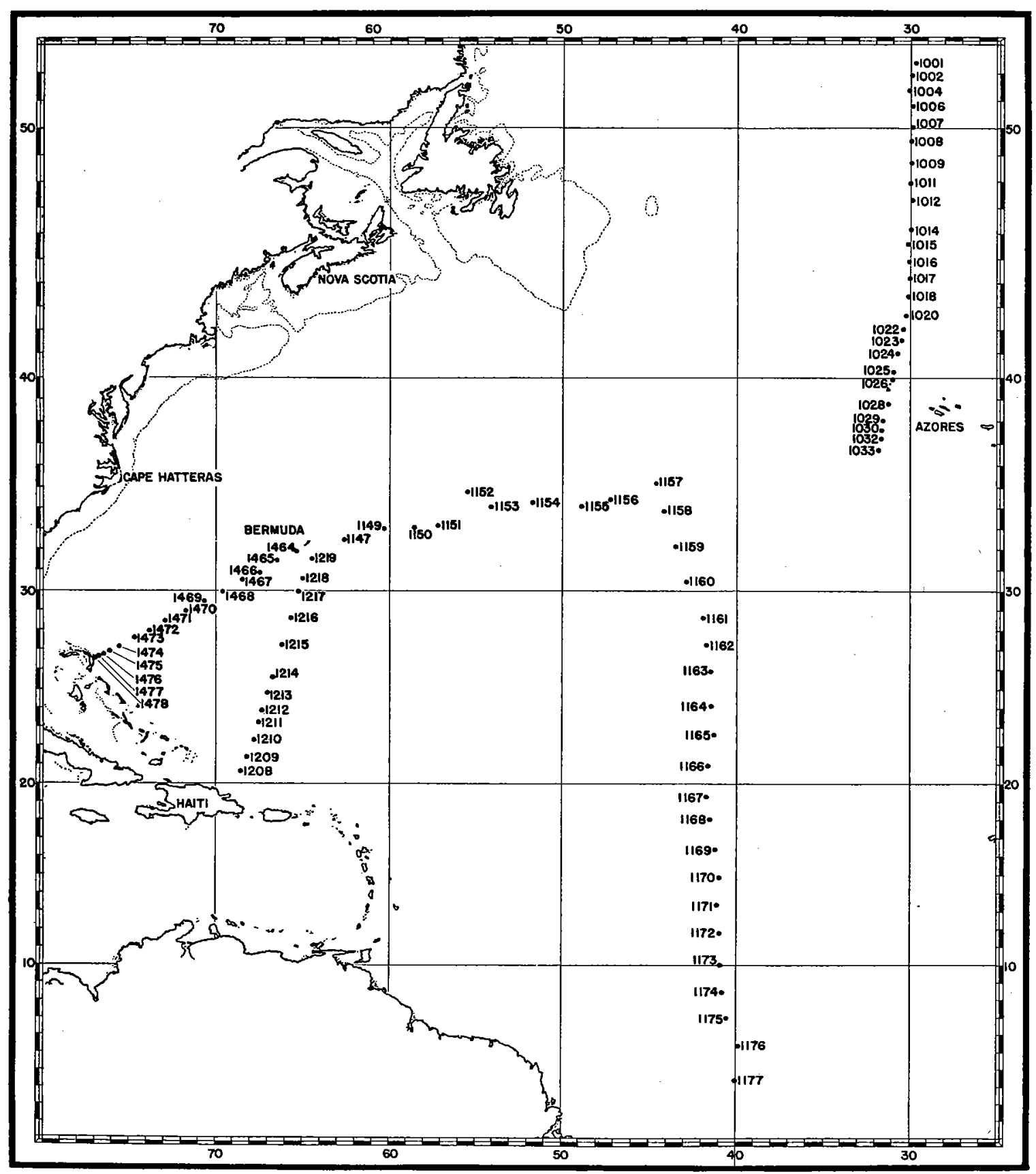

FIG. 28.-Locations of stations constituting the "Atlantis" mid-Atlantic and Antilles Current sections. 
The locations of these stations are given in Figs. 28 and 40. The sections will be discussed in three groups as follows:

a. Mid-Atlantic Sections.

I. The North Atlantic Current-July 26-Aug. 6, I931

Stations IOOI-IO33.

2. The Northern Equatorial Current-March 3-19, I932

Stations I I $57^{-1}$ I 77 .

b. Antilles Current Sections.

I. Bermuda to Haiti-April 7-13, I932

Stations I 208-I219.

2. Bermuda to Elbo Cay-Feb. I2-20, I 933

Stations $\mathrm{I}_{4} 64^{-\mathrm{I}} 478$.

c. Florida Current Sections.

I. Cape Canaveral-May i I, I933

Stations I6II-I6I7.

2. Jacksonville-May I 2-I3, I933

Stations r6r 8-1626.

3. Onslow Bay-May I6-I7, I933

Stations $1633^{-16} 62$.

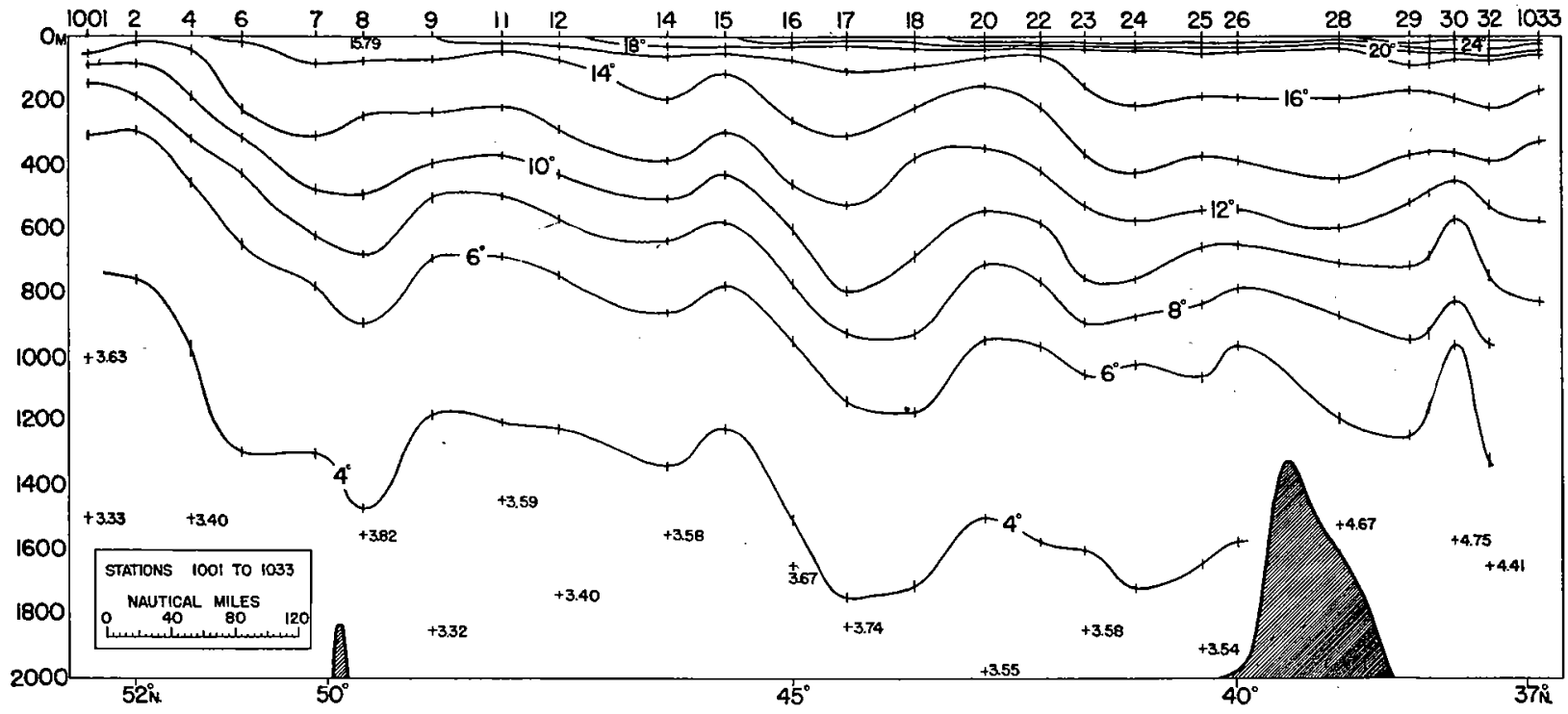

FIG. 29.-Temperature section along the Mid-Atlantic Ridge, July 26-Aug. 6, I93I.

Examination of these profiles will not only familiarize the reader with the distribution of temperature and salinity over much of the western North Atlantic, but will also enable him to judge critically any discussion of the permanent current system which surrounds the Sargasso Sea.

\section{Mrd-Atlantic Sections}

THE NORTH ATLANTIC CURRENT

Between July 26 and August 6, I93 I, while on her first cruise, the "Atlantis" occupied 25 hydrographic stations on a 950 mile line, closely paralleling longitude $30^{\circ} \mathrm{W}$ and ex- 
tending from latitude $52^{\circ} 28^{\prime} \mathrm{N}$ to a point some $\mathrm{I} 70$ miles south of the island of Flores. The observations were made, for the most part, just west of the crest of the Mid-Atlantic Ridge. According to Ekman (I928), the various branches of the Atlantic Current (as the continuation of the Gulf Stream beyond the Grand Banks is now generally called) in crossing this ridge must react to the shoaling of the bottom by first bending towards the south and then towards the north after the crest of the rise has been passed. This point should be kept in mind while examining this "Atlantis" profile (Figs. 29 and 30) for it may not have crossed any of the branches of the great easterly flowing current at right angles. Because of the shallowness of the Azores Bank, the southern stations of this line must cross an especially complicated system of eddies and curving currents.

Partly because of technical difficulties, and partly because too few unprotected thermometer readings were secured, this series of observations is not entirely satisfactory. No readings were taken from below 2000 meters and because of the wire angle many of the stations failed to reach even this depth.

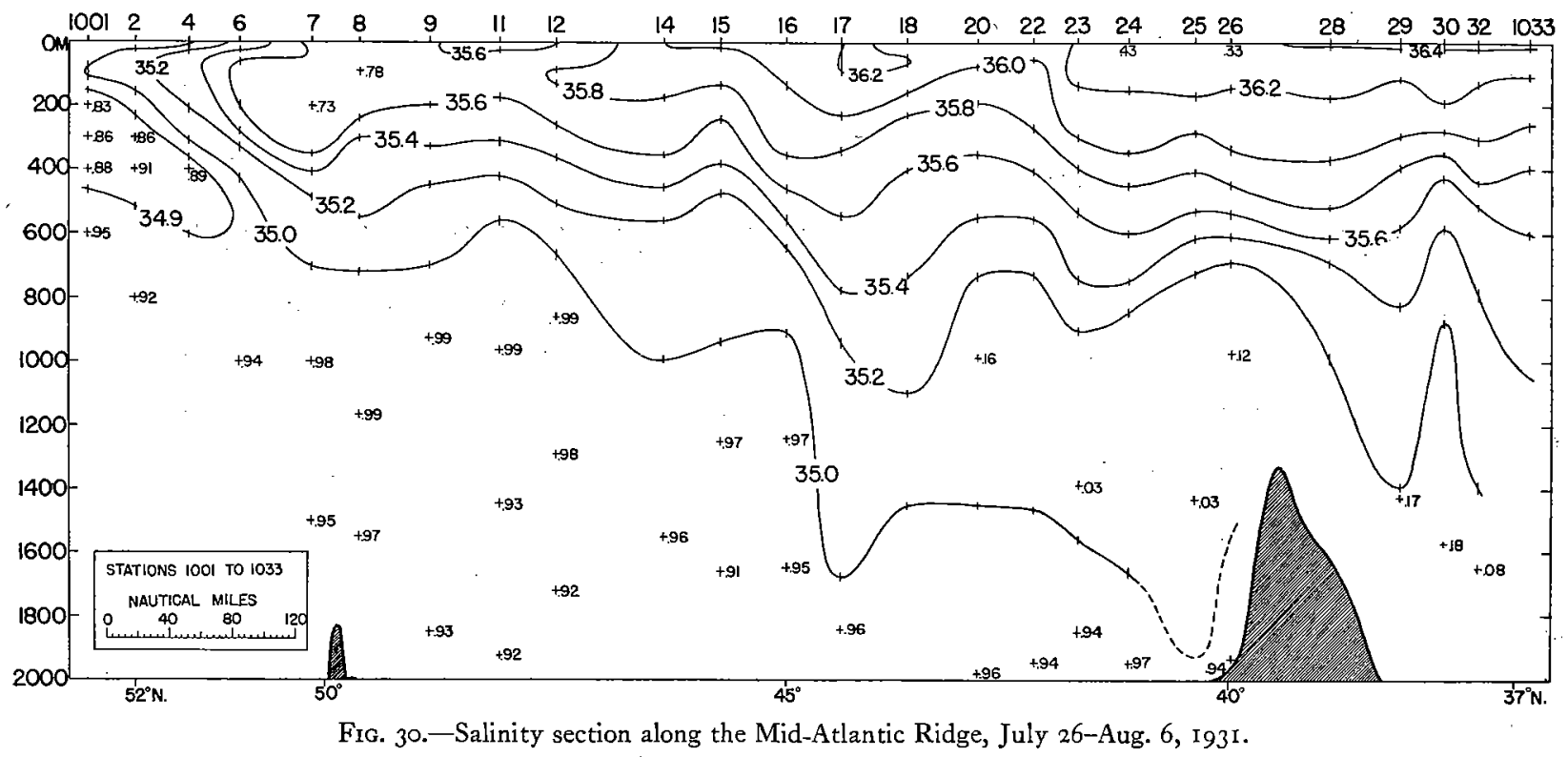

Figure 29 (constructed on the same scale as the Bermuda profiles) shows the temperature at the surface as increasing gradually from north to south, but the two major bands of slope exhibited by the deeper isotherms is evidence that the transition from the relatively cold northern waters to the warmer conditions of the eastern Sargasso Sea was not gradual, but was interrupted by several lines of relatively swift current. The most northern of these lay between latitudes $5^{\prime}{ }^{\circ} 27^{\prime} \mathrm{N}$. and $49^{\circ} 23^{\prime} \mathrm{N}$., where in the course of I 24 miles, the $10^{\circ}$ isotherm dipped downward by about 400 meters. The slope of the colder layers was even greater, because south of this most northern branch of the North Atlantic Current, the main thermocline layer had a greatly increased thickness.

In a second, less marked, band of gradient (between stations 1015 and 1017 ), the $10^{\circ}$ isotherm further sank to 800 meters, which is about its average depth everywhere in the Sargasso Sea (see page 70).

Although these two bands of current are the most pronounced feature of the temper- 
ature section, we cannot disregard the extremely wavy nature of the isotherms in the southern half of the profile. We have here to deal with a difficult problem, because it cannot be known with certainty whether such waves are caused by deep eddies or by oscillations in the depth of the thermocline layer. Evidence presented later (page $\infty \circ$ ) indicates that these distortions, though probably fluctuating in position, seem to result from deep bands of current.

The corresponding salinity section (Fig. 30) shows, in the south, almost identical distortions of the isohalines at mid-depths. But near the surface and at the northern end of the section, the distribution of salinity does not so closely follow the thermal trends, this being the first case which we have so far examined where the salinity and temperature sections at mid-depths do not agree. The distribution of salinity at the 5 northern stations calls for a southern component of the surface waters (above 40 meters). ${ }^{16}$ Then between 40 and 200 meters a wedge of higher salinity $(35.78 \%)$ was apparently spreading northward, while below it, an extremely fresh layer $(34.86-34.90 \%)$ was penetrating downward and in the reverse direction.

This situation can be further illustrated by the marked differences between the T-S diagrams for the 5 northern stations (rOOI-IOO7), all within the band of current, shown at the left in Fig. 3I, contrasted with the fact that the T-S correlation did not much further change south of station 1007 for the next I60 miles (stations I008-I0I2).

We can conclude that the most northern branch of the North Atlantic Current as it crosses this line is relatively shallow when compared to the true Gulf Stream between Cape Hatteras and Nova Scotia, and that there is a northern component to the movement of the waters just below the surface, while beneath this water of low salinity penetrates southward and downward along the slope of the $6^{\circ}$ isotherm. ${ }^{17}$ But in crossing the current the relatively fresh, intermediate layer is so subjected to turbulence that its very low salinities $(<34.90 \%)$ are soon absorbed and disappear. Since this water has clearly originated further north, the situation is the counter part of that reported by Wüst (I 928, I935) and others from the South Atlantic (Lat. $42^{\circ}-48^{\circ}$ S.). The "Atlantis" data indicate that in the North Atlantic the southward movement of Sub-Arctic water at mid-depths ("Sub-Arctic intermediate layer" according to Wüst's (1935) terminology) is relatively weak. In mid-ocean this fresher layer coming from the northern "polar front" was not traceable as a layer of minimum salinity south of about latitude $48^{\circ} \mathrm{N}$. It, therefore, cannot play an important role at mid-depths in the Sargasso Sea. The fact that this southward flow of relatively fresh water is so much weaker than its counterpart in the South Atlantic constitutes for mid-latitudes one of the major differences between the two oceans.

It is important also to note that this most northern branch of the Atlantic current carried no water warmer than $15^{\circ}$ or more saline than $35.7 \%$. Although it presumably originated from the Gulf Stream off the southern extremity of the Grand Banks, by midocean, mixture with northern water had greatly diluted the upper layers.

The details of the temperature-salinity correlation for the northern third of this "Atlantis" section can be examined at the left (Group A) in Fig. 31. For the layer

${ }^{16}$ This is probably a good example of the transfer of surface water to the right of the wind direction. The influence of the wind on the surface movements will be discussed later (page 82).

${ }^{17}$ Seven recent (Sept. I935) "Atlantis" stations on a line northward from latitude $40^{\circ} \mathrm{N}$. show the existence of this low salinity layer roughly 400 miles further to the west. Evidently the sinking and southward penetration of the relatively fresh, northern water begins to affect the northern branch of the Gulf Stream System only a short distance east of the
Grand Banks. 
bounded by the isotherms of $10^{\circ}$ and $6^{\circ}$, the readings are all considerably fresher than in Gulf Stream or Sargasso Sea water. Even at stations IOI I and IOI2, roughly 280 miles south of the northern edge of the band of strong easterly current, the salinities for $7^{\circ}$ water are 0.6 to $0.8 \%$ less than in the Bermuda sections. That the freshening of the northern branch of the North Atlantic Current is due largely to its absorption of the SubArctic intermediate layer and is not caused by its close proximity to the Labrador Current in the Grand Banks region, seems probable. With the exception of the shallow surface film, the main freshening of the current is clearly centered at mid-depths and the resulting temperature salinity correlations bare no stamp of a previous admixture of the much fresher and colder Labrador Current.

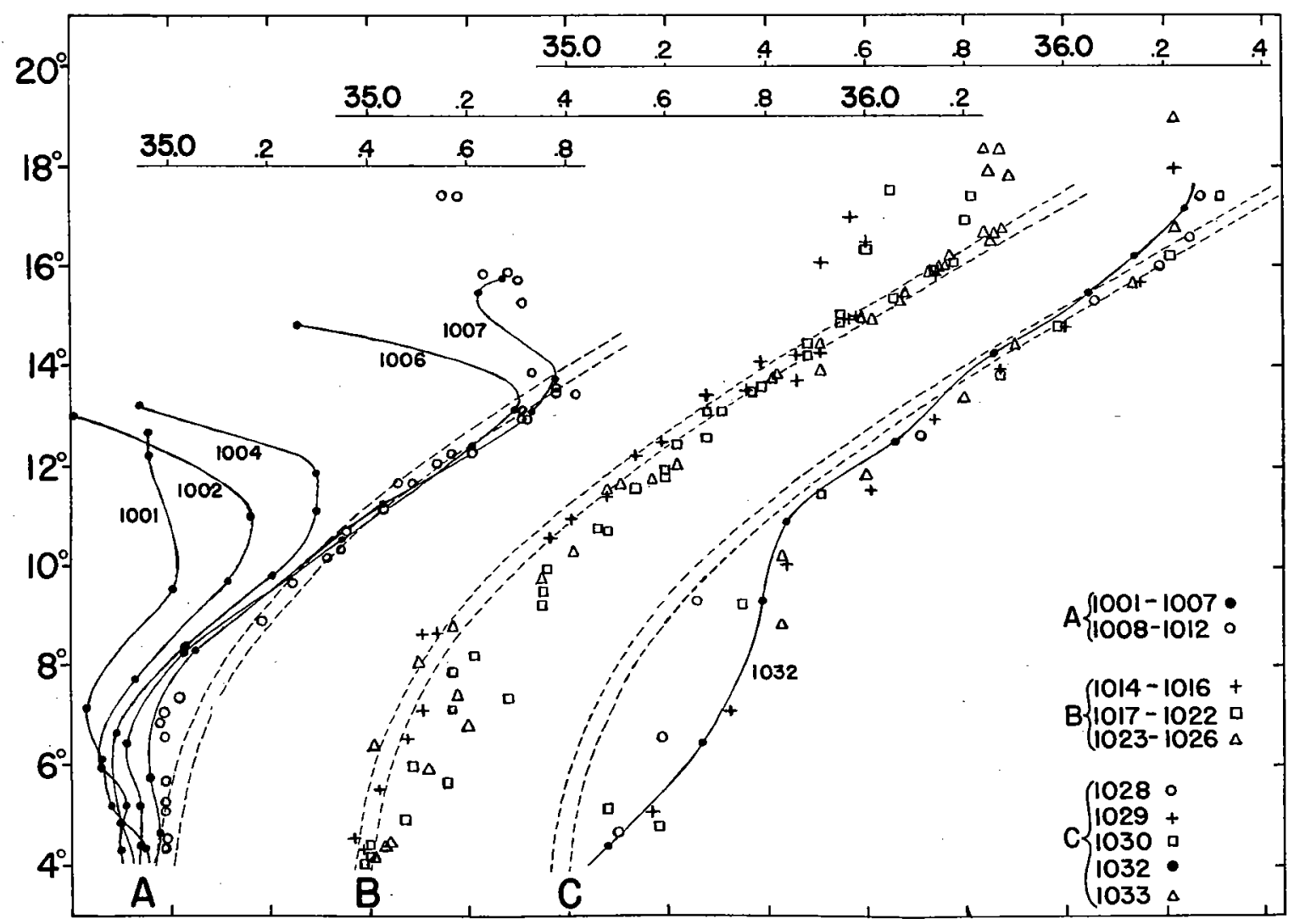
FIG. 31.-Temperature-salinity correlation along the Mid-Atlantic Ridge compared with the mean relationship (broken
curves) found in the western Sargasso Sea.

The T-S ratios of the central group of stations (group B Fig. 3I) on this "Atlantis" profile show a relative increase in salinity at mid-depths from north to south, but the observations are quite scattered and the change is not a gradual one. It should be noted that the observations from stations IOI 4 -IOI6 (Lats. $46^{\circ}-45^{\circ} \mathrm{N}$.) most closely resemble water from the western Sargasso Sea, while south of the second band of current the salinities at mid-depths are somewhat higher. In the same manner the observations from south of the Azores (group C Fig. 3I) show even higher relative salinities especially between the temperatures of $10^{\circ}$ and $5^{\circ}$. The curve giving the T-S correlation at one of 
these (I032) has been drawn and is clearly of the form shown by Jacobsen (I929) to be indicative of a strong admixture of water of Mediterranean origin. The extent of this layer influenced by the outflow from the Mediterranean is discussed on page 90 . We need only note here that for 200 miles north and south of the Azores, between the depths of 600 and 1600 meters, the salinities for a given temperature are usually considerably higher than in the western Sargasso Sea.

\section{The Northern Equatorial Current}

This section, consisting of $2 \mathrm{I}$ stations, paralleling longitude $4^{\circ}{ }^{\circ} \mathrm{W}$., and extending southward from latitude $35^{\circ} \mathrm{IO} / \mathrm{N}$. nearly to the equator is representative of mid-ocean conditions for the southern half of the North Atlantic. While its most northern stations lie in the eastern part of the Sargasso Sea and the southern stations in the doldrum belt, the great majority of the observations cut across the northeast trade wind region. Consequently the data are instructive for the study of wind currents.

While engaged in this work, the "Atlantis" experienced mostly fine weather. It was, therefore, possible to keep an accurate navigational record, and the trade winds being light during this period, little trouble was experienced from excessive wire-angles, except at the most southern stations where the current at the surface was observed to be extremely swift and shallow.

The distribution of temperature for this section is shown in Fig. 32. Because of the great length of the profile (about I950 nautical miles), in plotting the data it was advisable to decrease the longitudinal scale so that 3 nautical miles here equals 10 meters in depth (between 0 and 2000 meters). This produces a distortion of about $1: 547$, approximately $50 \%$ more than that to which the Bermuda sections are drawn. Since the stations extend nearly north and south, a latitude scale has been added below the observations. Likewise included is a record of the wind direction and velocity (Beaufort scale) experienced by the "Atlantis."

The main feature shown by this temperature profile (Fig. 32 ) is a concentration of the warmer isotherms $\left(26^{\circ}\right.$ to $\left.10^{\circ}\right)$ between the depths of 50 and 200 meters towards the southern end of the line, producing there great stability just below the shallow wind stirred surface layer. North of latitude $10^{\circ} \mathrm{N}$. this extremely sharp thermocline begins to deeperr and the isotherms separate gradually until at the northern end of the section the thermal arrangement of the water layers with depth is very similar to that found in the western Sargasso Sea. Since the greater part of this gradual deepening and decrease in intensity of the layer of most rapid thermal change with depth takes place between latitudes $10^{\circ} \mathrm{N}$. and $25^{\circ} \mathrm{N}$., the part of the section showing maximum thermal slope corresponds roughly to the trade wind belt.

The regular increase in surface temperature from north to south was to be expected because of the latitudinal range. On the other hand, the thickness of the wind stirred, superficial layer abruptly decreased south of latitude $32^{\circ} \mathrm{N}$. Probably the three northern stations showed this much deeper layer of small thermal stability because they lay far enough north to come under the influence of winter chilling and stronger winds. The three marked humps (at stations II 59, II63, II74) in the deeper isotherms are not so easily accounted for. But as the observations have been carefully checked, it seems improbable that the depth determinations at these stations were at fault.

The corresponding salinity profile (Fig. 33) shows that for the surface layer the changes in salinity did not parallel the gradual thermal trend. On the basis of salinity 


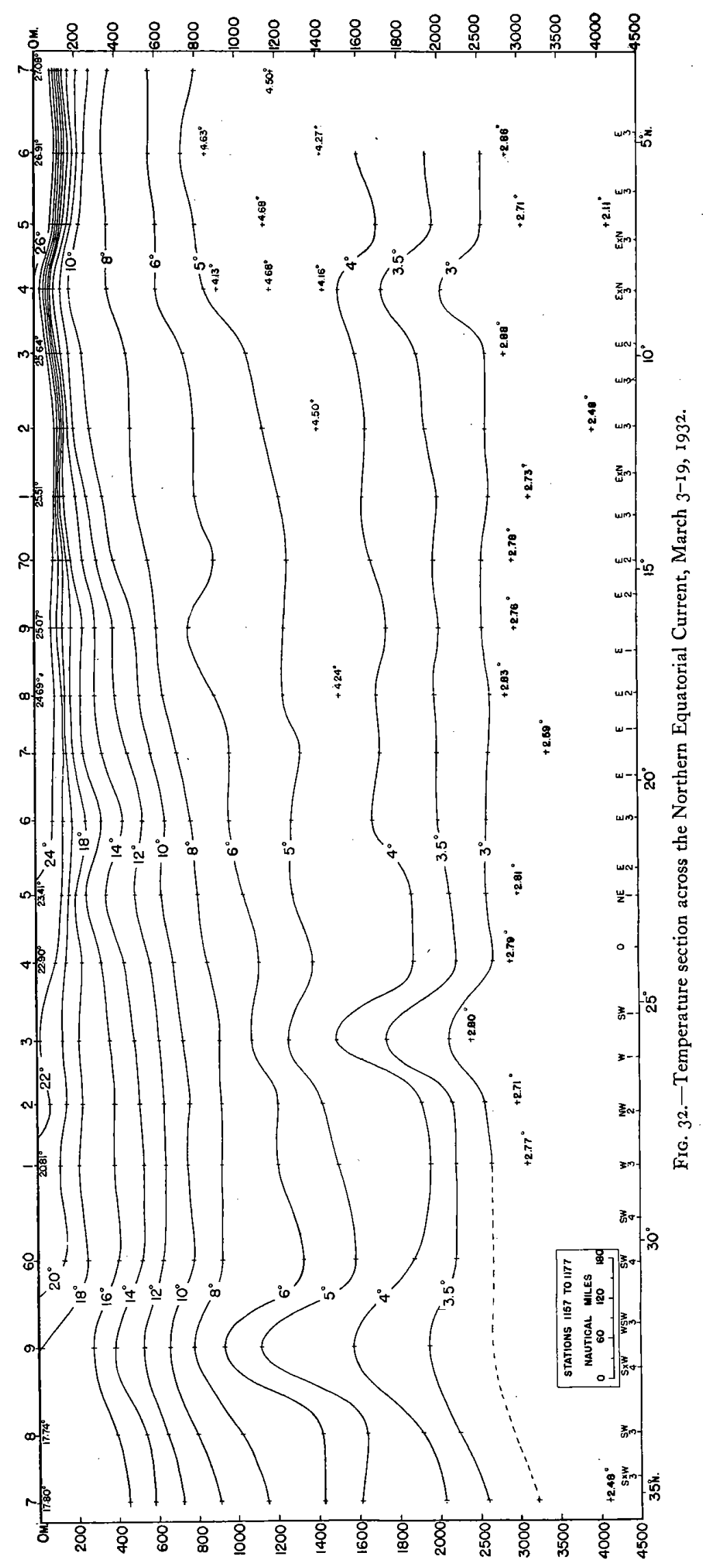




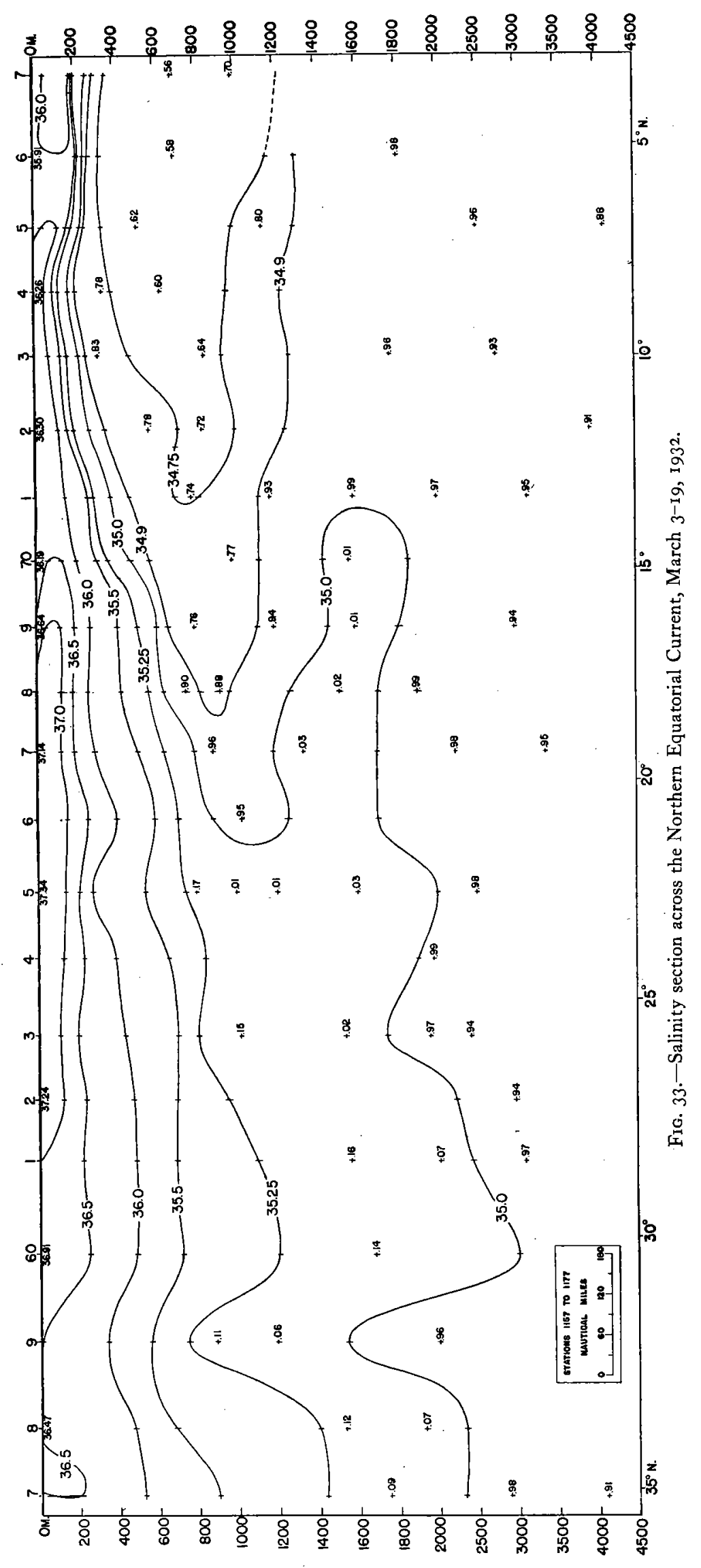


four marked zones can be distinguished. At the northern stations the surface readings (about $36.50 \%$ ) were very similar to the mean of the "Atlantis" winter observations near Bermuda. Then between latitudes $28^{\circ} \mathrm{N}$. and $\mathrm{I} 6^{\circ} \mathrm{N}$. was found a band having values higher than $37 \%$. Since at the time the section was run this region of highest salinity corresponded in position to the horse latitudes and to the northern third of the trade wind belt, it probably was the result of high evaporation and slight precipitation typical of those latitudes. South of station I 169 (Lat. I6 $6^{\circ} 2{ }^{\prime} \mathrm{N}$.) the salinity suddenly dropped to about $36.20 \%$. These fresher conditions near the surface were characteristic as far south as latitude $7^{\circ} \mathrm{N}$. (station I I75) where the even less saline waters $(<35.9$ $\%$ ) of the doldrum belt were first met with. ${ }^{18}$

Much more pronounced is the wedge-shaped mass of low salinity water at middepths in the southern half of the profile. The axis of this wedge sloped downward from south to north, for the minimum salinity $(34.56 \%$ was at about 700 meters near the equator, while its most northern tip (latitude $22^{\circ} \mathrm{N}$.) lay at a depth of 1000 meters.

It is now well established by. Wüst (I928, I935) and others that this layer of low salinity (Sub-Antarctic intermediate layer) has its origin at the surface in high southern latitudes. It is a much more widespread feature of the South Atlantic than are the high salinities found at similar depths in the eastern North Atlantic, resulting from the outflow from the Mediterranean.

The effect of the intermediate, low salinity layer on the distribution of density $\left(\sigma_{t}\right)$ in the southern half of this "Atlantis" section is shown in Fig. 34. Near the surface, the extremely marked thermocline of course produced a very stable layer, but below this, the disagreement between the trends of temperature and of salinity cause a much smaller slanting of the isopicnals than would be expected from the temperature distribution alone. In fact, below 600 meters, the mean slope of the isopicnals is actually reversed, that is, the density for a given depth very slightly decreases from north to south. In short, there is little evidence in this density profile that below a depth of 600 meters the trade winds produce any westerly flow.

While crossing the trade wind belt the "Atlantis" navigational record showed westerly currents varying between 8 and 20 miles per day. These conditions persisted as far south as station I 174 (Lat. $8^{\circ} 20^{\prime} \mathrm{N}$.). Then in a few hours 12 miles of easterly set was experienced and strong tide rips were seen at the surface. Since a reversal in slope of the isolines near the surface appears at this point on the temperature profile (Fig. 32) as well as the density profile (Fig. 34), we have in this instance a striking illustration of how the thermal trends are nearly always reliable evidence of current direction. This counter current was evidently only superficial and narrow, because the isopicnals do not show a reversal in slope below a depth of 300 meters, while south of station II 76 a westerly current was again encountered. The causes which might be expected to produce a shallow counter current in these low latitudes will be discussed later (page 86).

The correlation between temperature and salinity along this line of "Atlantis" stations (Fig. 35) shows that in the north (stations I I 57-I I63), the waters have much the same characteristics when plotted on a T-S diagram as at the stations of the Azores region (Fig. 3I). We can conclude that at least as far west as longitude $40^{\circ} \mathrm{W}$. and about as far south as latitude $25^{\circ} \mathrm{N}$. the influence of the outflow of water from the Mediterranean is a general feature of the eastern Sargasso Sea.

${ }^{18}$ The causes for these three abrupt changes in salinity are further discussed on page 82 . 


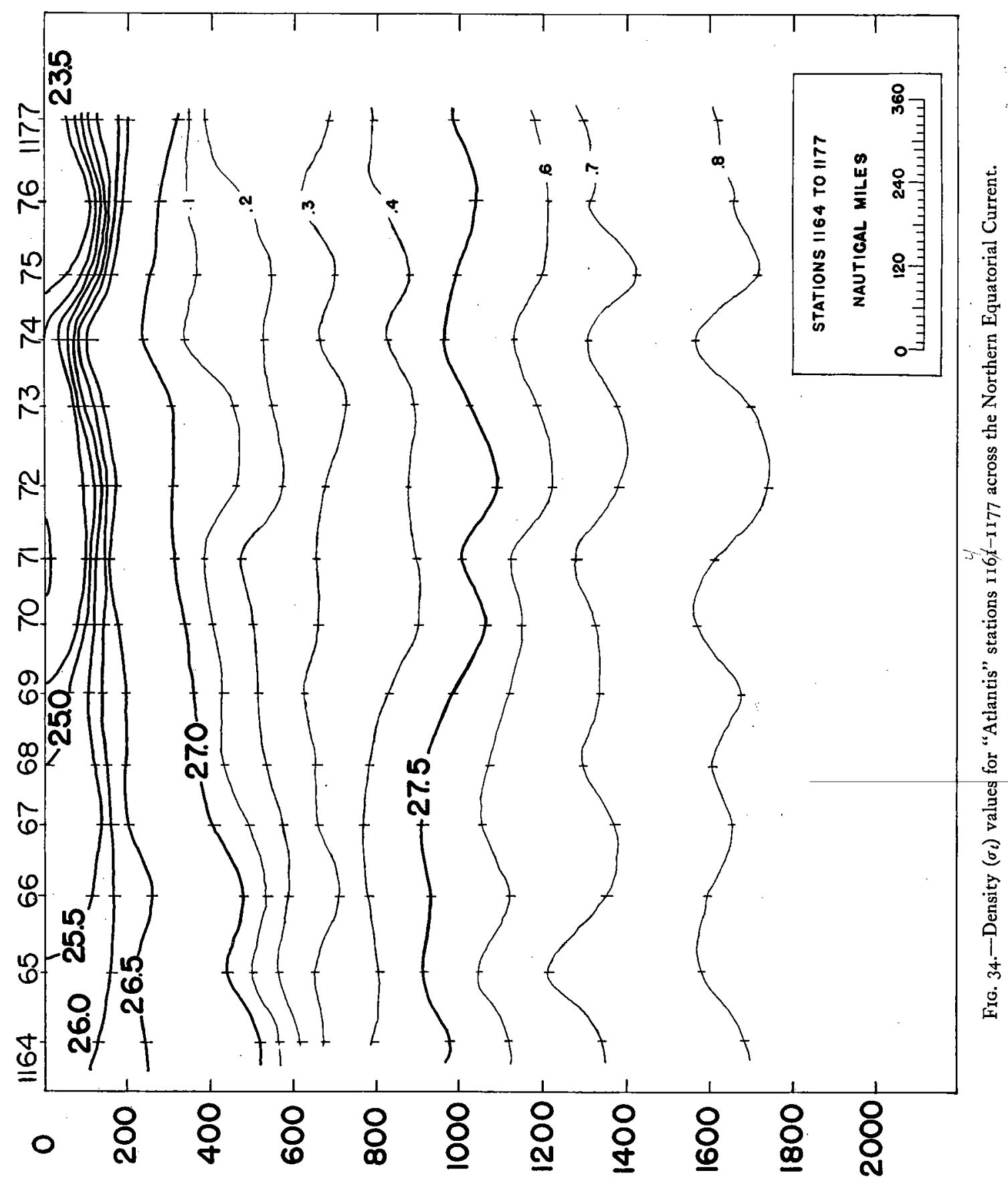




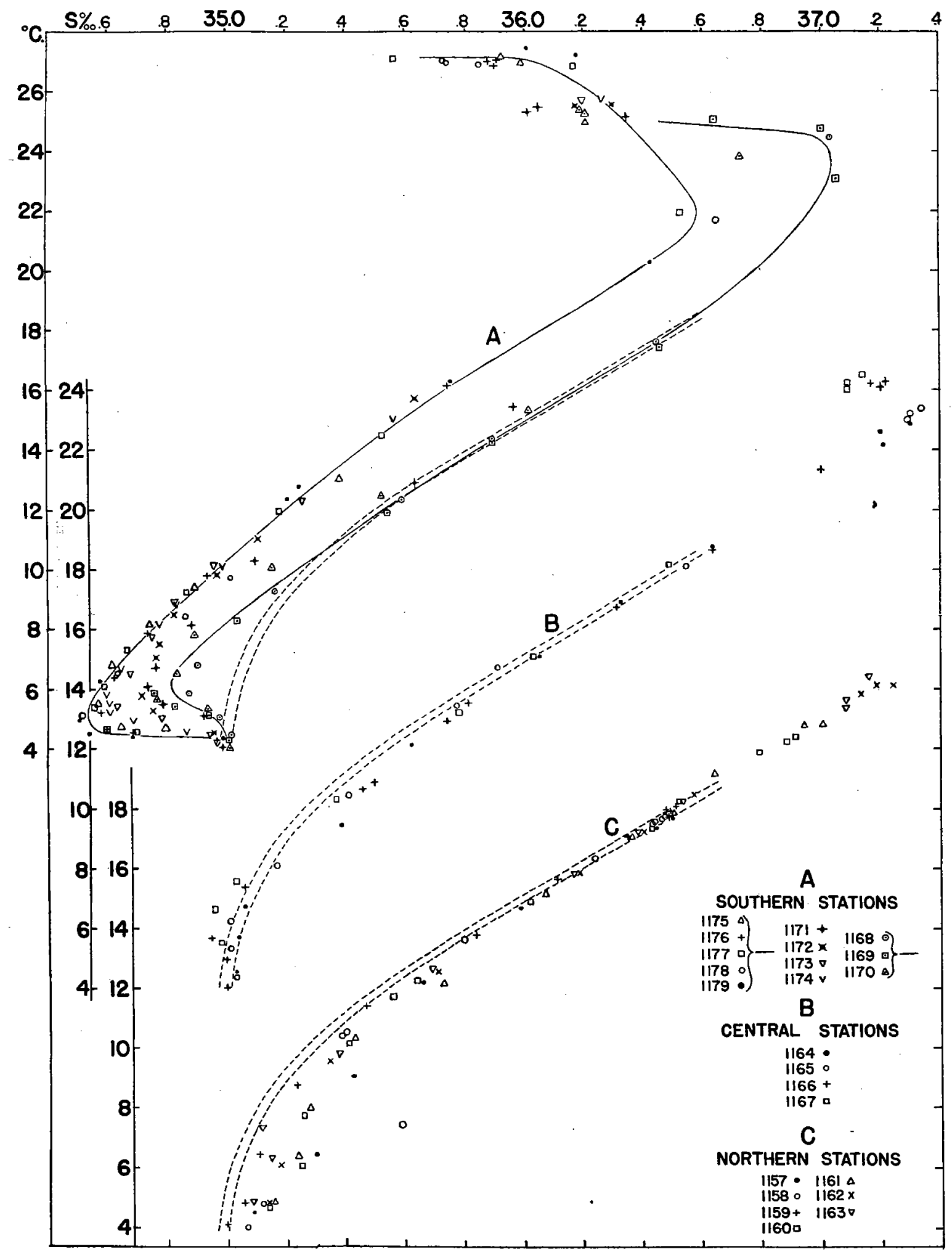

FIG. 35.-Temperature-salinity correlation across the Northern Equatorial Current compared with the mean relationship (broken curves) found in the western Sargasso Sea. 
The central group of stations (II64-II67) on this section show much the same T-S ratio as we have found characteristic of the Bermuda region, although only the observations of the two northern stations of this group fall entirely within the two parallel curves copied from Fig. 22.

Further south (beyond latitude $18^{\circ} \mathrm{N}$.) and at mid-depths the influence of the water from the South Atlantic becomes increasingly strong as evidenced by the two mean T-S curves (the three northern stations of this group on the right and the five southern stations on the left) and the points from intervening stations shown in Fig. 35. Above the layer of lowest salinity, and especially in water warmer than $10^{\circ}$, nearly all the observations fall along the two mean T-S curves and intermediate mixtures do not appear. This sudden change in T-S ratio comes between stations II $I$ I and II 72 (at approximately latitude $I 3^{\circ} \mathrm{N}$.) and is confined only to a shallow layer between the depths of 200 and 300 meters.

Since deeper down the changes in T-S correlation within the layer of Sub-Antarctic intermediate water are gradual from near the equator to the northern tip of the "wedge" (latitude $I 8^{\circ} \mathrm{N}$.), and since this layer has a considerable thickness (900-350 meters), the situation is favorable for a study of the coefficient of mixing. Unfortunately no accurate estimate can yet be made of the velocity of a particle of water in the heart of this "wedge." Although in the "Atlantis" section the northern component of this layer is clearly shown by the distribution of salinity, the westerly component is perhaps as great, due to the effect of the trade-winds, so that a given particle of water must move obliquely in a north-westerly direction. Because the time interval is not known for the change in $T-S$ correlation at mid-depths no reliable calculation for $\mu$, the coefficient of mixing, can be made by the method of Jacobsen (1928). However, if we assume an average value for $\mu$, which is generally assumed to be between I and 20 , we can make a very rough calculation of the time interval by means of Jacobsen's formula. If $\mu$ is given a value of Ioc.g.s. units and the data from stations II 76 and II 69 are used, we find that it would require about tooo days for internal mixing to produce the observed change in $\mathrm{T}-\mathrm{S}$ correlation at mid-depths (600 to 800 meters) between these two stations. In terms of velocity, the results work out at 0.65 miles per day for the northward component of the movement. Evidence presented later (page 93) indicates that this value may not be very. far from correct.

\section{Antilles Current Sections}

$$
\text { HAITI-BERMUDA }
$$

It is a well established fact that a considerable part of the Northern Equatorial Current enters the Caribbean Sea through the passages between the islands of the Lesser Antilles. This is especially true of the exceedingly strong, shallow westerly flow which is found just outside the continental shelf along the north-east coast of South America. Because the islands must offer some obstacle to the free entrance of the Equatorial Current, it seems reasonable to assume that an increase in velocity may result for that part of the westward flow which does not enter the Caribbean, but continues northwestward along the line of the Bahama Islands to join the outflow from the Straits of Florida, just north of Little Bahama Bank. This current is known as the Antilles Current, and according to Wüst's (1924) calculations it supplies the Gulf Stream with about half as much water as does the outflow from the Straits of Florida.

Since the flow of this current has a considerable northward component, it should be 
relatively warm at the surface. Furthermore, if any of the surface water from the equatorial region crosses Mona Passage without entering the Caribbean, we can expect to find a relatively fresh layer at the surface in the Antilles Current. Moreover, if this current is deep enough to carry any of the Sub-Antarctic intermediate water northward, it will also be characterized by relatively low salinities at mid-depths.

During the period April 7-13, 1932, the "Atlantis" occupied I2 stations on a line between Silver Bank (northeast of Haiti) and Bermuda. The first station was made in deep water 25 miles northeast of the banks. Since the section is approximately 690 nautical

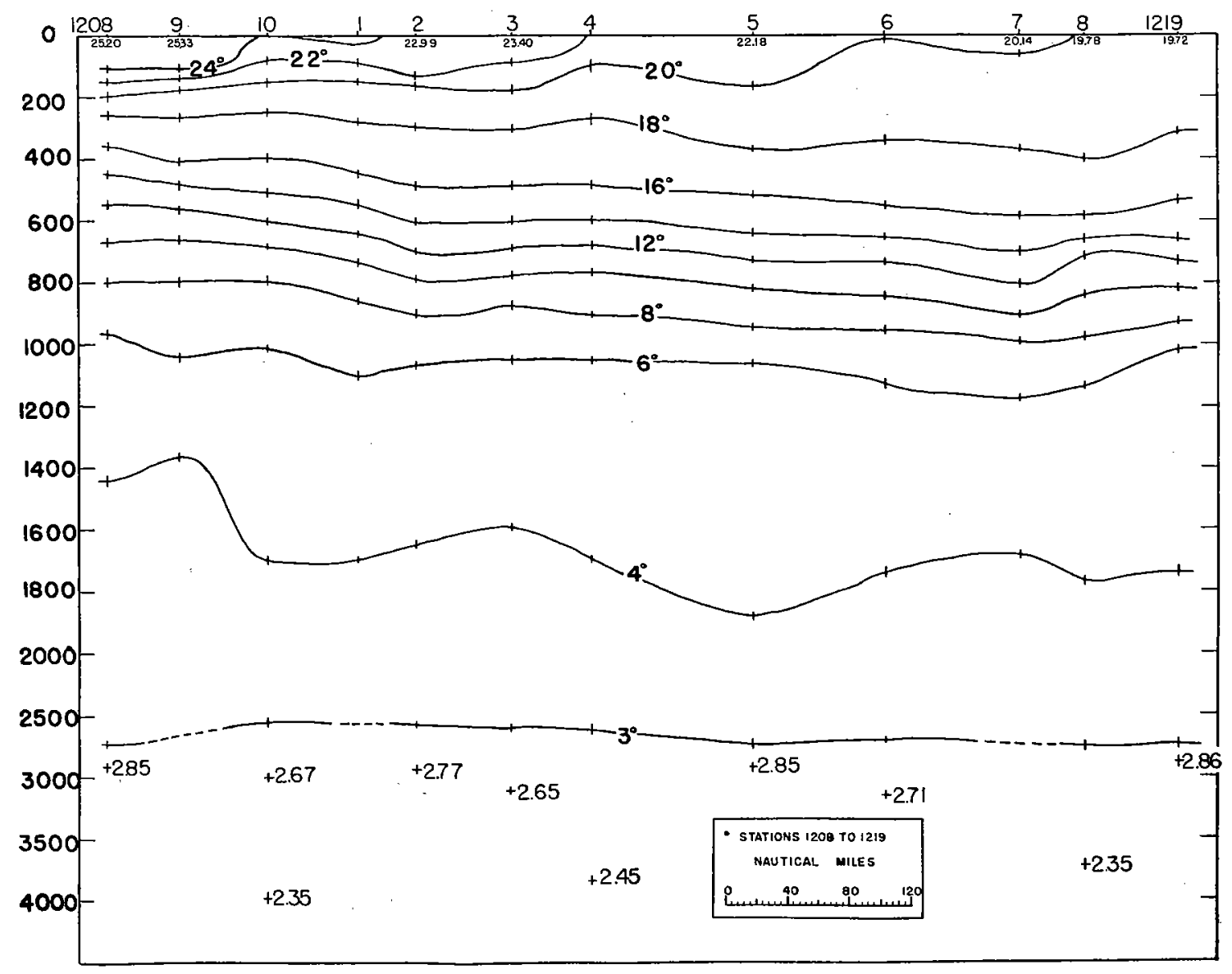

FIG. 36.-Temperature section, Haiti-Bermuda, April 7-13, $193^{2}$.

miles in length, the same scale is used in plotting the observations as for the lines west of Bermuda.

If the gradual deepening of the thermocline layer from south to north in this section (Fig. 36) is compared with the thermal changes for similar latitudes in mid-ocean (Fig. 32 ), we find that both the depths of the isotherms and their slope are very similar in both sections. Even the surface layer warmer than $24^{\circ}$ extends about the same distance north in both profiles. In short, the thermal trends in Fig. 36 indicate the same broad, slow type of westerly flow found at corresponding latitudes in mid-ocean. There is no thermal 
evidence for a much swifter current following the line of the banks northeast of Haiti.

The salinity section (Fig. 37) gives the same general picture. But while the correspondence between temperature and salinity is in general extremely close, there were two notable points of disagreement. First, near the surface at the southern end of the section (stations I 208 and I 209) can be seen a relatively fresh layer which in all probability has come from the equatorial region; second, at station I209 at mid-depths (800-I 200 meters), relatively low salinities again imply a southern origin. However, as will be shown later (Fig. 57) this freshness at mid-depths is not much greater than for the same latitude

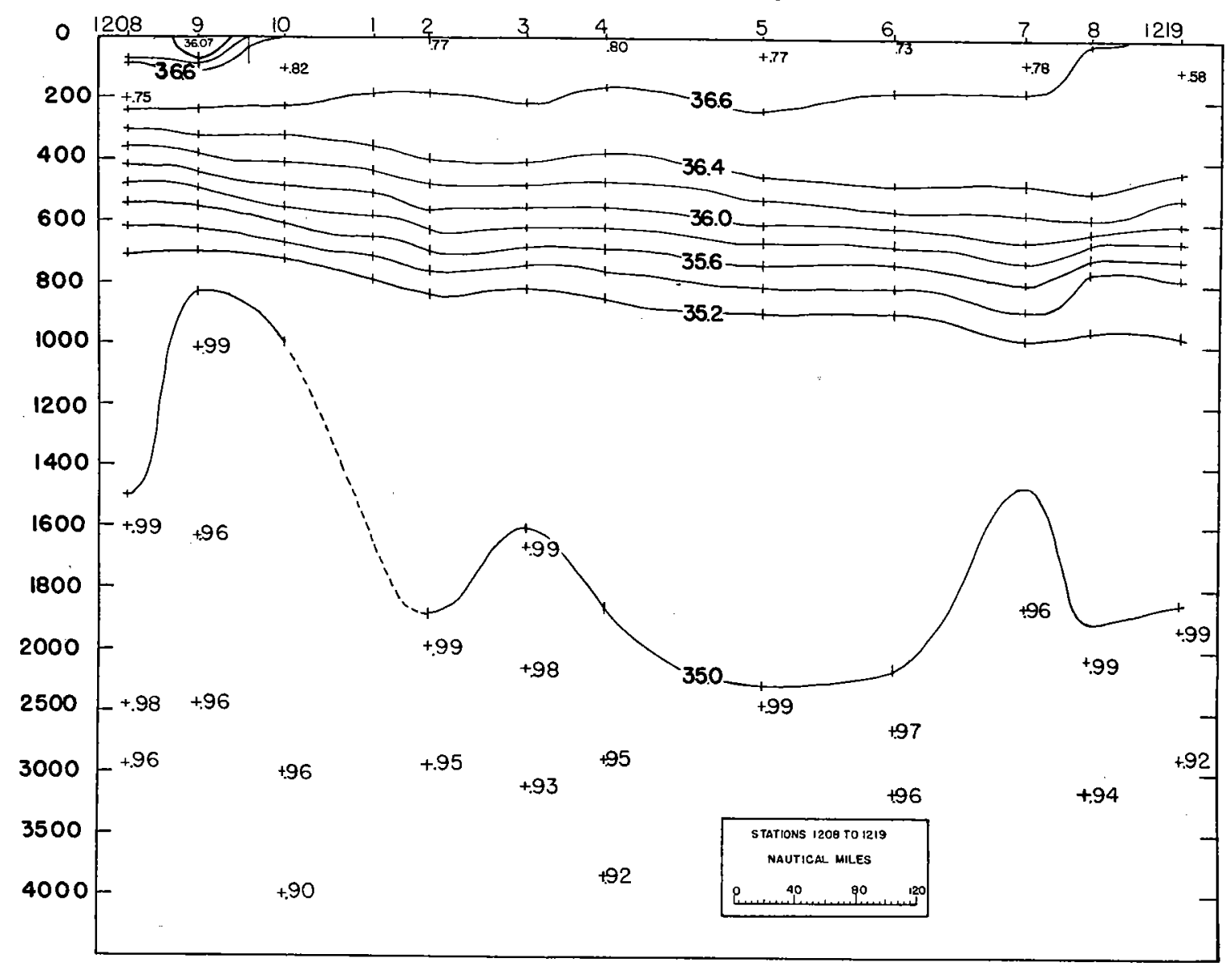

Frg. 37.--Salinity section, Haiti-Bermuda, April 7-13, 1932.

in mid-ocean and it is only at the surface that we can find certain evidence of a northwesterly drift from low latitudes. In short, the Antilles Current as shown by this April section is almost indistinguishable from the broad westerly flow characteristic of the northern half of the northeast trade wind belt. Except for the shallow, relatively fresh surface layer near the islands, there appears to be little justification of differentiating between the Antilles Current and the continuation of the Northern Equatorial Current.

At the northern end of this section, near Bermuda, the slight fall in temperature and salinity at all depths in the thermocline layer is additional evidence that this is the usual state. 


\section{BERMUDA TO ELBO CAY}

In February I933 a similar series of observations was secured across the southwestern quadrant of the Sargasso Sea, running from near Bermuda to within a few miles of Elbo Cay, in the northern Bahama Islands. These 15 stations on a line approximately 690 miles in length include observations from the zone of steep submarine slope, along which the Antilles Current might be expected to flow.

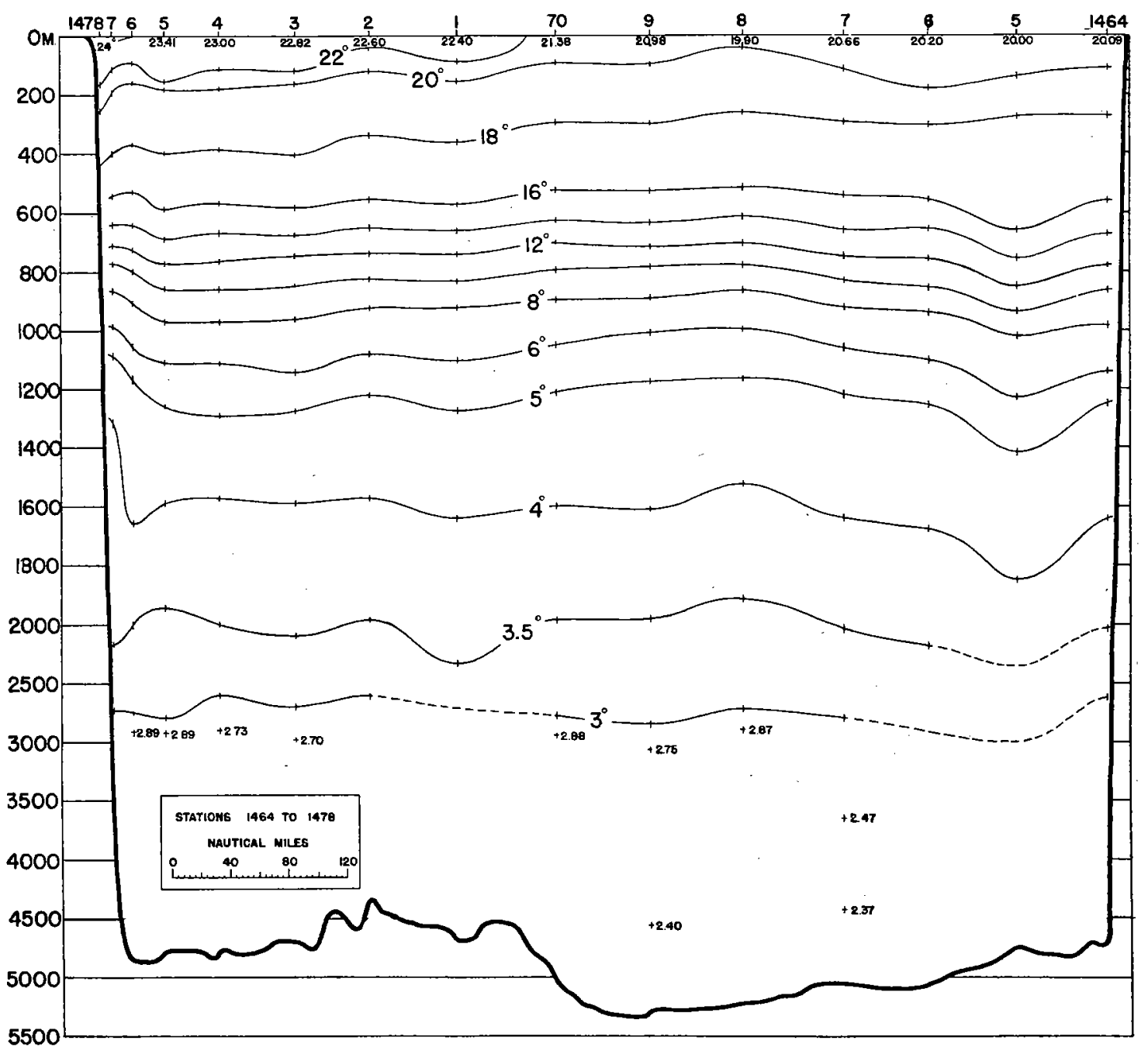

FIG. 38.-Temperature section, Bermuda-Elbo Cay, Feb. I2-20, I933.

Although the water near the surface warmed gradually from $2 \mathrm{I}^{\circ}$ in the center of the section to $24^{\circ}$ off Elbo Cay, the temperature section (Fig. $3^{8}$ ) shows nearly horizontal conditions throughout most of the thermocline layer and at greater depths. The three southern stations constitute the only exception. With this very regular distribution of temperature, except possibly near the Bahama Islands, only very moderate currents could have existed during the period covered by these February observations. 
The thermal trends at the southern stations cannot easily be interpreted. Apparently the slope of the isotherms down to a depth of 400 meters calls for a southward movement, but deeper down the gradient is reversed and at mid-depths the movement was probably northward. At any rate the "Atlantis" observations show no thermal evidence of a broad or powerful Antilles Current, readily distinguishable from the general westerly movement continuing from the Northern Equatorial Current.

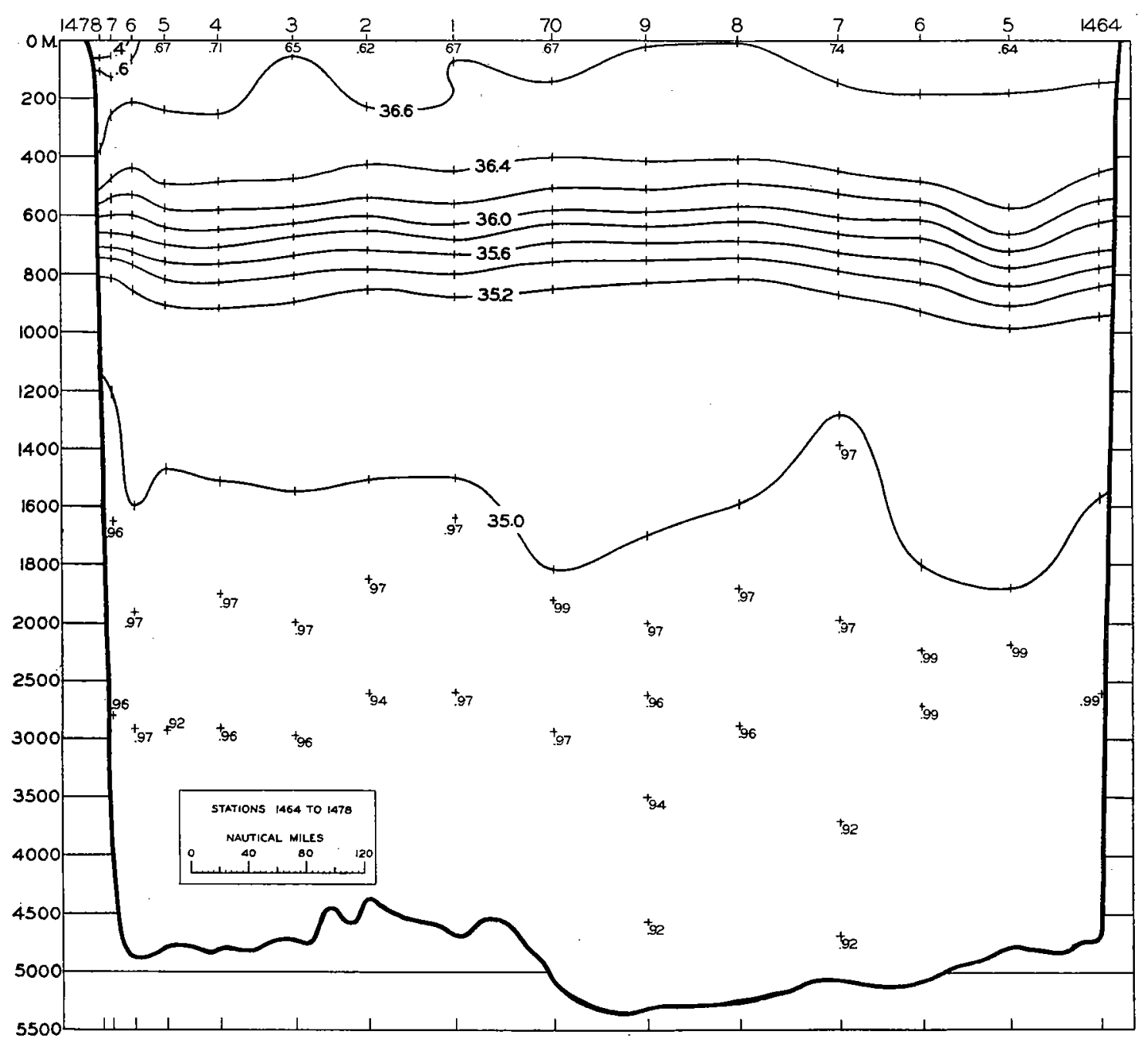

Fig. 39.-Salinity section, Bermuda-Elbo Cay, Feb. 12-20, 1933.

The corresponding salinity observations (Fig. 39), agreeing closely with the thermal trends, afford little further evidence of the character of the Antilles Current. Near the surface and at the three southern stations a relatively fresh layer is again indicative of a southern origin. It therefore seems probable that the northward flow at mid-depths along the continental slope was more powerful than the contrary movement near the surface and that the resulting current was narrow (about $4 \circ$ miles wide) and relatively weak. 
It must be remembered, however, that at other times of year, the Antilles Current may be much better developed. Since it is primarily a wind current, it is reasonable to suppose that in summer, when the trades follow the sun northward, the resulting flow as it passes Elbo Cay might be broader and swifter.

If the "Bache" observations (Bigelow I9I7, Wüst 1924) are to be relied on, immediately north of the Bahamas there must occur a narrowing of the broad gradient displayed in these two "Atlantis" profiles. Until further observations have been made, the term Antilles Current must remain somewhat indefinite. On the basis of the present data, the term had best be reserved for the shallow and weak stream of equatorial water near the islands. This appears to be superimposed on a broad general westerly movement, the continuation of the Northern Equatorial Current.

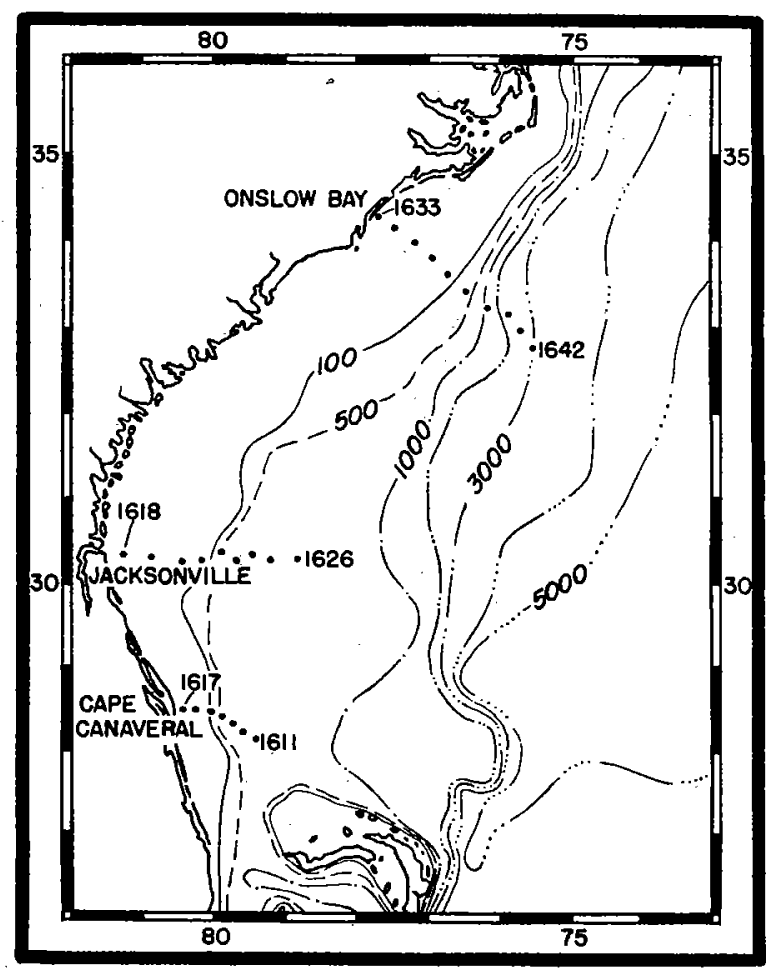

FIG. 40.-Locations of stations constituting the "Atlantis" sections across the Florida Current, May I I-17, 1933. The bathymetric contours (in meters) of the Blake Plateau are also shown.

\section{Florida. Current Sections}

In the latter part of April 1933, the "Atlantis" made three sections (Fig. 40) which show the changes that take place within the Florida Current as it flows along the continental slope between the Straits of Florida and Cape Hatteras: off Cape Canaveral, just after the current has emerged from the Straits; off Jacksonville, about I 20 miles northward; and off Onslow Bay, where it first reaches deep water. The first two lines show the current while it is flowing over the relatively shallow (less than tooo meters) Blake 
Plateau. ${ }^{19}$ Off Onslow Bay, on the other hand, the continental slope extends to much greater depths and is nearly as steep as north of Cape Hatteras.

In order that these profiles of the Florida Current may be directly comparable to the Gulf Stream sections off Chesapeake Bay, the same scale has been used in each case.

\section{CAPE CANAVERAL}

Because of the swiftness of the current and the difficulty in navigating across its path, the western stations on this line did not cut the axis of the stream at right angles (see Fig. 40). As a result, the slope of the water layers shown in the profiles (Fig. 4I) is not as steep as it would have been if the whole section had run east and west. In other words, although the actual distance between station I6I I (the most eastern station) and station I6I 5 (on the edge of the continental shelf) was 37 miles, if these observations were projected on a section normal to the current's path, the distance would be reduced to about 28 miles. Nevertheless, it is probable that the observations cross the greater part of the swiftly moving water in this part of the Florida Current.

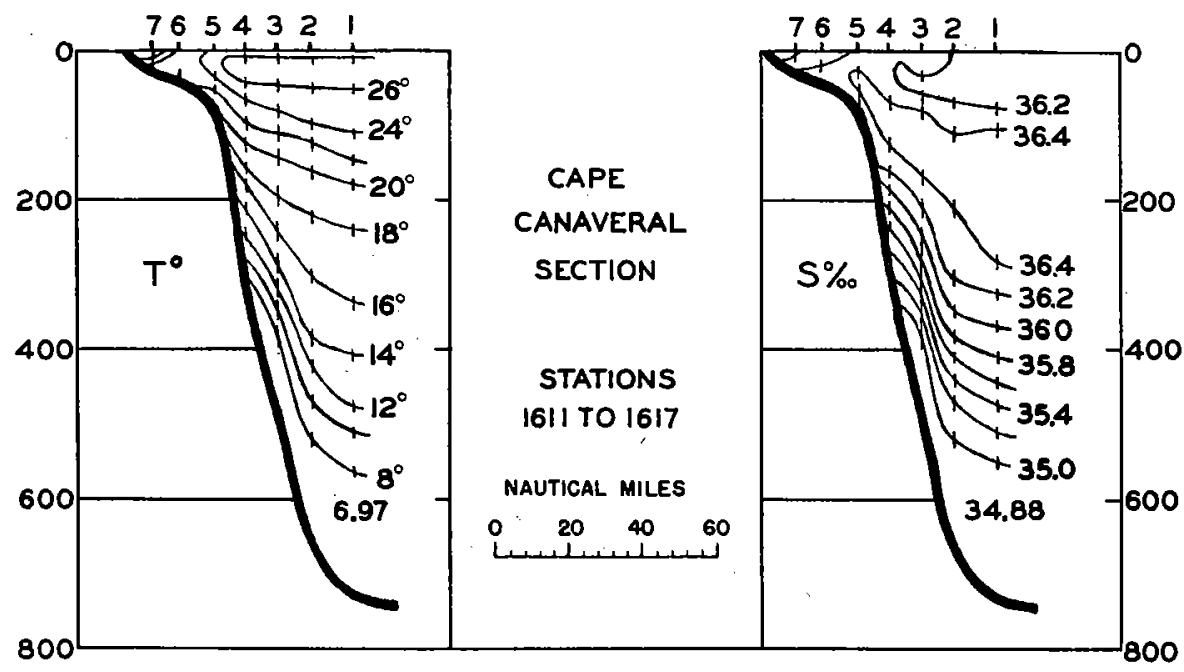

Frg. 4I.-Temperature and salinity sections across the Florida Current off Cape Canaveral, May II, I933.

The "Atlantis" section off Cape Canaveral can be compared with the "Bache" observations (Bigelow I9I7) off Jupiter Inlet ( 88 miles further south). A complete discussion of these and other earlier observations in the Florida Current has been published by Wüst (1924). The three western "Bache" stations cross about the same width of current as the five eastern "Atlantis" stations. Besides being less complete, the depths of the former observations have not been corrected for the wire angle as found by unprotected thermometers for this method had not then come into common practice. This perhaps accounts for the main difference between the two profiles. The "Atlantis" data (Fig. 4I) show a maximum slope at depths of from 300 to 500 meters between stations I 6 I 3 and I 6 I 4 while Wüst's drawing of the "Bache" isotherms and isohalines indicates a more gradual and even slope across the whole width of the Florida Current.

${ }^{19}$ In a previous paper (Iselin 1932), the author made the mistake of referring to this bathymetric feature as the Pourtales Plateau. 
In the surface layer (down to 50 meters) the "Atlantis" observations showed nearly horizontal isotherms, but the salinity diminished from west to east. Below this the temperature decreased gradually to $6.97^{\circ}$ at 610 meters at the most eastern station,

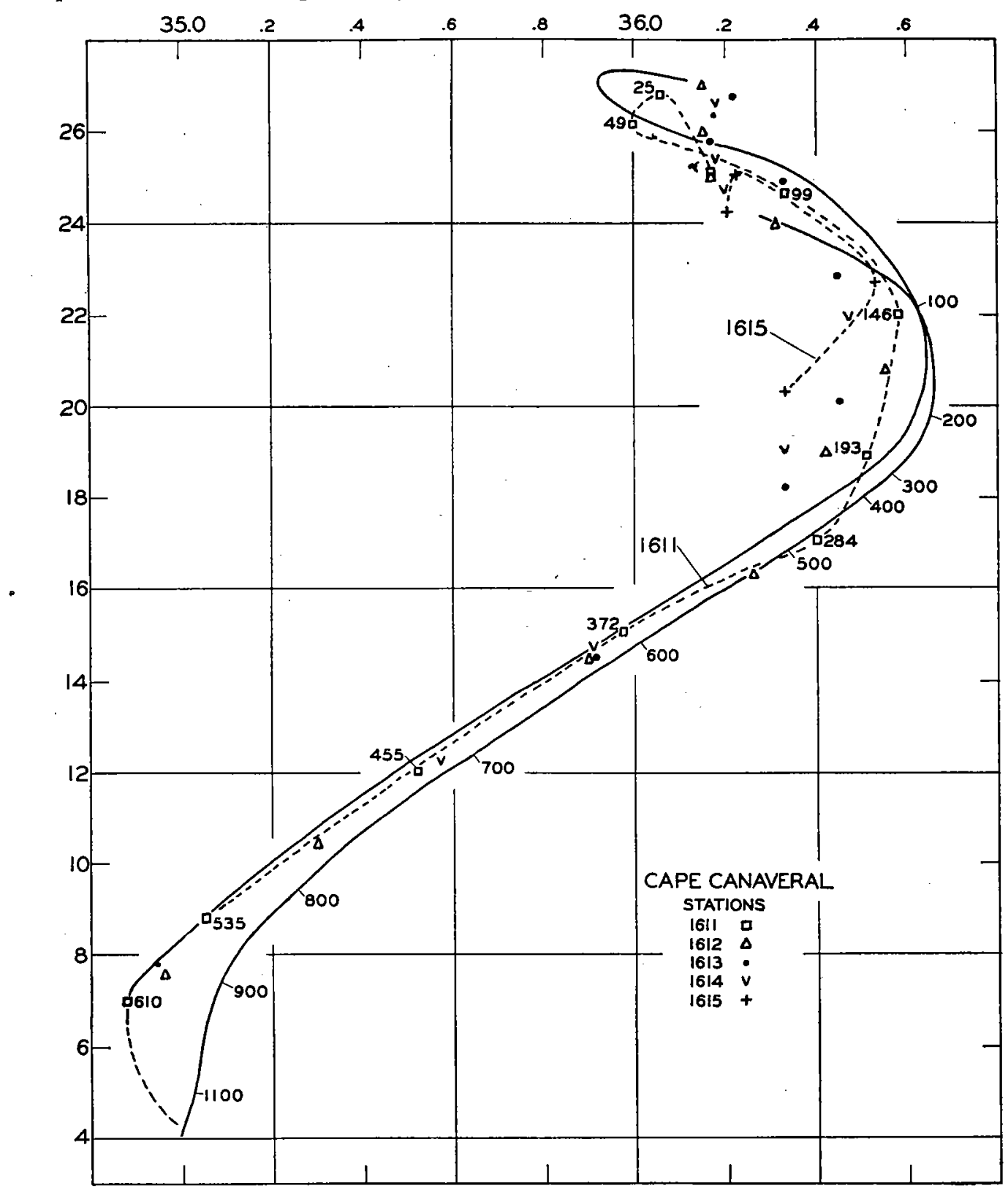

Fig. 42.-Temperature-salinity correlation across the Florida Current off Cape Canaveral compared with the mean relationship found in the Yucatan Channel (solid curve on the left) and in the Antilles Current off Elbo Cay (solid curve on the right).

and this value is probably near the minimum for water that has passed northward through the Florida Straits. On the other hand, the isohalines of from 36.4 to $35.0 \%$ were crowded into a layer about 280 meters thick. This disagreement between the trends 
of temperature and salinity was largely brought about by a wedge-shaped body of high salinity water (the maximum reading being $36.58 \%$ ) which occupied the depths immediately below the surface layer.

The temperature-salinity correlation across this section is plotted in Fig. 42 , a different symbol being used for the observations of each of the five stations. The points of the outside station (161 I) and of the inshore station (1615) at the edge of the continental shelf have been connected by broken lines to show the two extreme T-S curves for this group of observations. It can be seen that from east to west the maximum salinity at each station decreased. The diagram suggests that this was caused by a more complete mixture of the upper layers at the western stations. This explanation is supported by the fact that the slope of the isotherms at mid-depths calls for greater velocities over the continental slope than at the two eastern stations. In short, in the western half of the Florida Current the situation is favorable for turbulence to dilute the wedge-shaped layer of relatively high salinity both from above and from below.

There is another possibility which may play an important rôle in the disagreement between the trends of temperature and salinity above 200 meters in this part of the Florida Current. As has been pointed out by Nielsen (1925) and Parr (1935), most of the water flowing through the Straits of Florida has come directly from the Caribbean Sea and. has not made a circuit of the Gulf of Mexico, for the greater part of the current running northward through the Yucatan Channel turns sharply eastward around the western end of Cuba. However, it is possible that near the surface in the western part of the current off Cape Canaveral some water of true Gulf of Mexico origin may also be present. Until more complete data are available this question must remain in doubt, although the low salinity near the bottom at station I6I 5 appears to have resulted from this cause.

Fig. 42 also illustrates a point more important for our present purposes. In this diagram the right hand, solid curve gives the mean T-S ratio in the Antilles Current off Elbo Cay (stations $\mathrm{I}_{476}-\mathrm{I} 478$ ). The left hand, solid curve was constructed in a similar manner from the observations of six "Atlantis" stations ${ }^{20}$ (May 4-5, 1933) across the Yucatan Channel. Because of the shallowness of the Florida Straits opposite Bimini, the course of the lower part (water colder than $6.5^{\circ}$ ) of this curve does not concern us here. It can be seen at once that all the observations off Cape Canaveral in water colder than $16^{\circ}$ tend to fall near the Yucatan Channel curve and for any given temperature have salinities about $0.10 \%$ lower than Antilles current water. In other words, the T-S correlation in this most southern of the "Atlantis" Florida Current sections proves that in the deeper layers none of the water had an Antilles Current origin. At the two most eastern stations and from about 300 meters in depth two observations from the Cape Canaveral section are characteristic of the Antilles Current water at about 500 meters depth. While the discrepancy in depth makes it seem improbable that this resemblance is significant, nevertheless, it is possible that at about 300 meters some of the water at the two eastern stations had come from the Antilles Current.

Near the surface the salinities $(36.0-36.2 \%$ of this "Atlantis" section are somewhat lower than any observed off Elbo Cay and it is therefore probable that, with the possible exception of the 300 meter layer, the Antilles Current and the Florida Current remain separated until some point north of Cape Canaveral. In other words, east of this section the isolines must make a further dip downward as they cross the Antilles Current so as to enter the Sargasso Sea at their usual depths.

\footnotetext{
${ }^{20} \mathrm{We}$ are indebted to Dr. A. E. Parr for permission to use these data, as he is now engaged in preparing a report of the temperature and salinity distribution in.the Caribbean Sea and the Gulf of Mexico.
} 


\section{JACKSONVILLE}

Off Jacksonville, Florida, the trend of the whole line of stations is approximately at right angles to the current's path and the profile (Fig. 43) extends seaward about 75 miles from the 200 meter curve.

In the comparatively short distance (I 20 miles) northward from the Cape Canaveral to the Jacksonville section, the slope of the thermocline layer across the Florida Current's path has become steeper. On the northern profile this layer $\left(16^{\circ}\right.$ to $\left.8^{\circ}\right)$ again met the continental slope at about the same depths, but on the eastern end of the Jacksonville line it descended much deeper than off Cape Canaveral. This difference allowed a considerable increase in thickness at the eastern Jacksonville stations of the layer having salini-

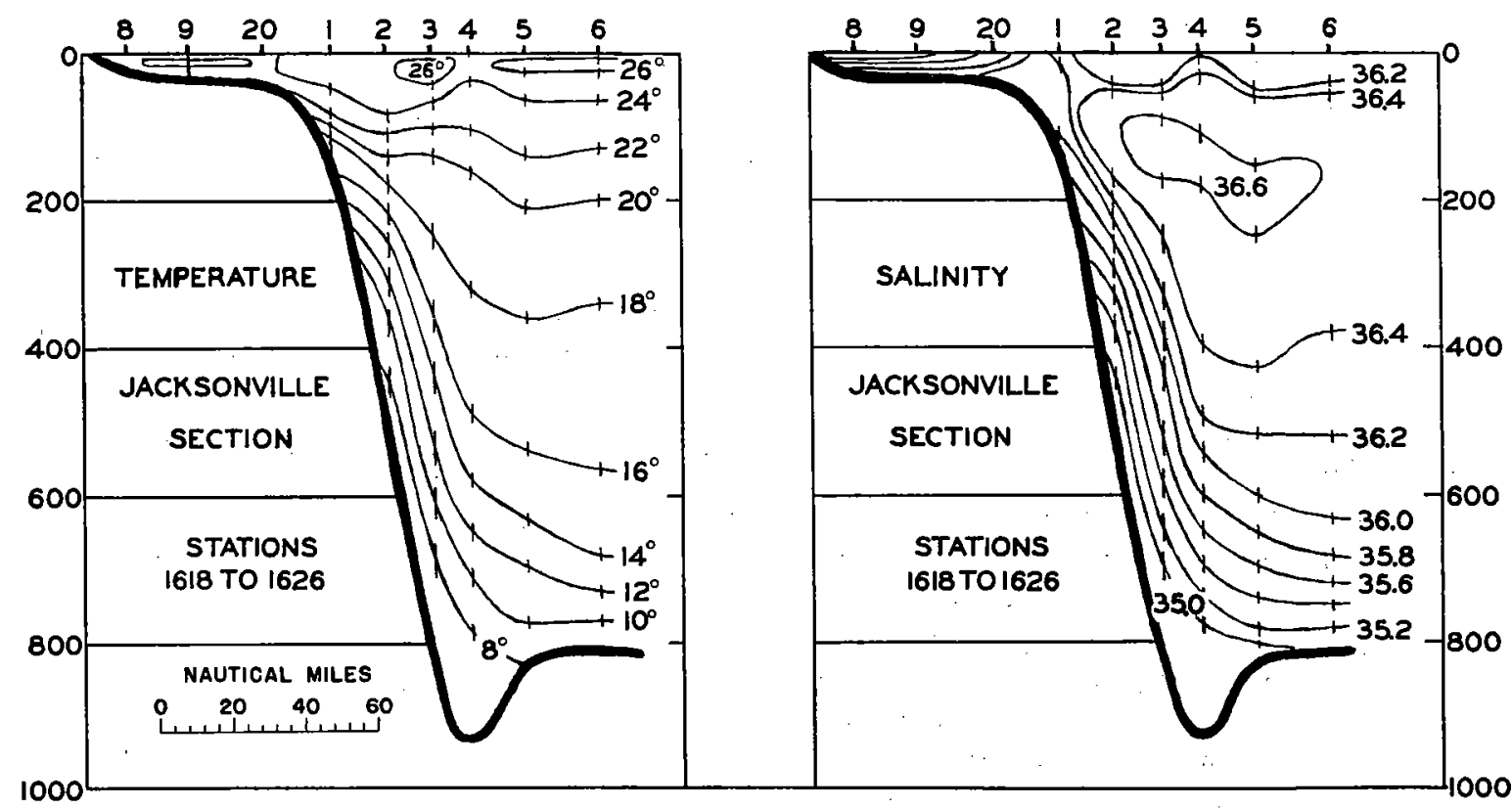

FIG. 43.-Temperature and salinity sections acròss the Florida Current off Jacksonville, May I2-I3, I933.

ties higher than $36.4 \%$. In short, the trend of the isotherms and isohalines off Jacksonville calls for a deeper and more powerful current, but the strongest flow, as evidenced by the steepest slanting of the isolines, is again in the waters just above the continental slope.

The correspondence between the temperature section and the salinity section is close for the waters colder than $16^{\circ}$ and less saline than $36.2 \%$. But a wedge of high salinity water, $(36.4 \%$ just below the surface layer again causes some disagreement. In this layer off Jacksonville, the isohaline of $36.6 \%$ bounds a core which has slightly higher salinity values than any of the Cape Canaveral observations. This slight increase is not significant in determining the source of the water in this layer because the maximum salinity in the Yucatan Channel is so nearly the same as in the Antilles Current.

The T-S diagram of this group of stations (Fig. 44) shows the deeper observations falling mid-way between the curves for the Antilles Current water off Elbo Cay and the Caribbean water in the Yucatan Channel, evidence that as it flows northward from 


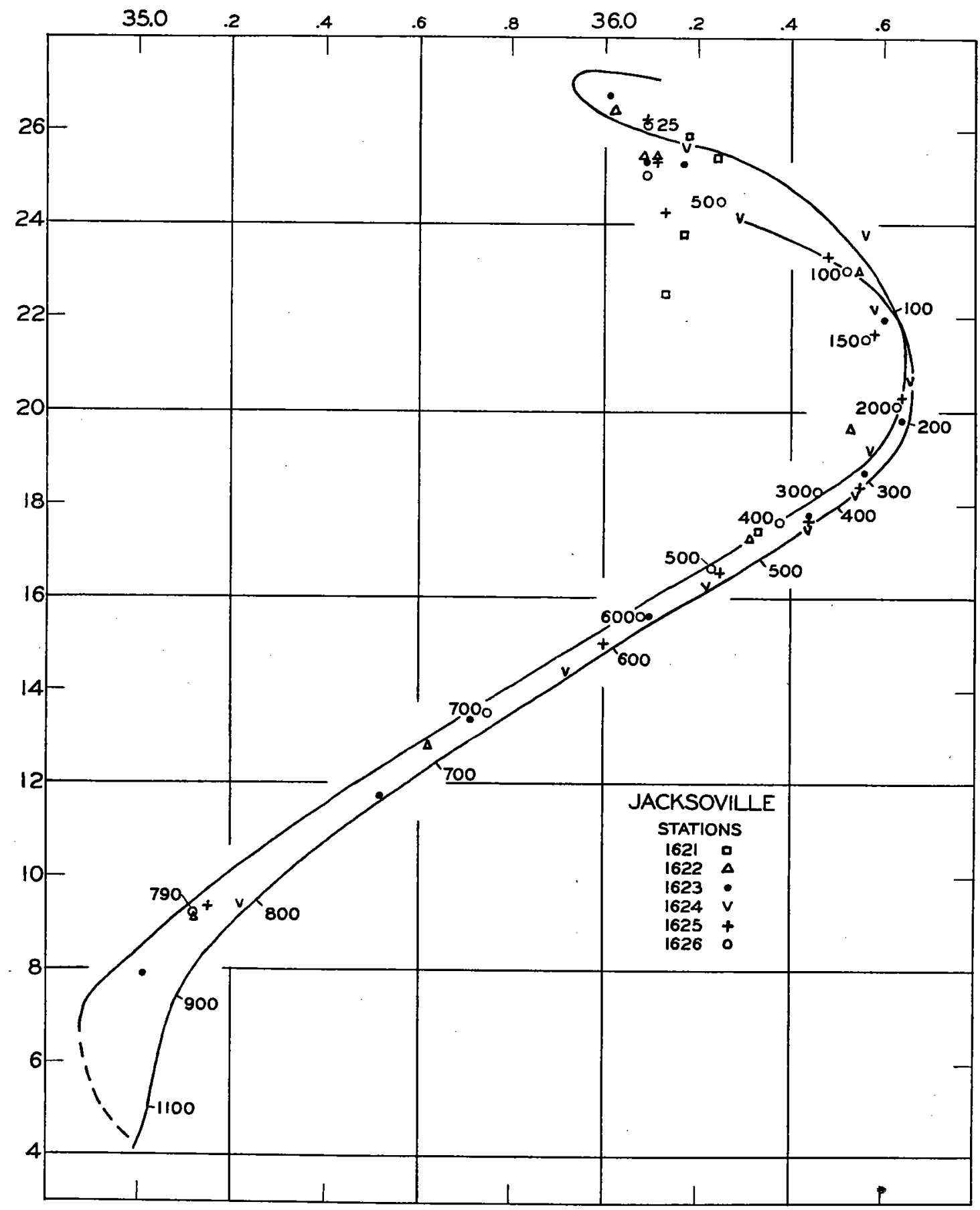

FIG. 44.-Temperature-salinity correlation across the Florida Current off Jacksonville compared with the mean curves of the Yucatan Channel (left) and of the Antilles Current off Elbo Cay (right). 


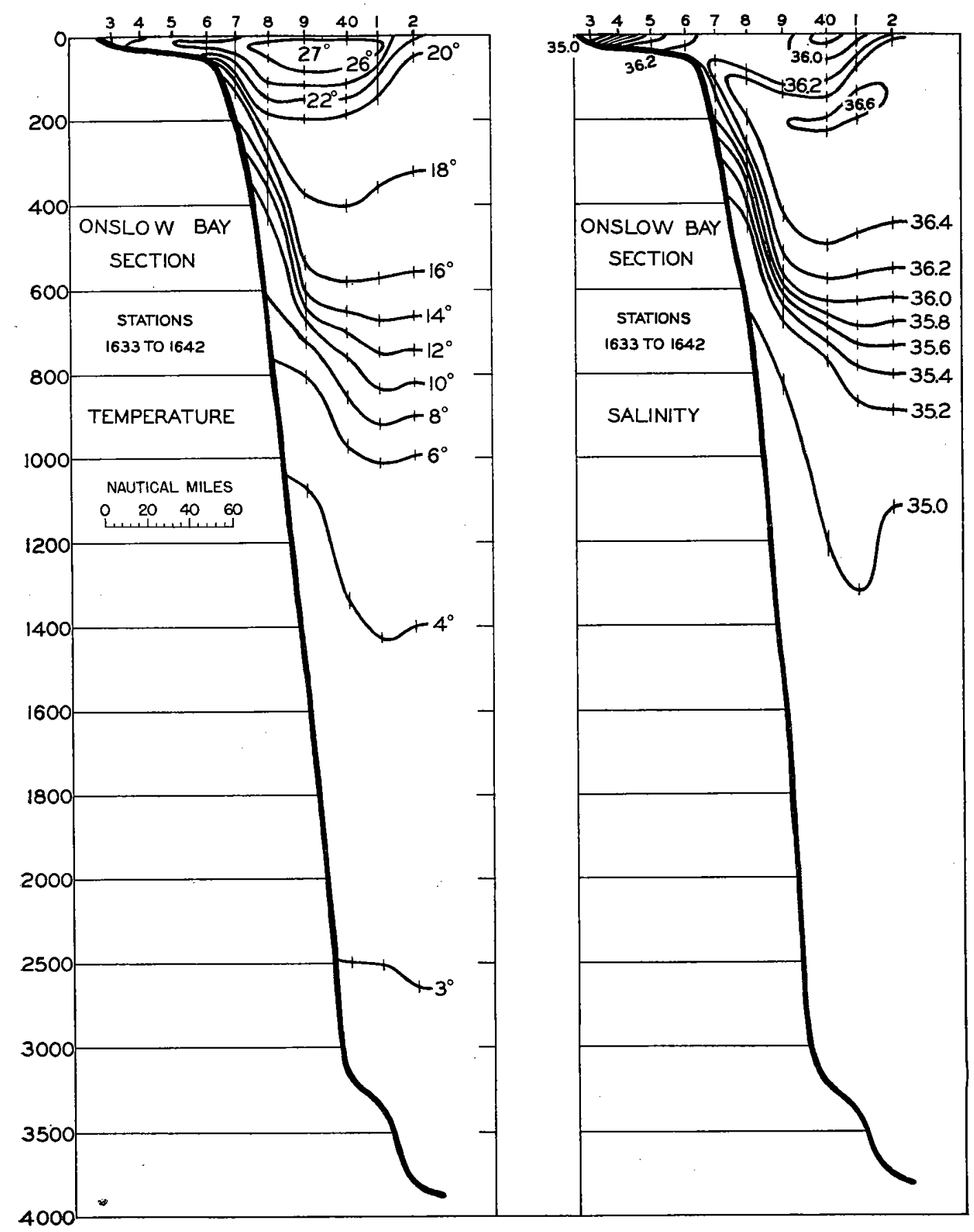

FIG. 45.-Temperature and salinity sections across the Florida Current off Onslow Bay, May I6-17, I933. 
Cape Canaveral the Florida Current receives a considerable admixture of off-shore water. Moreover, the depths of the observations from the most eastern station off Jacksonville correspond closely to the depth scale shown along the curve for Antilles Current water. In short, off Jacksonville, the depths for a given temperature at the "Atlantis" eastern station (I626) closely correspond to the conditions of the western Sargasso Sea, but the relatively low salinity values at mid-depths in the heart of the current are proof that a considerable proportion of Caribbean water still remains only slightly influenced by the union of the Antilles Current with the outflow from the Florida Straits. Whether or not the increase in volume of the Florida current which takes place just south of this Jacksonville profile should be entirely attributed to its union with the Antilles Current must for the present remain in doubt. Any water from the southwestern Sargasso Sea (with the exception of the surface layer) which might also at the same point join the northward flow could not be distinguished by the T-S diagram method for the reason that it would have so similar a temperature-salinity correlation.

\section{ONSLOW BAY}

Fig. 45 gives the distribution of temperature and salinity across the northern section of this group just after the current has left the Blake Plateau. The stations extend some 76 miles seaward from the edge of the continental shelf. For the superficial layers, the most noticeable change from the more southerly sections just examined is the increased volume of the warm, relatively fresh surface layer being carried northward by the current. Because of the more northerly location of this section, this increase is more apparent than real, for the temperature and salinity at the surface in the heart of the current off Onslow Bay contrasts sharply with the colder more saline waters just to the eastward. On the other hand, as off Jacksonville, below this pool of warm, relatively fresh surface water, a wedge-shaped layer of high salinity is again found. Likewise, at mid-depths a very similar distribution of temperature and salinity again shows that the steepest slope occurs in the thermocline layer of the waters nearest the continental slope. In short, the "Atlantis" section off Onslow Bay, down to a depth of 800 meters, closely corresponds to the Jacksonville line. Evidently on leaving the relatively shallow area of the Blake Plateau, the current undergoes no great structural change above 800 meters until it has passed Cape Hatteras and first becomes separated from the continental shelf by the slope water. Deeper down, the slant of the isolines is evidence that on leaving the plateau, the Florida Current greatly increases in depth and that a considerable volume of water colder than $8^{\circ}$, coming from offshore, joins in with the northeastward flow.

The T-S diagram of the Onslow Bay observations (Fig. 46) shows that in the heart of the current (stations I637-I639), water characteristic of the Caribbean can be found still. Further offshore and below 800 meters, the temperature-salinity ratio of the observations are very similar to those found at corresponding depths off Elbo Cay. But it is more probable that the deep water which has here joined the current came from the Sargasso Sea for it is logical to assume that after the great increase in volume south of Jacksonville little Antilles Current water remained un-united with the main northward movement.

The changing T-S correlation within the heart of the Florida Current as determined from "Atlantis" observations are tabulated below, as well as mean values from the three
chief sources of the current. 


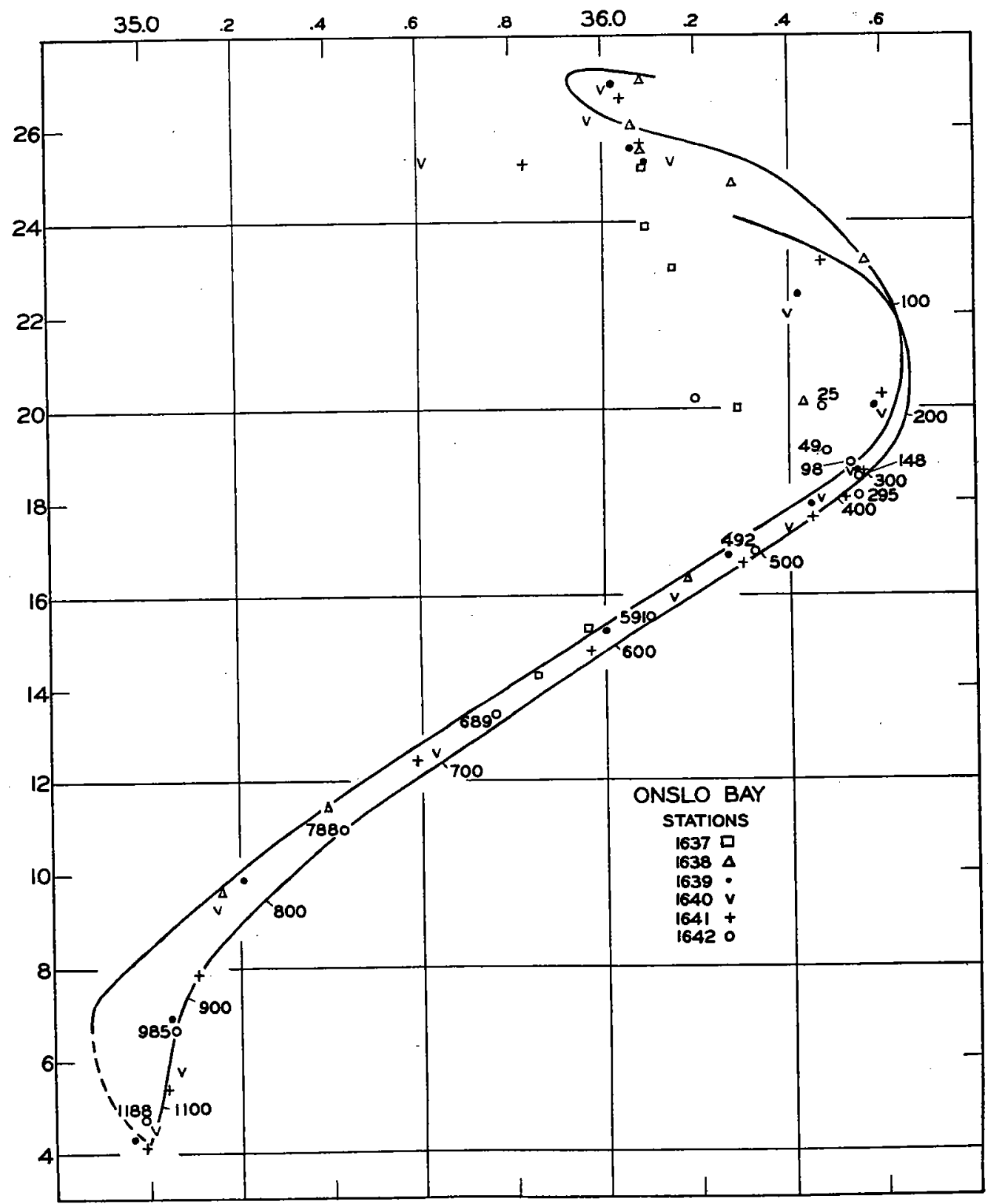

FIG. 46.-Temperature-salinity correlation across the Florida Current off Onslow Bay compared with the mean curves of the Yucatan Channel (left) and of the Antilles Current off Elbo Cay (right). 


\begin{tabular}{|c|c|c|c|c|c|c|}
\hline \multirow{2}{*}{ REGION } & \multicolumn{6}{|c|}{ Temperature } \\
\hline & $6^{\circ}$ & $7^{\circ}$ & $8^{\circ}$ & $9^{\circ}$ & $10^{\circ}$ & $\operatorname{Ir}^{\circ}$ \\
\hline $\begin{array}{l}\text { Yucatan Channel } \\
\text { Cape Canaveral } \\
\text { Jacksonville } \\
\text { Onslow Bay } \\
\text { Antilles Current } \\
\text { Southwestern Sargasso Sea }{ }^{21}\end{array}$ & $\begin{array}{c}34.88 \\
- \\
35.04 \\
35.04 \\
35.07\end{array}$ & $\begin{array}{r}34.88 \\
34.88 \\
- \\
35.06 \\
35.07 \\
35.10 \\
\end{array}$ & $\begin{array}{l}34.96 \\
34 \cdot 96 \\
35.02 \\
35.12 \\
35.12 \\
35.13 \\
\end{array}$ & $\begin{array}{l}35.07 \\
35.08 \\
35.12 \\
35.14 \\
35.20 \\
35.20\end{array}$ & $\begin{array}{l}35 \cdot 20 \\
35 \cdot 22 \\
35 \cdot 23 \\
35 \cdot 22 \\
35 \cdot 30 \\
35 \cdot 30\end{array}$ & $\begin{array}{l}35 \cdot 33 \\
35 \cdot 36 \\
35 \cdot 38 \\
35 \cdot 36 \\
35 \cdot 42 \\
35 \cdot 42\end{array}$ \\
\hline
\end{tabular}

THE DEPTH OF THE IO ${ }^{\circ}$ ISOTHERM IN THE WESTERN NORTH ATLANTIC

The broad structural features of the waters of the whole area covered by the "Atlantis" observations can be conveniently reviewed by examining in horizontal projection the regional differences in depth of the $10^{\circ}$ isotherm in the western North Atlantic.

This particular isotherm was chosen because its depth is great enough in the slope water band to lie for the most part below the layer subject to seasonal climatic changes, while in the Sargasso Sea it is not so deep as to be much below the center of the main thermocline layer. In other words, by tracing the $10^{\circ}$ isothermobath, we are really following the layer most influenced by the effect of the broad features of the circulatory system. ${ }^{22}$ Thus over much of the area the depth contours of this thermal plane coincide with the direction of flow of the permanent current system. Their concentration will be closely proportional to the current velocities at mid-depths.

In constructing the chart (Fig. 47) it was possible to use with advantage observations from many of the earlier expeditions. Because of the relative wealth of data in some parts of the area, it would be possible to draw the contour lines for intervals smaller than Ioo meters; nevertheless, this procedure would have no real significance because, as shown previously, the thermocline layer is subject to oscillations in depth of the order of magnitude of at least 100 meters.

The chart (Fig. 47) shows that in the slope water region the $10^{\circ}$ isotherm varies in depth between 200 and 300 meters, except in the eddy south of Cape Sable, previously mentioned (page 24). Although few pertinent data are available, there is reason to believe that a similar clockwise whirl occasionally develops off New York and perhaps also in the bight between Sable Island and the Grand Banks.

Continuing offshore from the North American continental shelf, the chart clearly demonstrates the steep downward slope of the $10^{\circ}$ isothermal surface as it crosses the Gulf Stream between Cape Hatteras and the tail of the Grand Banks. Then a long narrow trough shaped depression, bounded by the depth contour for 900 meters, marks the region in which $10^{\circ}$ water is occasionally found as deep as 1000 meters. Southeastward across the Sargasso Sea the water layers, though relatively undisturbed, slope very gradually upward as far as the 700 meter contour. Within this area only the observations from near Bermuda show local irregularities. As mentioned frequently above, the island is surrounded at mid-depths by water slightly colder for a given depth than else-

\footnotetext{
21 It will be shown later (page 76) that this contribution to the Gulf Stream comes from two sources: the northerly edge of the Northern Equatorial Current and the southern branch of the North Atlantic Current which curves back to the southwest just beyond the Grand Banks.

${ }^{22}$ Because of the close control on density which temperature exerts in the open ocean, the ro ${ }^{\circ}$ isotherm coincides in depth over most of the North Atlantic with the isopicnal $\left(\sigma_{t}\right)$ of 27.20 . The variations in salinity of $10^{\circ}$ water in the area under consideration in general only produce small deviations from this mean value. The extreme density values for $10^{\circ}$ water are 26.935 near the equator in the sub-antarctic intermediate layer and 27.315 near the Azores where the high salinities at mid-depths result from the admixture of Mediterranean water.
} 
where in the western Sargasso Sea. Complex factors are possibly at work here. A relatively weak anti-clockwise eddy seems to surround the islands and this may be dependent on the mixing effect of the base of the islands on the water-layers at mid-depths. In

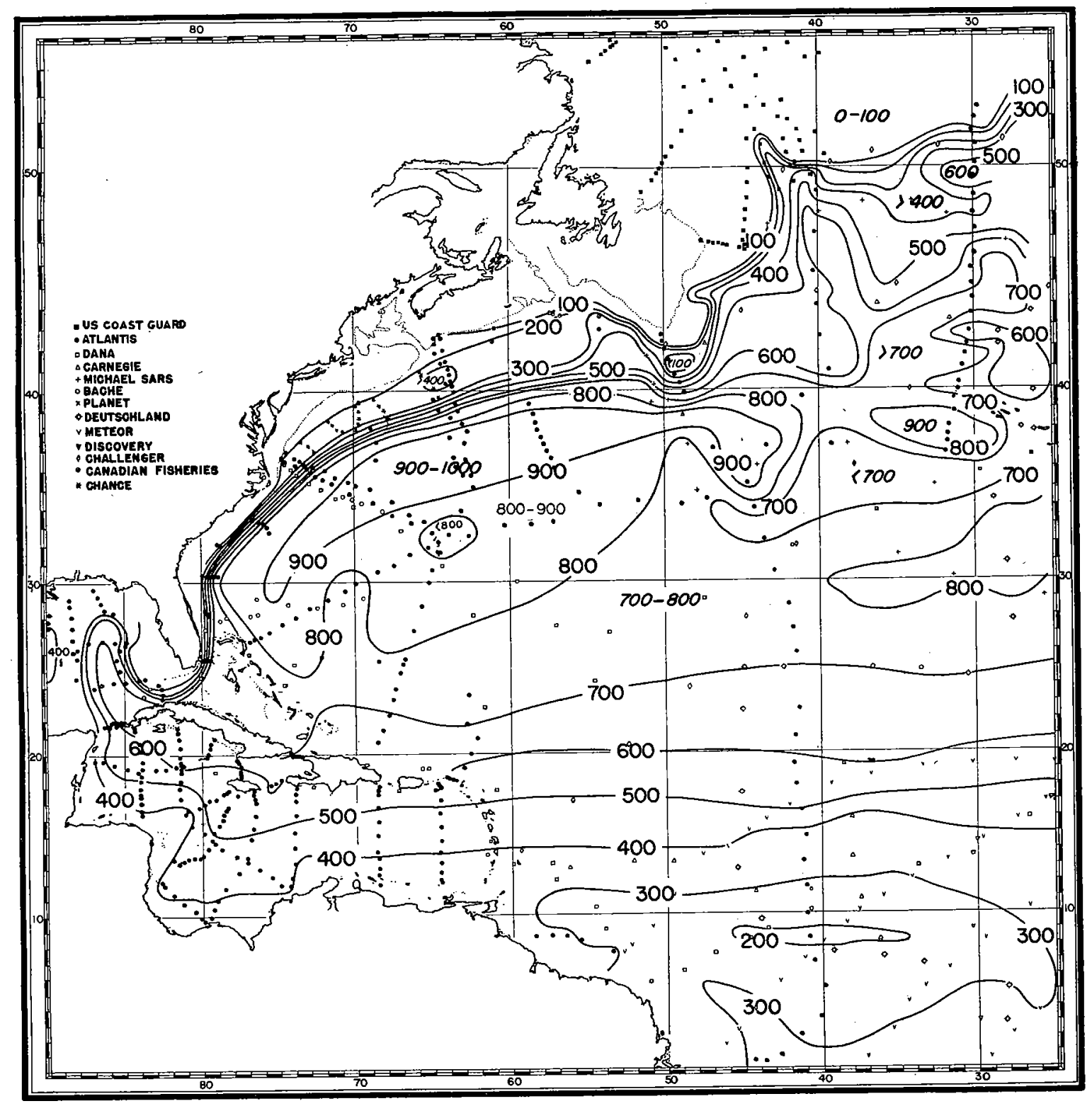

FIG. 47.-Chart showing the depth of the $10^{\circ}$ isotherm in the western North Atlantic.

short, the cone of the island perhaps acts as a stirring mechanism by which the deeper, colder waters are here mixed more rapidly with the warm surface layer than elsewhere in the Sargasso Sea. 
As will be discussed later (page 8I), the southern limit of the Sargasso Sea can logically be placed along the 700 meter contour line shown in Fig. 47. South of this point the more vigorous westerly flow of the Northern Equatorial Current is reflected by the increased upward slope of the water layers. The fact that southeastward from Bermuda as far as the 700 meter contour the $10^{\circ}$ isotherm is not strictly horizontal, but is inclined slightly upward, shows that within the Sargasso Sea the waters must be moving slowly in a clockwise direction. This gradient is very weak in the southern quadrant, but becomes stronger in the west as the flow begins to parallel the Gulf Stream System. Thus, unless the Sargasso Sea be given very much smaller boundaries, we must bear in mind that its waters, though relatively motionless, are to some extent taking part in the great anticyclonic current system which surrounds it.

In the surface layer, the boundary between the easterly moving waters of the northern Sargasso Sea and the westerly, wind driven flow of lower latitudes presumably coincides with the horse latitude belt. Because this zone of relative calm between the northeast trades and the prevailing westerlies fluctuates seasonally, and because the development of the Azores high is frequently disturbed in winter by the passage of severe storms to the northward, the wind system, and consequently the surface currents, cannot be said to revolve around a definite axis. However, the center of motion is generally well east of Bermuda.

In contrast to this fairly symmetrical though fluctuating pattern of the wind system and, therefore, of the superficial currents, the axis of rotation of the waters at mid-depths (i.e., of the thermocline layer) in the Sargasso Sea can be definitely located, according to Fig. 47 , as resolving around an elongated axis paralleling the Gulf Stream and lying well north of Bermuda. In short, it is difficult to escape the dynamic significance of the course of the 900 meter (Fig. 47) contour inclosing an elongated depression where $10^{\circ}$ water is occasionally found as deep as I000 meters. We have seen already (page 37) that in this part of the Sargasso Sea the temperature-salinity correlation is very constant and there can be no doubt in this region as to the interpretation of the isothermobaths in terms of general current direction at mid-depths. It is indeed surprising to find that Bermuda lies southeast of the axis of motion of the thermocline layer and that the prevailing wind there is contrary to the direction of flow at mid-depths.

Continuing southward, beyond the 700 meter contour the $10^{\circ}$ isotherm rises in a regular manner as shown by the parallel arrangement of the contour lines. Thus the flow of water at these depths across the trade wind belt appears to be independent of the bottom configuration and parallel to the latitude lines. In other words, the planetary effect described by Ekman (I928) is clearly dominant over the topographic effect. The extremely close approach to the surface of $10^{\circ}$ water in latitude $8^{\circ} 30^{\prime} \mathrm{N}$. already demonstrated in section (Fig. 32) is here confirmed by a number of observations from other expeditions.

In contrast to the regular and gradual type of current in the south, the region north and east of the Grand Banks is one of elaborately curving and branching narrow bands of current. It is evident that here the bottom topography begins to play an increasingly important part in determining the course of the various branches of current. Not only is this true of the shallower isolines (100-400 meters) as they curve around the Grand Banks and trend northward to the mouth of the Labrador Basin, but the two deepest contours ( 800 and 900 meters), which recurve to the right just east of the tail of the banks, follow the slope of the bottom around a considerable shoal area where the depth 
is less than 3000 meters. The course of the intervening isolines (500-700 meters) is somewhat doubtful owing to the scarcity of observations. Additional data will probably show that these lines also are influenced by the bottom configuration.

At the entrance of the Labrador Basin, where a ridge partly obstructs the deep channel, the northern branch of the current again turns eastward to cross the Mid-Atlantic Ridge in about latitude $5^{\circ} \mathrm{N}$. A second band of current, shown by the 500-700 meter contours in Fig. 47, crosses the ridge at about latitude $47^{\circ} \mathrm{N}$. and then curves southward towards the Azores.

It is clear from Fig. 47 that the area between the Grand Banks and the Mid-Atlantic Ridge is one from which much additional data are needed. While the course of the northern branch of the North Atlantic Current (100-400 meter contours) is fairly well established, the trends of the deeper lines are probably subject to wide fluctuations. In the same way, only the most pronounced features of the pattern of the stream lines are worth considering in the neighborhood of the Mid-Atlantic Ridge.

The depression indicated just south of the northern branch of current in mid-ocean possibly results from a clockwise eddy around Faraday Shoal (Lat. $49^{\circ} 40^{\prime} \mathrm{N}$., Long. $29^{\circ} \mathrm{W}$.). But the fact that the $10^{\circ}$ isothermal surface is nearer the surface just south of the central branch of the current probably has less dynamic significance, for it is partly caused by a deeper tongue of relatively warm and saline "Mediterranean" water (see Fig. 3I). The more widespread area south of the Azores, where the depth contours show values of less than 700 meters, also at least partly results from the same cause.

The current system which is called for by the trend of the contour lines as they cross longitude $30^{\circ} \mathrm{W}$. in Fig. 47 does not agree with the dynamic study made of this same region by Helland-Hansen and Nansen (1926), for their observations indicated that the branching of the main easterly current does not occur until after the Mid-Atlantic Ridge has been passed. Until a thorough survey has been made of this complicated region east of the Grand Banks, it is not worth while to speculate further.

\section{THE GULF STREAM SYSTEM}

\section{Previous Subsurface Investigations}

Having examined the distribution of temperature and salinity in the western North Atlantic, we are now ready to consider in more detail the current system which forms the western and northern boundary of the Sargasso Sea. Although the importance and magnitude of this phenomenon has long been appreciated, most early studies were based primarily on surface observations, so that many of the theories advanced by the pioneer investigators hardly come into discussion ${ }^{23}$ in the light of modern subsurface data. Even in recent times the chief obstacle for a better understanding of the general problem in the Gulf Stream has, of course, been the almost complete lack of subsurface observations in the current itself. After the pioneer temperature and salinity investigations of Bartlett in the Straits of Florida (I878) and the current measurements of Lt. Pillsbury (1886-7), twenty-seven years elapsed before the "Bache" section was made off Jupiter Inlet. Off Cape Hatteras, no really reliable section was made until the "Dana" Expedition (I92I). Off the Grand Banks, the "Michael Sars" occupied a line of stations in I9I I, while in the same region since I 926 the observations of the International Ice Patrol Service have oc-

${ }^{23}$ In a recent paper, Schumacher (1935) has given an excellent summary of the development of the descriptive approach to the problem of the Gulf Stream System. 
casionally extended out to warm water. Except for these few scattered stations, the distribution of temperature and salinity across the Gulf Stream's path has remained a matter of conjecture. The difficulty that until recently blocked most attempts at accurate work arose from the swiftness of the current. Only since the development of unprotected thermometers has it been possible to observe with precision the slope of the mov. ing water layers.

\section{The Three Subdivisions of the Gulf Stream System}

The first result of the "Atlantis" sections in the western North Atlantic is to emphasize the subsurface changes in structure, already pointed out by Wüst (I930), along the length of the current system which marks the western and northern limits of the Sargasso Sea. We have seen that from the Straits of Florida to Cape Hatteras the current presses close to the continental slope. Then between Cape Hatteras and the Grand Banks, it is separated from the continental shelf by a relatively motionless band of water which we have called slope water. Beyond the southern corner of the Grand Banks the single band of current begins to split up so that by mid-ocean several major branches will probably eventually be distinguished.

The whole of this current system has generally been called the "Gulf Stream." Unfortunately, as most early studies of the current were by means of surface observations alone, this term has too of ten been associated only with the warm superficial layer of the stream and is, therefore, unsuitable for the complicated, relatively cool, deep terminal branches in the northeastern North Atlantic. Nielsen (I925) has pointed out that since the Gulf of Mexico contributes little to the volume of water flowing through the Straits of Florida, the word "Gulf" is particularly misleading and both he and Wüst (1924) prefer to use the name Florida Current for the strong northward flow along the continental slope of the southern Atlantic coast states. Of recent years oceanographers have begun to speak of the North Atlantic Current, meaning the easterly flow in mid-latitudes beyond the Grand Banks. Since there is obviously need of a uniform and fully defined terminology among students of this current system, the following has been proposed (Iselin I933) by the author as a possible solution to the existing confusion and is presented here in greater detail. As far as shipping and popular usage are concerned, it would be difficult, if not unwise, to urge any change in the meaning of the term "Gulf Stream" as it is ordinarily employed. However, among scientists there is a real need to restrict and define its meaning.

Gulf Stream System.-This includes the whole of the northward and eastward flow, beginning at the Straits of Florida and including the various branches and eddies found in the eastern North Atlantic whose paths can be traced back, as continuous distortions of the isosteric surfaces at mid-depths, to an origin off the "tail" of the Newfoundland Banks.

This terminology, which has been accepted by Wüst (I 934), recognizes the fact that the current, though continuous, is complex. The words "Gulf Stream" are retained because, as a general term, they have become too widely used to discard now.

On the southeastern side of the current, the boundary is seldom clearly marked because the swiftness of the flow decreases gradually in a horizontal direction (see Fig. 27). Not only is it at times difficult to determine the boundary at the surface between the Gulf Stream System and, for example, the Sargasso Sea, but the deep limits of the current are also somewhat vague unless a minimum velocity is set to define what is part of 
the Gulf Stream System and what is not. On the basis of the present study Io $\mathrm{cm}$. per sec. seems a logical and convenient boundary to arbitrarily set for the current.

Because of changes in structure, the Gulf Stream System can be subdivided longitudinally into three major parts.

I. The Florida Current. This includes all the northward moving water (with velocities greater than $10 \mathrm{~cm}$. per sec.) from the Straits of Florida to the point just beyond Cape Hatteras where the current ceases to follow the continental slope. The current through the straits should also be included. The starting point might most logically be placed on a line south of Tortugas where eventually observations may be expected to show that the water from the Yucatan Channel is joined by a smaller outflow from the Gulf of Mexico. Since the union with the Antilles Current of the water which has passed through the straits causes no change in the structure of the Florida Current, no further subdivision of this sector of the Gulf Stream System seems necessary.

The three chief characteristics of the Florida Current are that it greatly increases in volume as it travels northward, that it flows most swiftly along the continental slope, and that for the greater part of its length (because of the bottom conformation) it remains relatively shallow. For the latter reason, it transports northward no water colder than about $6.5^{\circ}$ until after the northern limit of the Blake Plateau has been passed.

2. The old term Gulf Stream is best reserved for the middle sector of the current and therefore is here restricted to the northeasterly flowing water (having a velocity greater than $10 \mathrm{~cm}$. per sec.) from the point just north of Cape Hatteras, where the current first leaves the continental slope, to the region east of the Grand Banks, where the stream begins to fork.

The name Gulf Stream has been so generally applied to this part of the current that it would only add to the confusion to suggest a new term. Since this name is not entirely logical, it seems wise to give it a rigid definition so that among scientists at least, there will be no chance of misunderstanding. Especially, it seems best to use this name for the whole depth and width of the current (within the proscribed velocities) rather than limiting the meaning, as has often been done, to just the warmer surface layers. Eventually perhaps the unfortunate connotation of heat which the name now carries will be lost.

When a shallow displacement of the warm surface layer is found in the slope water region, it should be spoken of as "water of Gulf Stream origin," for though it has come from the Gulf Stream, it has none of the characteristics of a major current, i.e., no deep slanting of the isosteric surfaces would be found, because these movements are only superficial. Likewise, when through fluctuations in the transport of the main stream or through other causes, tropical water is met with in the center of an eddy (see Fig. I5) and entirely separated from the Gulf Stream, it should be given a suitable designation. Frequently, in the past, coastal sections terminating in the centers of such eddies have been thought to extend out to the Gulf Stream itself.

Finally, the chief characteristics of the Gulf Stream are that it is separated from the continental shelf by the relatively dead slope water, that it flows deeply without further greatly increasing the transport, and that the flow is normally in one band as evidenced by the uninterrupted slope of the water layers across its path.

3. The North Atlantic Current is the name most often applied to the third (most easterly) section of the current system. Until more is known about the paths which the various branches follow, this must be used as a general term covering all the easterly and northerly currents from the point east of the "tail" of the Grand Banks, where the 
Gulf Stream first divides. Included are all the lines of flow (with velocities greater than Io $\mathrm{cm}$. per sec.) which can be traced back as continuous, deep (below 200 meters) distortions of the isosteric surfaces to a common origin from the Gulf Stream.

In the eastern North Atlantic the paths of the branches of the North Atlantic Current are often masked by a shallow, widespread and variable wind driven surface movement, commonly known as the "North Atlantic Drift."

Only through subsurface observations can the exact courses of the terminal branches of the Gulf Stream System eventually be determined. It is well established that one of these swings northward to supply the Irminger Current and that a branch of it also enters the Norwegian Sea, where it is called the Norwegian Atlantic Current. Other more southerly branches have been traced by Helland-Hansen and Nansen (I926) who find that they terminate in great eddies off the European Coast. When more is known about the permanence and paths of these complicated eddies, they can each be given appropriate names.

The chief characteristics of the Atlantic Current are that it is usually not traceable from surface observations alone and that the transition from northern conditions to those of the Sargasso Sea does not take place in one deep slanting of the water layers, as in the case across the Gulf Stream, but in a number of steps, the bands of flow being separated by dead water or even by counter currents and eddies.

\section{The Sources and Character of the Gulf Stream System}

Fig. $4^{8}$ shows diagrammatically the sources (broken lines) and the path (solid lines) of the Gulf Stream System. Although we are concerned in this report primarily with a study of the current between the Straits of Florida and the point where its terminal branches cross the Mid-Atlantic Ridge, nevertheless, as suggested in the chart, the water emerging from Florida Straits has a considerable past history which we cannot entirely neglect.

We have seen that the Northern Equatorial Current is a broad (I 200 miles wide) relatively slow and, especially in the south, somewhat shallow type of movement. Obviously the portion of this current which passes through the northern Caribbean must approximately equal the outflow from the Straits of Florida, provided no significant amount of water is added to the Gulf of Mexico by land drainage and rainfall. For our present purposes these factors can be disregarded, because the volume of water added to the Gulf of Mexico can amount to but a small fraction of the discharge through the Florida Straits, which, according to Wüst ( 1924 ), approximates $25 \times 10^{6}$ cubic meters per second. ${ }^{24}$ More than three times this volume $\left(82 \times 10^{6}\right.$ cubic meters per second) was transported by the Gulf Stream off Chesapeake Bay in April $1932^{25}$ (page 43 ). Moreover, it has been shown (Fig. 47) that the total slope across the Northern Equatorial Current is only slightly less th an that across the Gulf Stream. In other words, it can be argued that the volume of the Northern Equatorial Current (plus the volume of the southwestward flow across the central Sargasso Sea must approximately correspond to the total transport of the Gulf

${ }^{24}$ For example, the maximum volume of the Mississippi River only amounts to .I2XIO cubic meters per second.

${ }_{25}$ These volumes and those given in the succeeding pages seem to be representative of the current's transport. While fluctuations in depth of the thermocline layers on each side of the Gulf Stream off Chesapeake Bay during I932 (see page 32) must have been accompanied by a change in volume of about $20 \%$, the April stations give a middle value for the transport during 1932.

The figures given here include the movements having calculated velocities of less than $10 \mathrm{~cm}$. per sec., although this is inconsistent with the definition of the Gulf Stream given above (page 73). The water moving at less than $10 \mathrm{~cm}$. per sec. accounts for only about $13 \%$ of the total northward flow. 
Stream off Chesapeake Bay and that less than one-third of this water has passed through the Caribbean.

Presumably the Caribbean receives a representative sample from that part of the Equatorial Current which has crossed the ocean between latitudes $10^{\circ}$ and $19^{\circ} \mathrm{N}$. In

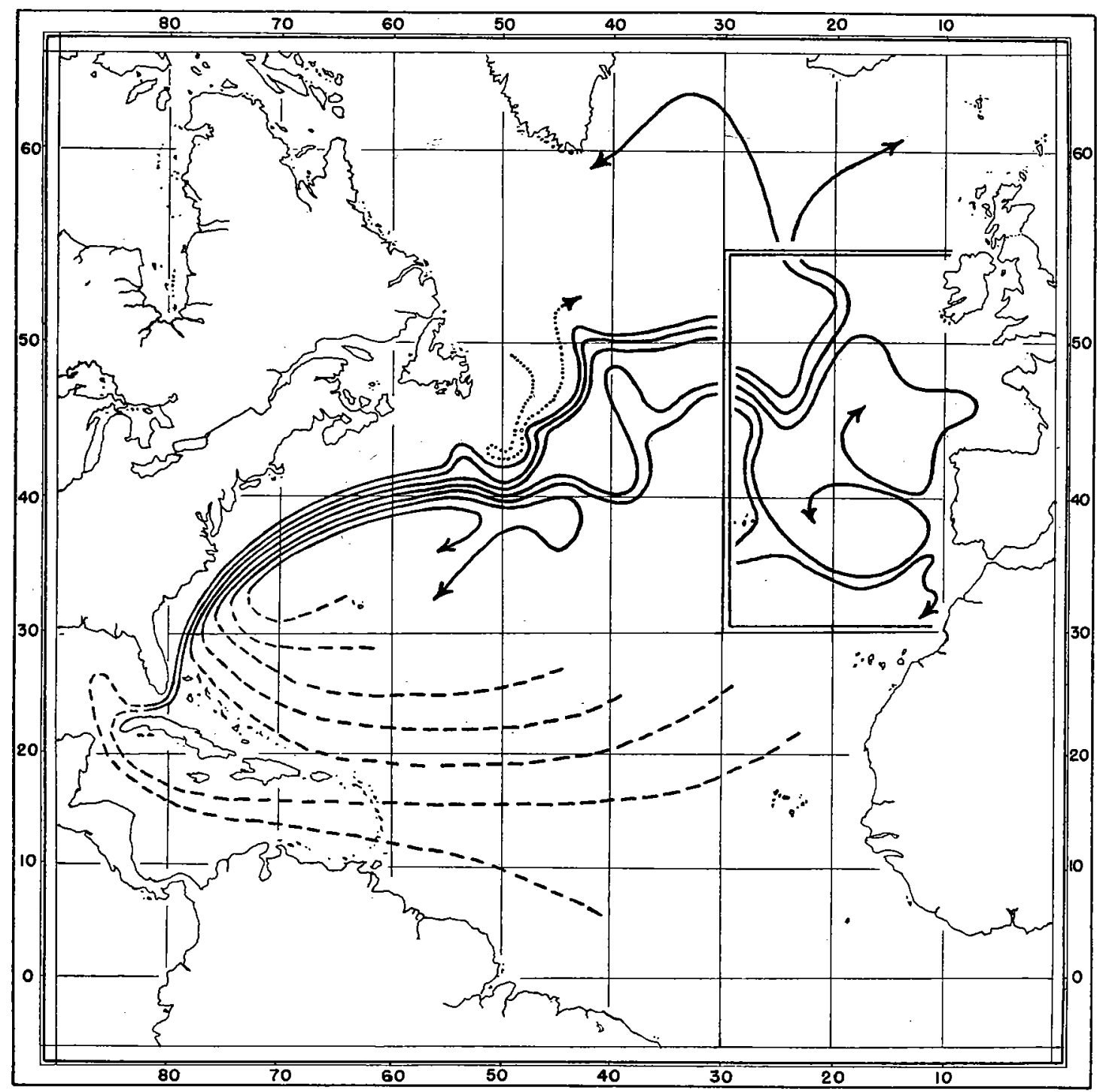

FIG. 48.-Diagrammatic chart showing the sources (broken lines) and pattern (solid lines) of the Gulf Stream System. In the Western half of the ocean each streamline represents the transport of approximately $12 \times 10^{6}$ cubic meters per second.

this band the Sub-Antarctic intermediate layer increases in intensity from north to south (Fig. 33). Thus the water at mid-depths which enters the Caribbean at the latitude of Barbados, for example, will be somewhat different from that which flows through Anegada Passage. In other words, as the slow wind driven movement advances westward across the Caribbean, it may be expected at mid-depths to vary somewhat in T-S ratio 
from north to south, because of the considerable differences in latitude of the various points of entrance. These slight differences must gradually disappear through mixing as the northern Caribbean is reached, for we have seen (Fig. 42) that the waters at middepths in the Florida Current off Cape Canaveral are very uniform in T-S correlation.

The channel across the southern Caribbean basin is some 315 miles broad at its narrowest point south of Hayti. The Yucatan Channel has a width of about 105 miles, while the Florida Straits opposite Bimini are only 44 miles wide. Thus in cross section the current is successively reduced as it flows northward and, therefore, must increase correspondingly in velocity. The transverse area of the channel (above the depth of 700 meters) diminishes approximately according to the following ratio: Caribbean eastern basin Ir, Yucatan Channel 3, Florida Straits I. Thus for depths not greater than the shoalest part of the Straits of Florida, the mean velocity of the flow across the Caribbean must be less than $\frac{1}{10}$ of that at the same depth in the narrowest part of the Florida Current. These considerations have been introduced to emphasize the narrowing and intensifying of the flow which takes place south of latitude $25^{\circ} \mathrm{N}$. in contrast to the gradual broadening of the Gulf Stream System north of this point.

Emerging from the straits, the Florida Current is soon joined by the Antilles Current. According to Wüst (1924) this additional contribution, which from the "Atlantis" observations appears to take place south of the Jacksonville line (page 67), amounts to about $\mathrm{I} 2 \times 10^{6}$ cubic meters per second. From this point northward it is probable that the current gains steadily in volume until it leaves the shallow depths of the Blake Plateau. Here it experiences a relatively sudden and great increase in depth by the joining in from the southwestern Sargasso Sea of considerable water having temperatures lower than $8^{\circ}$. During the remaining short distance northward to the Chesapeake Bay-Bermuda section, any increase in the volume probably takes place at all depths along with the widening and deepening of the current.

If these considerations are in the main correct, and if we realize that the original outflow from the Florida Straits must be continually diluted through turbulence, the Gulf Stream velocity section off Chesapeake Bay (Fig. 27) can for the purposes of discussion be rationally broken up as in Fig. 49 .

The area marked $A$ includes all water warmer than $20^{\circ}$. The velocity calculations show that in this part of the current, the transport amounts to about $10.6 \times 10^{6} \mathrm{cubic}$ meters per second. ${ }^{26}$ For the same layer in the Florida Straits, Wüst's diagrams indicate a volume of about $13 \times 10^{6}$ cubic meters per second, and in the Antilles Current, $4 \times 10^{6}$ cubic meters per second. These amounts, when added together considerably surpass the transport of the warm layer off Chesapeake Bay, but it seems probable that this part of the flow as it moves northward not only varies widely in volume depending on the wind's direction, but also on the whole, gradually loses water through chilling and horizontal stirring. At any rate, it can safely be assumed that the part of the current bounded by the isotherm of $20^{\circ}$ does not gain in volume, as it flows northward from the mouth of the Florida Straits because of the admixture of inshore or offshore water.

Area B (Fig. 49) includes only water colder than $8^{\circ}$, the greater part of which has presumably joined the current since it passed the northern edge of the Blake Plateau. The transport of this subdivision of the current, according to the "Atlantis" velocity

${ }^{26}$ It should be pointed out again that these figures are based only on the "Atlantis" April profile (Figs. 5, 6, and 27). Wüst's values for the transport through the straits are possibly slightly more reliable in that they are derived from a study of several sets of data. 
calculations, amounts to about $\mathrm{I} 2.7 \times 10^{6}$ cubic meters per second and only a very small part of it can have passed through the Florida Straits.

It seems probable that after passing Cape Hatteras some of the slope water is drawn by friction into the flow northward. Area C, having velocities less than $20 \mathrm{~cm}$. per sec.

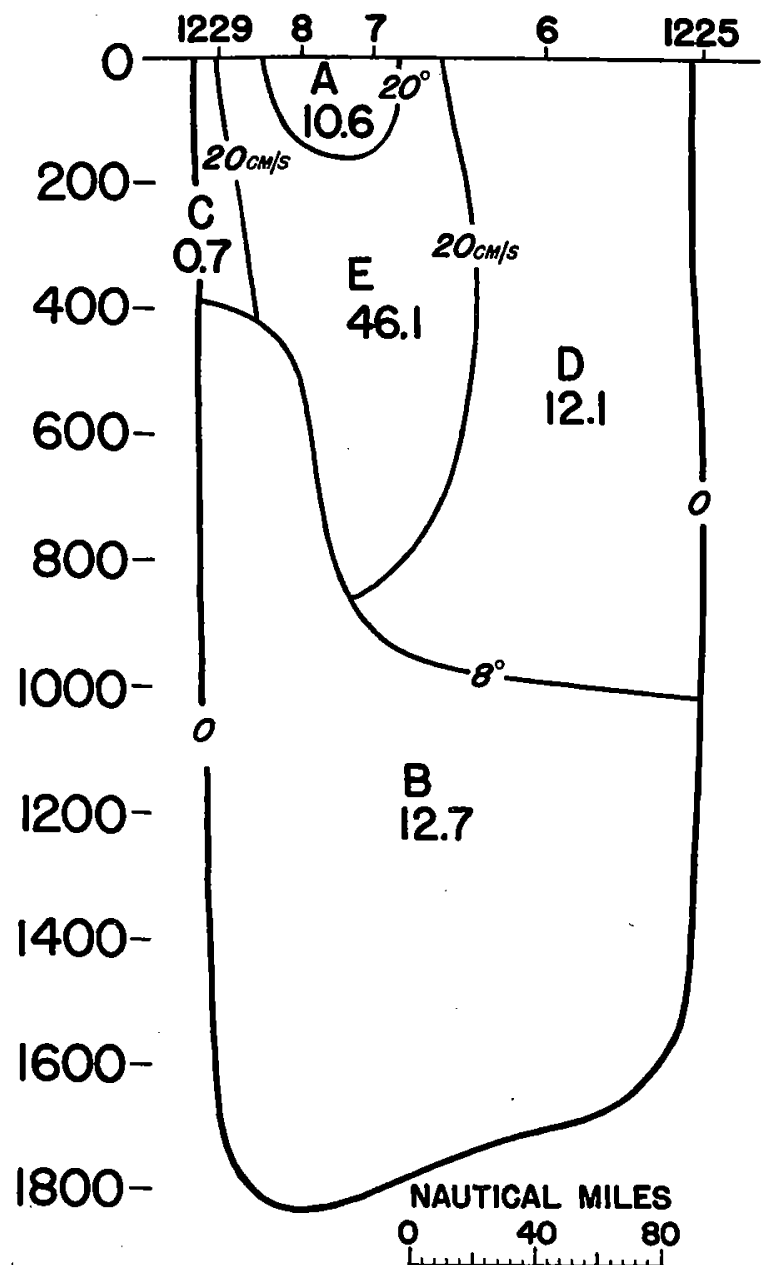

Frg. 49.- Subdivisions of the velocity profile across Gulf Stream off Chesapeake Bay, April 20-22, I932. The figures give the transport (in millions of cubic meters per second) of the different parts of the current.

is an arbitrary attempt to mark off the profile in question that part of the Gulf Stream containing a strong admixture of slope water. Area $\mathrm{C}$ accounts for a transport of only $0.7 \times 10^{6}$ cubic meters per second.

In the same way, it might be supposed that on the eastern side of the current the waters having corresponding velocities had recently joined from the Sargasso Sea. This part of the current (Area D) has a volume of approximately I 2.I $\times 10^{6}$ cubic meters per second.

The remaining division (Area $\mathrm{E}$ ) carries $46 . \mathrm{I} \times \mathrm{IO}^{6}$ cubic meters per second. From Wüst's figures we find that this part of the current was originally supplied with less 
than $26.4 \times 10^{6}$ cubic meters per second of Florida Strait and Antilles Current subsurface water. Thus it can be argued that even in the heart of the current, where about half the total volume is carried, the original water is about $50 \%$ diluted in the course of only 600 miles of northward flow. While off Onslow Bay, as we have seen (page 69), there still remains a small core of nearly undiluted, $10^{\circ}-\mathrm{II}^{\circ}$ water characteristic of the Caribbean, by the time this comes abreast of Chesapeake Bay these low salinities have been considerably increased through further mixing with surrounding waters as is shown by the following data:

$\begin{array}{lcc} & 10^{\circ} & \mathrm{II}^{\circ} \\ \text { Onslow Bay } & 35.22 & 35 \cdot 36 \\ \text { Chesapeake Bay } & 35.28 & 35 \cdot 4 \mathrm{I}\end{array}$

The immense increase in volume which the Florida Current experiences as it flows northward comes from three main sources. It seems probable that the contribution from the Antilles Current is by far the smallest of these. If we accept Wüst figures, which seem high in the light of the two "Atlantis" sections discussed above (pages 55 and 60), there still remains about $45 \times 10^{6}$ cubic meters per second to be divided between the two other sources; namely, the water arriving to the southwestern Sargasso Sea from the northern edge of the Northern Equatorial Current, and the return flow from the Grand Banks region (see Fig. 48). Possibly, these two contributions are of about equal volume as has been indicated by the stream lines in Fig. 48 . If this is so, in the western half of the ocean each of the diagrammatic stream lines shown in this illustration can be considered as representing the transport of about $12 \times 10^{6}$ cubic meters per second. Until we know more about the fluctuations in volume of the great North Atlantic eddy, there would be no advantage in attempting to arrive at more exact values for the various subdivisions.

It might be supposed that the comparatively narrow, swift type of flow so characteristic of the Florida Current and of the Gulf Stream results from the confining effects of the Florida Straits. But this seems not entirely the case when we consider the immense volume of slowly moving water from the southern Sargasso Sea across which the gradient narrows as it joins in with the Gulf Stream System south of Cape Hatteras. It is suggested that the character of the great Atlantic eddy is greatly influenced by the NE-SW trend of the continental shelf of North America. Thus even if the Straits of Florida did not exist, there would be a tendency towards a narrowing and intensifying of the broad circulatory movement initiated by the trade winds as the flow reaches the western margin of ocean and is forced to make a right angle bend to the north. Indeed this is also the case in the North Pacific.

After passing Cape Hatteras, the Gulf Stream System reaches its full development and the available observations indicate no marked change in the structure of the current until longitude $60^{\circ} \mathrm{W}$ is reached. From this point eastward to the southern extremity of the Grand Banks there is some indication that the flow begins to broaden out and to weaken. The few reliable stations off the mouth of the Laurentian Channel call for the northward loop of part of the current as indicated in Fig. 48 . However, it is by no means improbable that in this region part of the flow recurves completely to the left and becomes absorbed by the slope water, for beyond doubt the latter is continually losing water to the Gulf Stream further west. This important question is now being investigated.

Beyond the tail of the Grand Banks, the breakdown of the current becomes more evident. Not only is it well known by navigators that surface velocities are lower, but the 
available subsurface data call for a complicated branching of the main stream (Fig. 47). Moreover, it is in this region that the northern branch of the current first begins to absorb Sub-Arctic intermediate water and thus the temperature-salinity correlation at middepths begins to change markedly.

Unfortunately the conditions within the current in the important sector south of the tail of the Grand Banks is very imperfectly known. The work of the International Ice Patrol has proved that, though subject to variations, the Labrador Current, after rounding the southern extremity of the banks and flowing some 60 miles westward, ordinarily curves back to the left and turns eastward paralleling the Gulf Stream. This is the situation diagramatically represented by the dotted line in Fig. 48.

It has often been suggested that the close proximity of these two currents off the tail of the banks might result in intermixture (and even cabbeling) on a large scale. When the available observations are examined in detail, because of the horizontal distribution of density, no situation can be found favorable for such mixing. It seems more probable that the Labrador Current never comes in actual contact with the Gulf Stream in the region south of the Grand Banks. The warming and the increase in salinity which the cold water experiences can be attributed to its mixing with eastern slope water and the latter may in turn exert a freshening effect on the surface layer of the Gulf Stream, which is thereby only indirectly influenced by the arctic water.

The evidence is also fragmentary for the course of the Gulf Stream System immediately after it has rounded the southern extremity of the Grand Banks. In general it is well established that the main current follows the bottom contours northward, parallel with the eastern face of the banks as far as the entrance to the Labrador Basin (latitude $50^{\circ} \mathrm{N}$ ). However, it is clear that by no means all the water makes this northern circuit. On the evidence of Fig. 47, the southern half of the current appears to proceed eastward to about longitude $40^{\circ} \mathrm{W}$ where part of it bends northward and part southward, the latter fraction returning, as shown in Fig. 48 , to the southwestern Sargasso Sea.

In contrast to our uncertainty as to the course and intensity of the two southern branches emanating from the Gulf Stream, the path of the northern branch is fairly well known through recent post-season cruises of the International Ice Patrol (Fig. 47). Especially in the region of the deep entrance to the Labrador Basin, a number of reliable stations call for a sharp eastward bend of the current. Apparently the ridge, which partly blocks the deep channel, helps to turn the current at this point.

Through the "Atlantis" observations in mid-ocean (longitude $30^{\circ} \mathrm{W}$ ), the internal structure of the northern branch of the North Atlantic Current can again be examined (Figs. 29 and 30). Here the current was about I4O miles wide in July I93I and the observations clearly show the freshening effect of the northern water, both at the surface and at mid-depths (200-600 meters).

In Fig. 48 the terminal branches of the Gulf Stream System have been copied from Helland-Hansen and Nansen (1926) and are therefore marked off from the lines of flow called for by the more recent observations. The disagreement along the Mid-Atlantic Ridge is not as great as might at first appear. Only a relatively slight readjustment of the streamlines is necessary to logically connect up the two areas. It is also probable that this part of the current system is subject to wide variations.

Until further observations are made in the region just west of the Mid-Atlantic Ridge, it is fruitless to seek to locate closely the longitude where the Gulf Stream System first 
begins to split up or to attempt a quantitative estimate of the transport of the various branches. On the other hand, the available observations are sufficient to demonstrate some of the characteristics of the North Atlantic Current, which can be summarized as follows:

I. The broad, uninterrupted type of flow found in the trade wind latitudes does not reappear in the great North Atlantic eddy when it comes under the influence of the prevailing westerly winds.

2. The flow continues deep and follows several lines, their paths not being apparently as much influenced by the wind as by the bottom contours.

3. The gradient across each of the eastward flowing bands of current remains relatively steep, possibly because of the increase of the Coriolean force in higher latitudes.

4. Only one branch (the most northern and also the shallowest) carries water out of the great North Atlantic eddy. This branch probably acts near the surface as the northern boundary for water more saline than $35 \%$. Thus the fluctuations in its path in the eastern half of the ocean may produce the apparent expansions and contractions of "Atlantic water" which have led to the transgression theory of LeDanois (I934).

5. A second and less powerful branch crosses the Mid-Atlantic Ridge in about latitude $4^{\circ} 6^{\circ} 0^{\prime}$ and, being protected by the northern stream, remains relatively uncontaminated by Sub-Arctic water. In the eastern half of the ocean this current dissipates its energy in two great eddies off the coast of central Europe.

6. From this region the water is probably transferred to the Northern Equatorial Current System by the local wind and, therefore, must be withdrawn mainly from the superficial layers.

7. A third and most southerly subdivision of the Gulf Stream water recurves to the right after passing the Grand Banks and after broadening out moves southwestward as a slow, deep current to rejoin the Florida Current south of Cape Hatteras.

8. The various deep branches of the North Atlantic Current (and especially their final dissipation) are partly masked by a shallow and variable wind-driven movement generally known as the North Atlantic Drift. For this reason shallow observations have not greatly aided the understanding of the current system in the northeastern quarter of the ocean.

\section{THE SARGASSO SEA}

\section{ITS BOUNDARY}

While the limits of the western half of the Sargasso Sea are clearly marked by the Antilles Current, the Florida Current and the Gulf Stream, in terms of circulation the exact course of the remainder of its boundary, amounting to slightly more than half, is a matter for speculation. Possibly it is more rational to think of the Sargasso Sea as blending gradually to the south into the Equatorial Current than to try to assign it a definite, southern, hydrological boundary. In the same way, in the southeast it may prove difficult to point out any natural line of separation between the Sargasso Sea and the Canaries Current. To the northeast, the middle branch of the North Atlantic Current may prove, on closer investigation, to be sufficiently permanent and unmistakable to be classed as a natural current boundary. 
In the case of the southern and eastern quadrants, any limitation to the area known as the Sargasso Sea must take into account the north and south migration of the trade wind belt. Thus the Sargasso Sea is to some extent a shifting subdivision of the ocean and the term has its greatest use when the area is not given too rigid bounds, but merely applied in a general way to the relatively slow-moving core of water around which the swifter flow of the great North Atlantic eddy revolves.

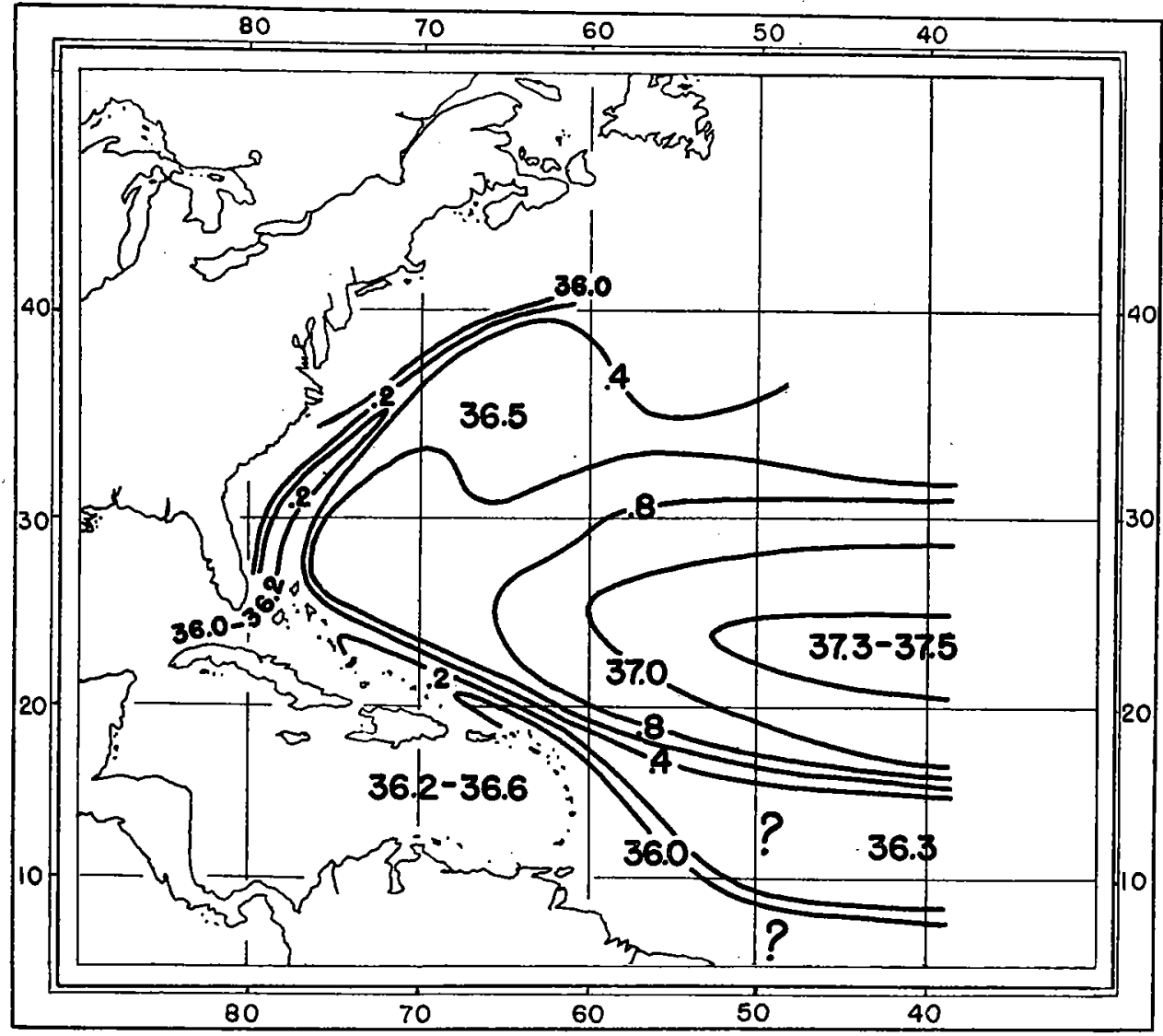

FIg. 50.-The distribution of salinity during the winter months at the surface of the western North Atlantic.

We cannot logically point to any surface feature as even roughly marking the limits of this area (except of course in the western quadrant) because of the shifting and variable nature of the climatic factors. If we look below the surface, the course of the $10^{\circ}$ is othermobath for 700 meters seems to be a reasonable choice (Fig. 47), as this will presumably shift seasonably with the wind, and also is representative of the line normally dividing the slow movements in the Sargasso Sea from the swifter currents which surround it.

\section{The Surface Movements in Relation to the Wind}

We have seen that at mid-depths the water layers of the Sargasso Sea are relatively undisturbed by currents and that variations of temperature and of salinity occur only 
slowly in a horizontal direction. Because of the rather gradual climatic transitions from region to region in the central North Atlantic, it might be expected that the surface layer would likewise only show gradual changes. Indeed, such studies as have been made of the surface temperature distribution (Kon. Ned. Meteor. Inst. I9I8, Harwood and Brooks 1933) give support to such a view, for the isotherms in general are shown as extending east and west, and the temperature as inçreasing in a regular gradation from north to south. However, in an area as large as the Sargasso Sea the density of the surface water cannot be everywhere the same, and in different parts of the region the climatic factors are probably altering the water at different rates. Thus it is most important to try to discover whether or not the surface movements are influenced by the horizontal distribution of density as well as by the frictional force of the wind at the surface.
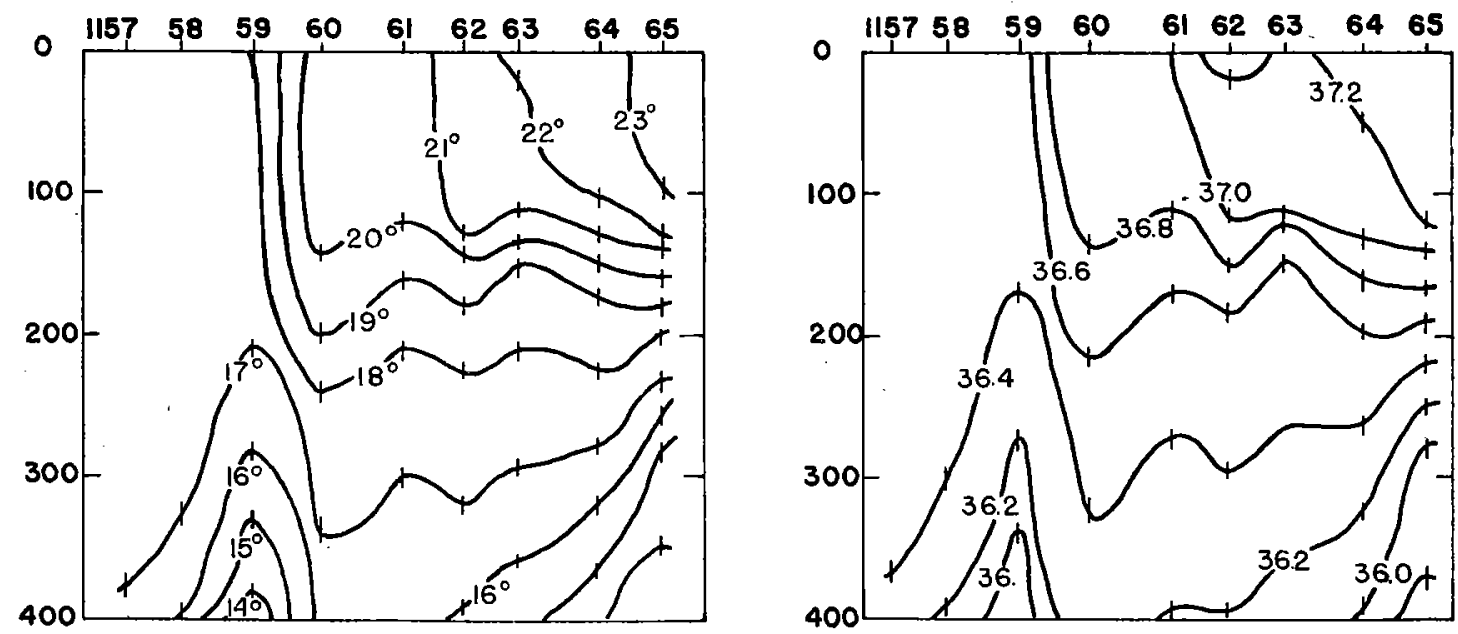

FIG. 51.-Detail of the trends of temperature and salinity in the surface layer across the northern edge of the Sargasso Sea high salinity belt, March 3-10, I932.

The "Atlantis" observations have at last made it possible to construct a surface salinity chart of part of the Sargasso Sea for the winter months (Fig. 50) and we are now able to examine the superficial movements with greater assurance than is possible by a consideration of temperature alone. While the number of data are few for such a vast area, when combined with some of the earlier observations they enable us to point out certain features that would not appear readily if the usual method of averaging all available surface readings from each $2^{\circ}$ square were resorted to. In particular, Fig. 49 brings out the two extremely sharp zones of transition in mid-ocean lying just north and just south of the isohaline of $37 \%$. Another abrupt change at latitude $7^{\circ} \mathrm{N}$ marks in midocean the northern limit of the relatively fresh equatorial water. This fourfold division of the surface layer into bands of relatively uniform salinity was also mentioned on page 52. The explanation of this situation must be sought partly in the climatic factors, and partly in the effect of the clockwise wind system.

According to Ekman's (1928) mathematical studies, there should result in the surface layer under the action of a steady wind a net transport to the right (in the northern hemisphere) of the direction from which the wind blows. Since the prevailing winds of 
the North Atlantic are easterly in low latitudes and westerly further north, there should be a tendency for the surface water to accumulate in the center of the Sargasso Sea, the return being effected presumably either by a sinking ${ }^{27}$ in the horse-latitude belt, or by an opposite movement just below the depth of direct wind action. The former scheme of circulation for the surface waters has been for some years generally accepted (Sandström I919, Merz and Wüst I922) but the modern data recently have brought the latter to the fore (Defant 1936). The "Atlantis" observations only partially support these views; especially there is no evidence of the accumulation of a deep homogeneous layer in the center of the wind system.
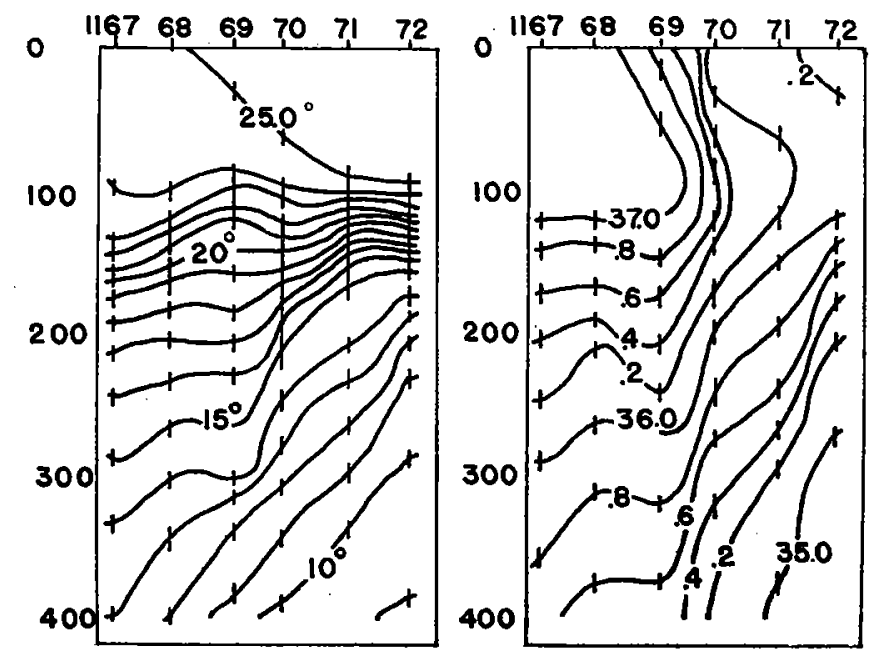

FIG. 52.-Detail of the trends of temperature and salinity in the surface layer across the southern edge of the Sargasso Sea high salinity belt, March I I-15, 1932.

At the time the "Atlantis" observations in mid-ocean were made, the horse-latitude belt was encountered between latitudes $23^{\circ}$ and $26^{\circ} \mathrm{N}$. In other words, the relatively calm belt between the trades and the prevailing westerlies occupied a zone, coinciding with, but somewhat narrower than, the band of water having the highest salinity (Fig. 50). Here the homogeneous layer had a depth of between Ioo and I IO meters. North of latitude $30^{\circ} \mathrm{N}$, the stronger westerly winds had mixed the water thoroughly to a depth of 300 meters. South of the water more saline than $37 \%$, the homogeneous layer decreased in depth somewhat irregularly.

The abrupt ${ }^{28}$ nature of the northern zone of transition (Fig. 50 ) between the isohalines of $36.6 \%$ and $37 \%$ gives no support to the type of lateral transfer near the surface demanded by Ekman's studies, although at the time this sudden change was en-

${ }^{27}$ It is not necessary to assume that a mass sinking occurs. The same effect would be produced if the assimilation of surface water through turbulence takes place at an increased rate in the central area. That such a mechanism is not very effective seems probable when we consider that at the center of the eddy forces tending to produce turbulence are at a minimum.

${ }^{28}$ Because of the distortion in the diagram, the isohalines appear to be vertical above the depth of 100 meters. We should bear in mind that the actual slope may have amounted to only roo meters downward in a distance of I0o miles, an angle of less than $0.1^{\circ}$ from the horizontal. 
countered, the wind was steadily SW and force 4 Beaufort. On the other hand, the southern zone of salinity convergence, well within the trade wind belt, did show some recurving of the isohalines (Fig. 52), indicating at first glance either that the easterly trade winds were here able to bring about a northward shift of the surface layer or that the saline water was spreading southward with an axis at roo meters. The situation in the north seems more in accordance with the early scheme put forward by Sandström (I9I9, page $24 \mathrm{I}$ ), ${ }^{29}$ while only at the southern convergence does the trend of the isohalines appear to agree with Ekman's results, the mathematical basis of which cannot be questioned.

None of these interpretations of the data are to us entirely satisfactory. It seems more reasonable to conclude that in the Sargasso Sea the surface movements, which theoretically should be set up by the wind, are opposed to some extent by powerful climatic factors. This explanation is supported by a consideration of the horizontal distribution of density. For example, in the northern Sargasso Sea the belt of water having salinities of between 36.5 and $36.45 \%$ and which is thoroughly mixed in winter down to a depth of about 300 meters, has a density $\left(\sigma_{t}\right)$ not far from 26.5 , while the more saline and lighter core of water to the south has densities of between 25.65 and 25.10 (Fig. 34). Since these two contrasting layers were separated by a rather sharp zone of transition, it is evident that mixed water is not found in any considerable quantity. It is also evident that along the northern edge of the saline central core, the frictional force of the wind at the surface opposes the Archimedian tendency of the lighter water to spread out over the colder and deeper layer to the north. But it is most unlikely that these two forces could remain balanced for long and it, therefore, seems probable that the full explanation cannot be had without a study of the internal dynamic forces.

Unfortunately at the time these "Atlantis" observations were made, it was not suspected that the surface conditions of the Sargasso Sea were as complex as they now appear to be. For a satisfactory study of the situation disclosed in Figs. $5 \mathrm{I}$ and 52 the stations should have been made at much closer intervals and readings obtained from additional depths. The evidence at hand suggests that while the contrast in density between the stormy, well stirred northern water and the more saline, warmer band to the south is undoubtedly maintained by a well-marked climatic difference, the sharpness of the zone of separation is best explained as the result of a shallow easterly current caused by the contrasting densities of the two masses of water in question. Such a current would carry off the mixed water and thus maintain a sharp boundary. It seems probable that shallow, narrow currents of this type are a more general feature of oceanic, surface circulation than has previously been supposed and that the forces which maintain them are much the same as those which produce coastal currents. In both cases two bodies of water of contrasting densities are separated by a narrow zone of current, across which there is often found a rapidly changing temperature-salinity correlation. Thus it may be a mistake to interpret movements in the surface layer on the basis of either temperature or salinity alone. In the case of coastal currents at any ate, the zone of most rapid current seems to be very resistant to the frictional force of the wind.

As mentioned above, at the southern boundary of the high salinity belt the observations (Fig. 52) can perhaps be interpreted either as a southward penetration of the most

\footnotetext{
${ }^{29}$ Sandström stressed the screwing movement of the water as it spirals inward towards a sinking center. His diagrams indicate that the sinking mainly occurs around the edge of a central core of water. Thus under this scheme there would be little tendency for the fresher northern water to overlay the margins of the highly saline, central mass.
} 
saline water with an axis of movement at about Ioo meters ${ }^{30}$ or as a northward movement of the surface layer under the frictional force of the wind. However, the corresponding temperature section shows that there existed only a very gradual change in temperature across this zone of salinity convergence. This consideration precludes any vigorous north-south transfer of the superficial water. Again we are forced to fall back on a shallow current, (in this case also towards the east) maintained by the difference in density of the two masses of water for which it marks the boundary.

This discussion of the surface conditions demonstrated by the "Atlantis" observations would not be complete without some further mention of the Equatorial Counter Current met with in latitude $5^{\circ} \mathrm{N}$ and already demonstrated in section (Figs. 32, 33 and 34). In a recent paper, Defant (1935) has more fully set forth the extremely complex conditions which exist within the surface layer in low latitudes. Here again one cannot but feel that sufficient attention has not generally been given to the effect of the high rainfall near the equator and the resulting low density of the surface layer.

Near the equator the density of the shallow homogeneous layer is maintained in winter not far from 23.5 (Fig. 34). Through the Archimedian tendency and also aided by the easterly wind, this relatively light water must seek to spread northward over the denser (24.5) water produced in the southern part of the northeast trade wind belt. However, on advancing only a short distance north of the equator it is drawn into the Counter Equatorial Current, which as Sverdrup (1932) and Defant (1935) have shown, owes its existence to the fact that the equatorial currents are not symmetrical with the geographical equator. While the forces which are chiefly responsible for the Counter Equatorial Current are of an underlying nature, they are aided by the surface distribution of density. The relatively fresh equatorial water, which is drawn into the band of easterly current and thus subjected to vigorous mixing with the heavier, more saline water to the north, is continually being carried off to the east and therefore the sharp surface boundary zone is main tained.

We are here dealing with a factor not yet fully understood, but apparently of widespread importance in the superficial circulation of the ocean. When in a limited region the production of relatively light surface water is sufficiently continuous, the wind forces seem not to be able to offset the current brought about by the horizontal density contrasts.

In my opinion, the conditions which assist in maintaining the Counter Equatorial Current are partly responsible for its narrowness and swiftness and are comparable to those which cause the sharp changes in surface salinity further north, only in the latter cases the resultant currents are so narrow and weak that they have not yet been observed. Conclusions on these complex questions must remain tentative because until recently only very few observations existed to demonstrate the sharpness of the stratification (both vertical and horizontal) of the superficial layers of the open ocean between latitudes $30^{\circ} \mathrm{N}$ and $30^{\circ} \mathrm{S}$.

On the basis of the new data it seems evident that as far as the superficial movements are concerned in an area such as the Sargasso Sea further observations and special studies are required. Although in many parts of the ocean, and especially in winter in the

${ }^{30}$ By far the most exhaustive study of surface conditions in low latitudes has recently been published by Defant (1936). Unfortunately the present manuscript was already in the hands of the printer. As far as can be seen from a hasty reading of Defant's study of the North Atlantic Tropospheric layer, his interpretation of the "Atlantis" observations does not fundamentally disagree with that given here. However, in order not to delay the publication of this report, it seems best not to attempt here to discuss the new ideas advanced on the basis of the "Meteor" data. 
northwest quadrant of the Sargasso Sea, the water is homogeneous down to a sufficient depth so that Ekman's drift current theory cannot be criticized on the basis of vertical stratification, the surface layer is not homogeneous in a horizontal direction. The transition zones at the surface between bodies of water of different density are extremely sharp, either because of the inability of waters of different density to mix readily or, as seems

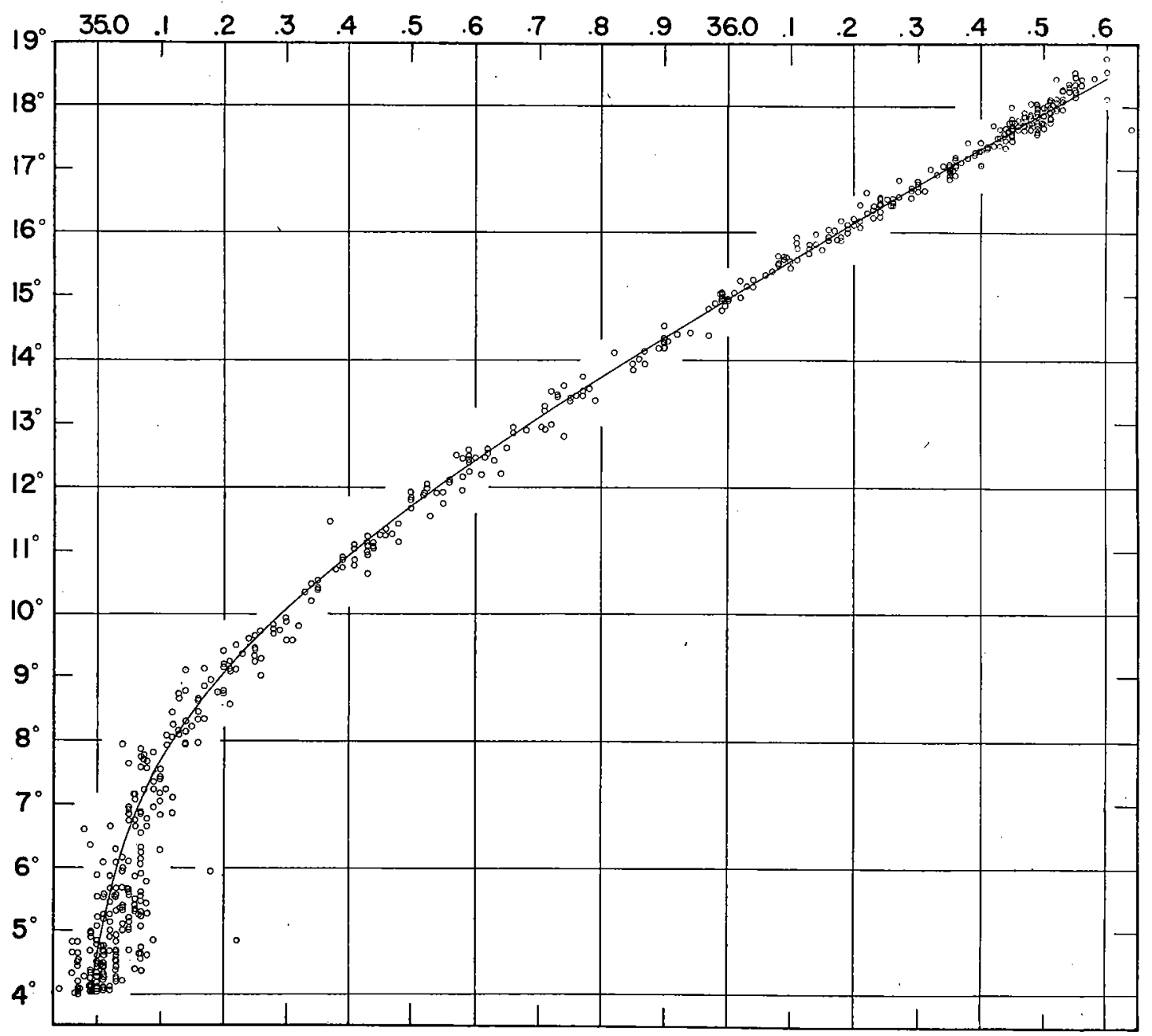

FIG. 53.-Temperature-salinity correlation at all "Atlantis" stations within the Sargasso Sea.

more probable, because of shallow currents which are set up in response to the local dynamic forces. Whatever the final solution to these puzzling problems, there must be a mechanism in the vast areas where surface conditions change only gradually to transfer downward the frictional force of the wind, for one fact is certain, only through the wind can the broad, slow, deeper type of currents found at mid-depths in the trade wind latitudes be accounted for. 


\section{The Lateral Movements at Mid-Depths}

It has been shown (page $3^{8}$ ) that west of Bermuda and below the depth of seasonal variations (300 meters), the "Atlantis" observations within the Sargasso Sea were remarkably consistent in temperature-salinity correlation. The question at once arises whether or not the typical T-S curve (Fig. 22) holds good for other regions within the Sargasso Sea. As a first approach to the problem, the observations from the 96 available "Atlantis" stations within the area bounded by the 700 meter contour of the $10^{\circ}$ isothermal plane (as shown in Fig. 47) are plotted in Fig. 53. Through these points a smooth curve has been drawn reproducing the mean $T-S$ correlation for the region west of Bermuda (Fig. 22). It can be seen that especially at mid-depths a considerable number of the observations depart from this curve by more than the observational error in salinity. However, it can be shown that these departures occur in a fairly regular manner, and that they can be traced back to the two major lateral movements at mid-depths.

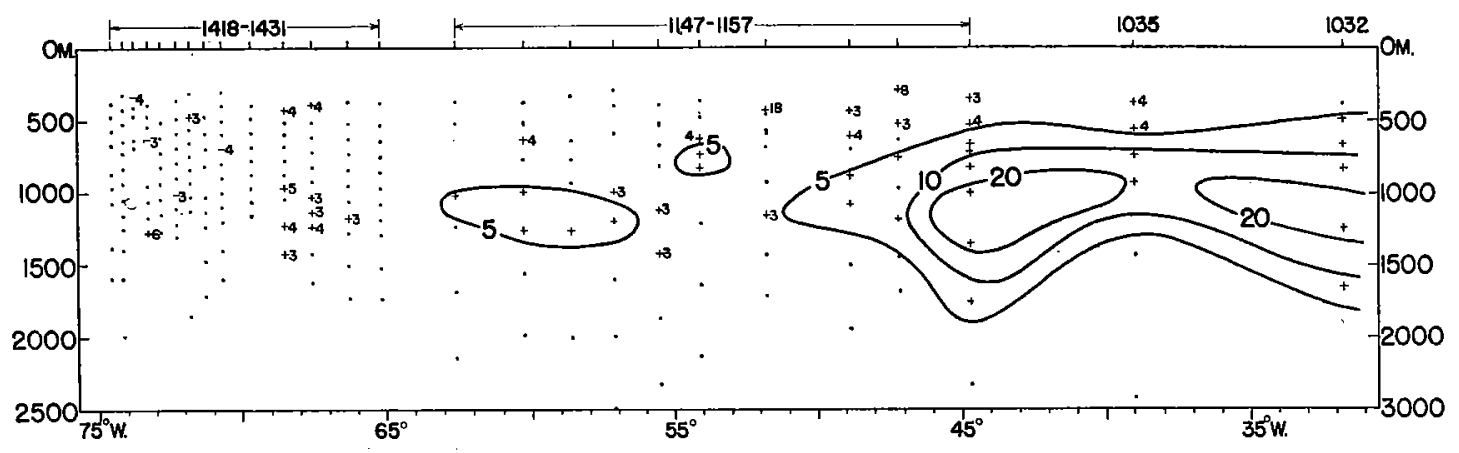

Fig. 54.-Salinity anomaly section from Chesapeake Bay eastward to mid-ocean. Each dot represents an observation yielding 0 anomaly. The sign of the anomalies within the isolines has been recorded, but not their values. Because of seasonal changes, no observations from depths shallower than 300 méters have been plotted.

The salinity anomaly method, first used extensively in deep water by HellandHansen and Nansen (I926), is the best available means of examining the mid-layers of the Sargasso Sea. The anomalies plotted in Figs. 54 to 57 were calculated from the curve given in Fig. 53. Departures in salinity were measured horizontally. Negative values have been assigned to observations falling to the left of the curve, positive to those on the right. The values correspond to parts per hundred thousand in salinity. Anomalies of 2 or less have been disregarded, being within the observational error. In other words, a departure of $\pm .02 \%$ in salinity from the mean curve is considered as having 0 anomaly.

It has been shown repeatedly (Helland-Hansen and Nansen I926, Jacobsen I929) that the relatively high salinities centering at I 200 meters in the eastern North Atlantic result from the outflow and downward mixing off the Straits of Gibraltar of the highly saline Mediterranean water. By a somewhat different method, Wüst (I935) has traced this movement westward in horizontal projection. However, the sensitiveness of the salinity anomaly method enables us to point out several details that otherwise are not apparent.

After reaching mid-ocean in relatively strong concentrations (anomalies $>$ Io in Fig. 54) the main wedge-shaped tongue of Mediterranean water becomes somewhat broken up by the internal circulation of the Sargasso Sea. On the evidence of the "At- 
lantis" stations (Fig. 54) bodies of water carrying small positive anomalies here become separated from the main movement and drift southwestward in the slow clockwise eddy to reappear frequently in the Bermuda sections. Thus for about 700 miles east of Bermuda the anomalies are somewhat scattered and of lower values than are often observed just west of Bermuda or further south. Nevertheless some effect of the Mediterranean outflow can be followed as positive anomalies eastward from Gibraltar (with an axis at I 200 meters) for a surprisingly great distance.

The small negative anomalies at the western end of this section and at a shallower depth (300-500 meters) were to be expected because of the relative freshness of the thermocline layer in the slope water band (Fig. 23).

Even more impressive is a similar plotting of the "Atlantis" equatorial current profile (Fig. 55) which shows in cross section at its northern end the southward extension

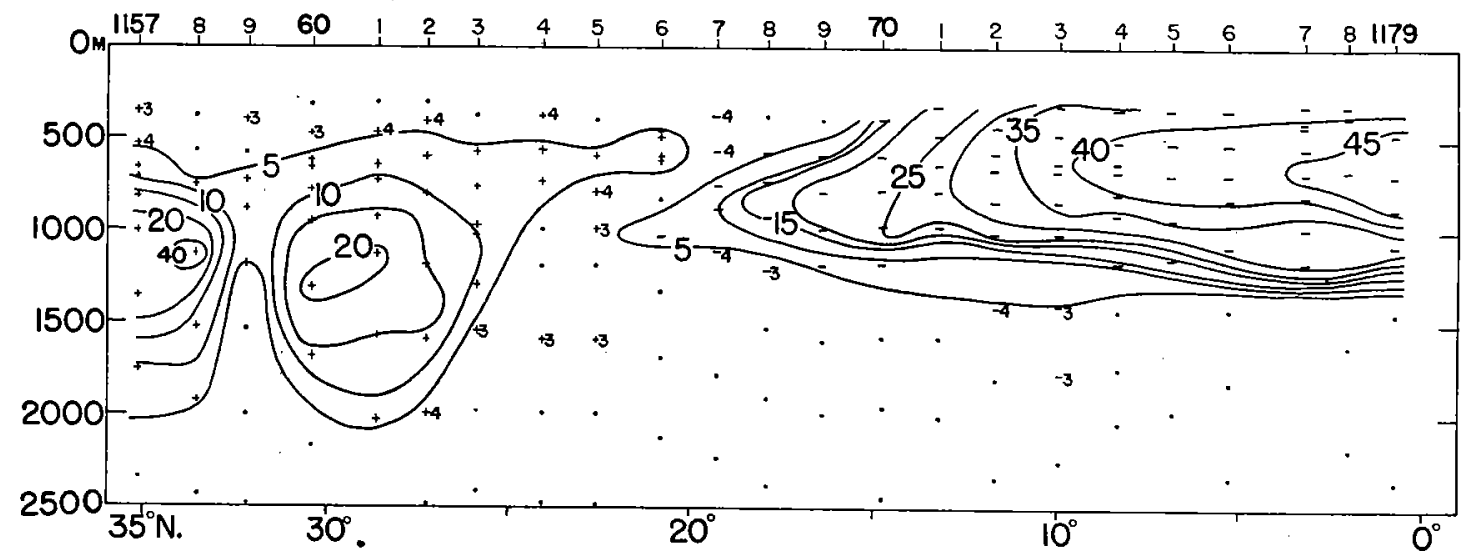

FIG. 55.-Salinity anomaly section across the Nationad Equatorial Current. Each dot represents an observation yielding $o$ anomaly. The sign of the anomalies within the isolines has been recorded, but not their values.

in mid-ocean of the layer of Mediterranean influence. This diagram is evidence that positive anomalies as high as +ro are present at mid-depths in the eastern Sargasso Sea as far south as latitude $26^{\circ} \mathrm{N}$. At a shallower depth (500-700 meters), where the westerly current is more rapid, positive values higher than 5 were found to extend at least 300 miles further south. Between the depths of 1500 and 2000 meters (in other words, below the layer of maximum influence) small positive anomalies $(+I$ and +2 ) were consistently observed even as far south as latitude $15^{\circ} \mathrm{N}$.

As mentioned above, in Wüst's recent paper (1935) a number of diagrams have been published showing the influence of the Mediterranean outflow on the distribution of temperature, salinity and oxygen. This author has named the layer in question, "upper North Atlantic deep water," and by choosing as an axis a level sloping downward towards the equator, has traced the movement southward into the South Atlantic and even to high southern latitudes. On the evidence presented in Fig. 55 it seems to be a mistake not to differentiate more clearly between the influence of the Mediterranean outflow with its axis at about 1200 meters, and the general southward movement which at slightly greater depths carries water into the South Atlantic. The main strength of the southward component of the Mediterranean outflow appears to be dissipated along the northern edge of the Northern Equatorial Current where it meets and mixes with the relatively fresh Sub-Antarctic intermediate layer. Only at slightly greater depths, where 
the characteristics of the water indicate a mixture of bottom water and water from the under side of the Mediterranean tongue, is there any evidence that the influence of the saline layer can be traced further south.

The same diagram (Fig. 55) can be used with equal effect to study the northward and somewhat shallower penetration of the Sub-Antarctic intermediate water. Between latitudes $20^{\circ}$ and $25^{\circ} \mathrm{N}$ the two opposite influences to some extent counteract each other through mixture, so that four observations from this region (1000-I 300 meters) show 0 anomalies. Further west where the strength of the Mediterranean water is somewhat less, future stations may show a larger area where greater quantities of water having 0 anomalies are produced by the blending of these two great lateral movements. The relative importance of this mechanism in the production of typical Sargasso Sea water cannot be judged until we know what percentage of the Sub-Antarctic intermediate water

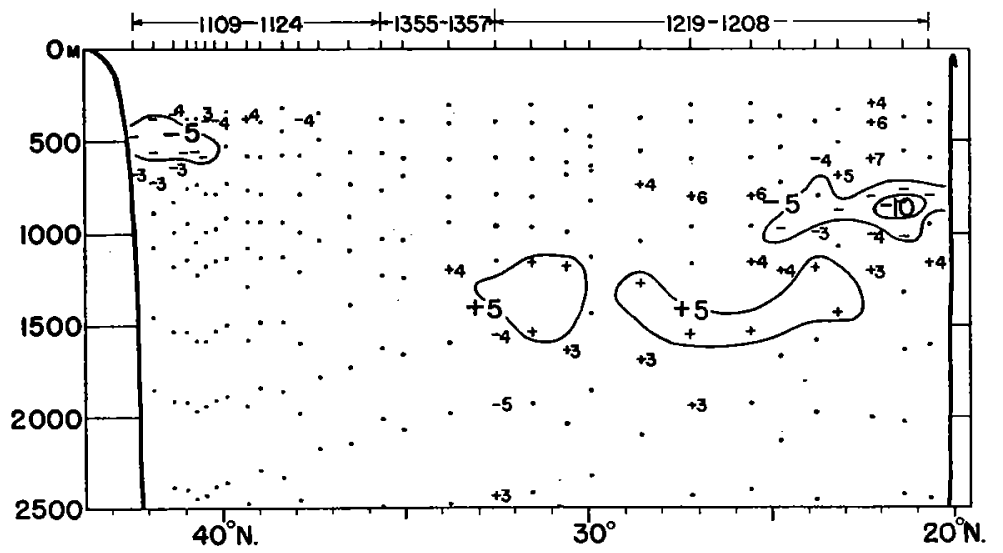

FIG. 56.--Salinity anomaly section, Nova Scotia-Haiti. Each dot represents an observation yielding 0 anomaly.

The sign of the anomalies within the isolines has been recorded, but not their values.

is drawn into the Caribbean by the westerly currents of low latitudes, and how much of it is absorbed along the northern edge of the trade wind belt.

A more westerly section, also crossing the Sargasso Sea in a longitudinal direction, is shown in Fig. 56. In the north, between the depths of 300 and 600 meters, the negative anomalies are again, evidence of the fresher conditions of the slope water area. Then in the central part of the western Sargasso Sea, below a depth of about r I 00 meters, a number of positive anomalies show the widespread influence of the water affected by the Mediterranean outflow. In the south, the fact that these rather scattered positive readings are interrupted by a tongue of relatively fresh water extending as far north as latitude $27^{\circ}$ is evidence that the general clockwise circulation of the Sargasso Sea carries the remains of the Sub-Antarctic intermediate layer far to the northwest before it finally disappears.

The influence of the two important lateral movements at mid-depths in the Sargasso Sea cannot easily be shown in a three-dimensional diagram. But the main facts demonstrated by the three sections just examined can be drawn in flat projection provided depth is to some extent disregarded. In general, the greatest positive anomalies are at about 1200 meters depth, while because of the slope of the water layers across the Northern Equatorial Current, the largest negative values are found at about 750 meters near the equator and at about 1000 meters along latitude $20^{\circ} \mathrm{N}$. 


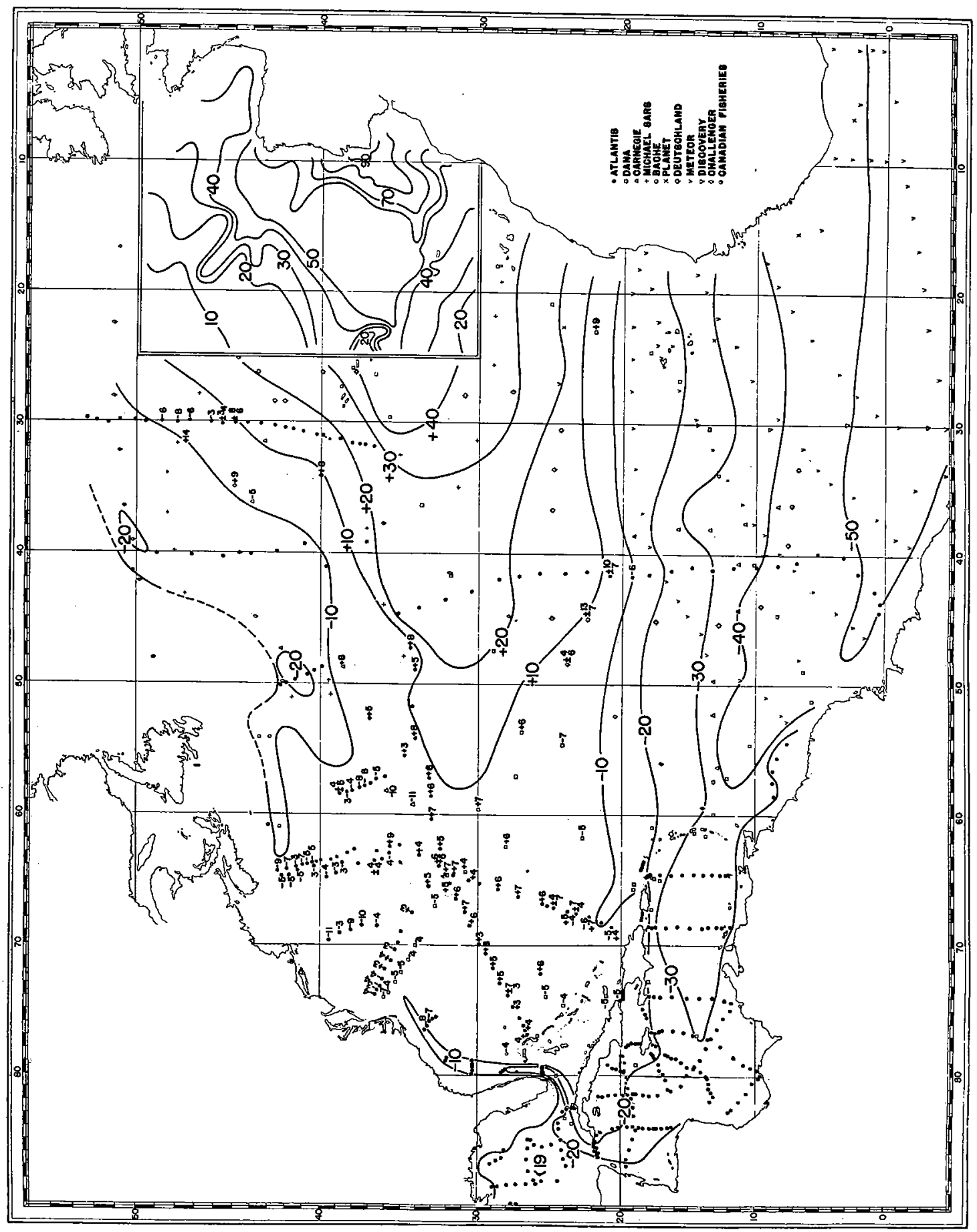

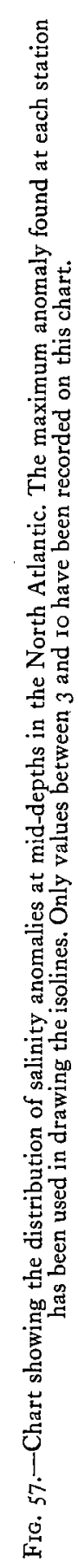


In Fig. 57, showing the horizontal variations of the observations yielding greatest positive and negative anomalies over the greater part of the North Atlantic, the observations of nearly all previous expeditions could readily be combined with those of the "Atlantis." In the northeastern sector of the ocean the anomalies have been copied from a chart published by Helland-Hansen and Nansen (1926) and since their standard curve was based on stations from the eastern half of the ocean, the resulting anomalies are slightly lower than those determined from the average curve of the Bermuda region.

As has been shown by Wüst (I935), the main influence of the Mediterranean water spreads westward in a fairly symmetrical manner, the course of the isolines for anomalies of +20 and + Io (Fig. 57) offering further illustration of this point. However, the positive anomalies lower than +10 are mainly concentrated in the southwestern Sargasso Sea as might be expected from the general clockwise movement of the great North Atlantic eddy. It appears, however, that another factor also influences the salinity anomalies in the western Sargasso Sea, for the chart (Fig. 57) shows a large area to the northeast of the Grand Banks where at 300-500 meters negative anomalies higher than Io are found, these being the result of the southward spreading of Sub-Arctic intermediate water mentioned previously (page 47 ). Although the evidence is as yet inconclusive, this influence seems to extend west of the tail of the Grand Banks in two branches: the first, north of the Gulf Stream in the eastern slope water and, the second, south of the Gulf Stream where the return flow from the most southern branch seems to carry negative anomalies in the direction of Bermuda. Thus it is that only west and north of Bermuda can be found any considerable area having no deviation from the $T-S$ curve here used as a standard.

South of the main tongue showing Mediterranean influence a few stations are found which give both negative and positive anomalies, the latter being from slightly shallower depths. We have already examined this situation in profile (Fig. 55).

Of greater interest is the wide-spread influence of the Sub-Antarctic intermediate water in the Caribbean and Gulf of Mexico. Here the axis of the greatest negative anomalies occupies depths varying between 600 and 800 meters. However, it is clear from Fig. 57 that much of this relatively fresh layer is able to escape through the Straits of Florida, proving that at the shallowest part of the straits the outward flow exists down to the bottom. In the Florida Current the same layer which carries negative anomalies greater than Io northward nearly to Cape Hatteras is characterized by minimum oxygen readings (Rossby 1936). Within the current this layer is of course inclined downward towards the east, its axis closely following the slope of the $8^{\circ}$ isotherm.

It would be extremely helpful if we could learn something about the rates at which the two main movements disclosed in Fig. 57 take place. Since at the present time so little is known about the relative values of horizontal and vertical turbulence, it is perhaps permissible to enter here into some rough calculations even though the nature of the data and our lack of understanding of the processes of turbulence preclude any possibility of arriving at values which can be trusted except as to their orders of magnitude.

In the case of the Mediterranean outflow, we are at first on fairly certain ground, Nielsen (19I2) having made a study of the amount of undiluted Mediterranean water (salinity $38 \%$ ) which each year must flow into the North Atlantic. In view of the dimensions of the channel of the Straits of Gibraltar and of the character of the currents observed there, his estimate of 56,200 cubic kilometers per year, seems entirely reason- 
able. In passing through the straits, this water must mix with (and thereby carry downward ${ }^{31}$ ) a much greater volume of Atlantic water (salinity $>35.5 \%$ ) for at 1200 meters off the western side of the straits the salinity of the so-called Mediterranean water ${ }^{32}$ is already diluted from a value of 38 to about $36.1 \%$.

If the effect of the downward admixture of Atlantic water in the immediate vicinity of the Straits of Gibraltar be disregarded, a simple calculation will show that on the basis of Nielsen's figures an amount of salt, sufficient to produce the observed positive anomalies, is poured into the North Atlantic from the Mediterranean in a period of about I2I 5 years. Having neglected the effect of the downward mixing Atlantic water, we can feel sure that the actual rate of renewal is more rapid than this. Thus there can be no doubt that the interchange between the two oceans remains close to equilibrium.

Since the distance from Gibraltar to the western edge of the positive anomalies $>$ IO shown in Fig. 57 is more than 2500 miles, the order of magnitude of the average westerly component in the axis of this movement is about 200 miles per year, or at least 0.5 miles per day, on the above basis.

It would seem reasonable that if $56,200 \mathrm{~km}^{3}$ of water of salinity $38 \%$ sinks in a year to mid-depths off the Straits of Gibraltar and at the same time carries down some Atlantic water, the Sub-Antarctic intermediate layer must supply the mid-depths of the North Atlantic with a volume of water carrying a corresponding deficit of salt. Such a calculation is of course extremely rough, not only because of the unknown nature of the mixing in the neighborhood of the straits, but also because in the case of the Sub-Antarctic intermediate layer no reliable figure can be assigned to the average salinity. However, if the mean value is placed at $34.6 \%$, at least seven volumes of Sub-Antarctic intermediate water must mix with one volume of pure Mediterranean water to counteract the latter's influence on the salinity at mid-depths in the North Atlantic.

The uncertainty is admittedly even greater when this argument is extended one step further. However, further speculation is perhaps justified because additional evidence as to the value of the coefficient of vertical mixing in oceanic water is much needed. If reasonable average dimensions are assigned to the thickness and width of the SubAntarctic intermediate layer as it enters the North Atlantic and if it is assumed that the layer roughly compensates for the effect of the Mediterranean outflow, on the basis of Nielsen's figure for the latter's volume, it can be shown that on the average the relatively fresh water must advance northward at least 0.5 miles per day. Since this is in agreement with the value of 0.65 miles per day which was arrived at by Jacobsen's method (page 55 ), we have supporting evidence that the coefficient of mixing at a depth of 600-800 meters in the tropical North Atlantic may indeed have a value of about ro c.g.s. units.

It seems probable that when more complete data are available the general method outlined above may become extremely useful in calculating both the rate of the deeper movements in the sea and the variations of the mixing coefficient from layer to layer. Perhaps on these grounds this preliminary study of the influence in the Sargasso Sea of the two great lateral movements can best be justified.

${ }^{31}$ On page 8I, when discussing the connection between the two southern terminal branches of the North Atlantic Current and the beginning of the Northern Equatorial System, it is stated that some of the water arrives at the region east of the Azores as a relatively deep current, while the main outflow, under the action of the wind, must be from the superficial layers. Off the Straits of Gibralter the downward mixing of Atlantic water probably serves as a mechanism for the removal of some of the deeper layers carried eastward by the Gulf Stream System.

${ }^{32} \mathrm{It}$ is now quite customary to refer to the relative saline waters at mid-depths in the eastern North Atlantic as Mediterranean water, although it only exists there in a much dilu ted state. 


\section{The Internal Mixing}

Below the depth of seasonal variations the greater part of the observations from the Sargasso Sea, especially from its western half, depart only slightly in temperature-salinity correlation from the smooth curve given in Fig. 53 and it is evident that the variations from this mean relationship can be explained chiefly by the lateral movements at mid-

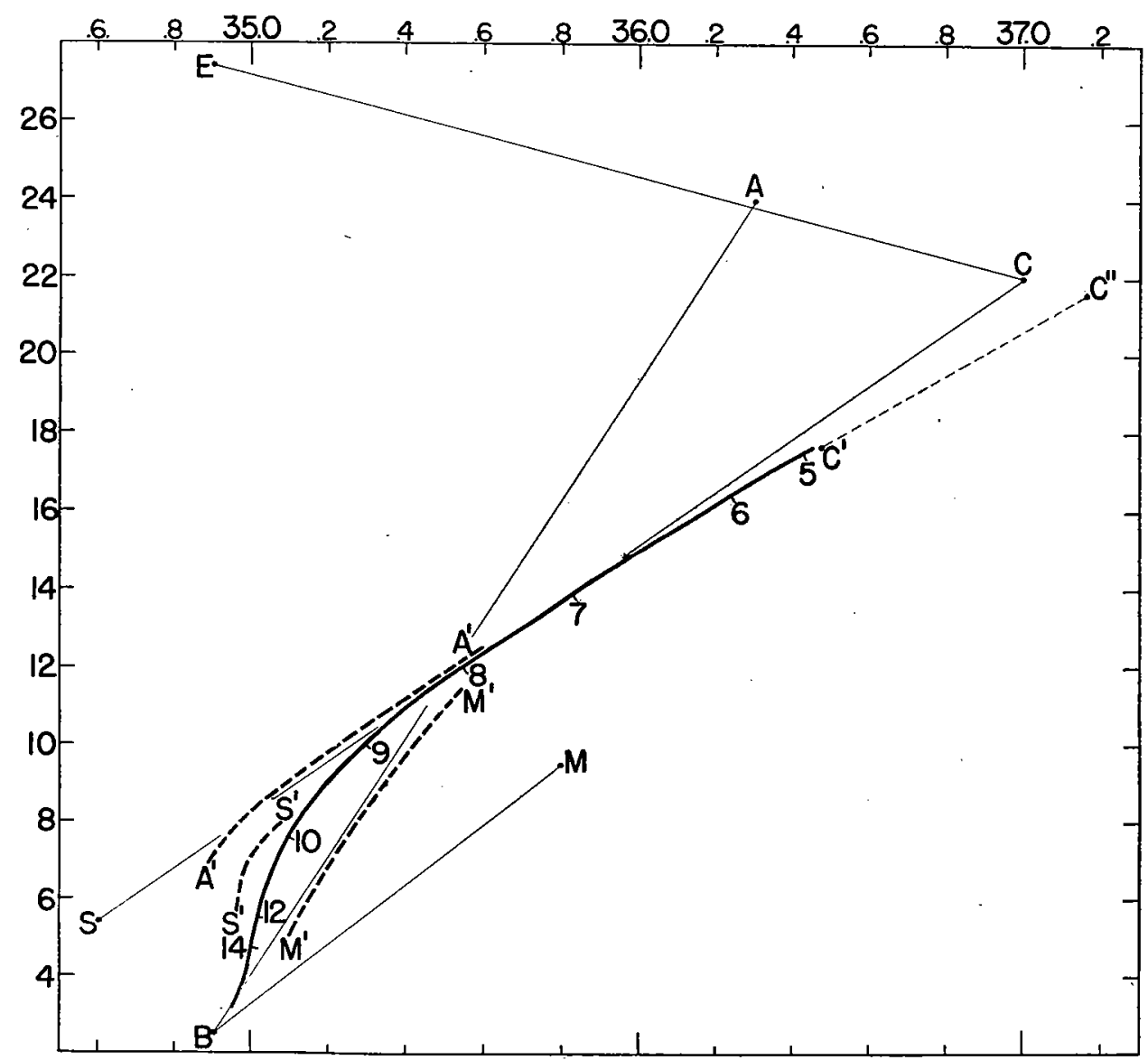

F1G. 58.-Temperature-salinity diagram showing the characteristics of the various bodies of water (broken curves), the gradual assimilation of which tends to produce the typical curve of the Sargasso Sea (solid curve). A depth scale (in hundred of meters), which is approximately correct for the Bermuda region, is also shown.

depths which have just been examined. But a clear demonstration of all other factors that may influence the shape of this curve is difficult, because a full understanding of the circulation of the North Atlantic is required.

Jacobsen (1929) has attempted to account for the shape of T-S curves of stations from the North Atlantic on the basis of the mixing of six primary types of water which can be plotted as points on the diagram. These points $(E, A, C, S, M, \& B)$ and the connecting straight lines used by Jacobsen are reproduced in Fig. 58 along with the mean T-S curve (solid curve) for the Sargasso Sea copied from Fig. 53.

As pointed out by Jacobsen, most T-S curves from the central North Atlantic follow 
closely the S-C line for the major part of their length. But the layer having the characteristics of this part of the curve is comparatively shallow (300-900 meters). Moreover, a study of the "Atlantis" mid-ocean section (Fig. 55) shows that unmixed S water (SubAntarctic intermediate) and $\mathrm{C}$ water (surface water from the central Sargasso region) probably never occur within 1200 miles of each other. Other serious difficulties can be found on attempting to explain the course of Sargasso Sea T-S curves by the scheme advanced by Jacobsen.

An equally preliminary, but perhaps more satisfactory, approach to this problem can be outlined as follows. If the Sargasso Sea were not affected by lateral movements at mid-depths, its waters would be nearly a pure mixture of bottom water and surface water, in which case, the relationship between temperature and salinity could be expressed by a straight line connecting a point close to $\mathrm{B}$ with one near $\mathrm{C}$ on Fig. 58. The variations in the nature of bottom water are very slight, especially in the western basin of the North Atlantic, so that no serious difficulty arises in supposing that the characteristics of bottom water can be represented as a single point on the diagram. For the surface water the situation is more complex. Probably in winter in any given locality, the water is at the lowest limit of the homogeneous surface layer varies only slightly from year to year (Fig. 20). It is also probable that in considering the characteristics of the surface water which are transferred downward through turbulence, the winter conditions are all important, for it is only at this season that wind stirring extends downward to a considerable depth. A plotting of the "Atlantis" winter observations over much of the Sargasso Sea shows a great majority of the points falling near $C^{\prime}$ (Fig. 58), another group near $C^{\prime \prime}$, and a smaller number along the broken line between. Apparently the point $C^{\prime}$ is characteristic of the winter surface conditions in the western and northern Sargasso Sea, where the mixing is most vigorous, and the point $\mathrm{C}^{\prime \prime}$ of the highly saline, central area. It is purely by chance then, that the T-S ratio of the superficial layer over most of the central North Atlantic closely parallels Jacobsen's line SC (Fig. 58).

It seems probable that were it not for lateral movements at mid-depths, internal mixing would produce for the Sargasso Sea a temperature-salinity correlation which could be expressed by a straight line joining the point $B$ with a point $C^{\prime}$. The maximum departure of the mean curve given in Fig. 60 from this simplified situation occurs for $10^{\circ}$ water and amounts only to about $0.4 \%$ on the salinity scale. In other words, the main thermocline layer is only slighly less saline than would be produced by a pure mixture of surface and bottom water. The comparative freshness of the water at mid-detphs seems to be explained by the important rôle which the Sub-Antarctic intermediate layer plays in the western North Atlantic.

There are two ways in which the mid-layers of the Sargasso Sea receive water of relatively low salinity. In the first place, there arrives directly from the south a supply of water having the characteristics of the curved line $S^{\prime} S^{\prime}$, which was constructed from the observations at mid-depths at "Atlantis" stations I 66 and i 67 , situated near the tip of the wedge-shaped Sub-Antarctic intermediate layer (Fig. 55). Secondly, according to Wüst's (I924) figures for the Florida Straits, there is introduced indirectly ${ }^{33}$ in to the Sargasso Sea by way of the Florida Current a large volume (at least $3 \times 10^{6}$ cubic meters per second) of water having the characteristics of the curved line $\mathrm{A}^{\prime} \mathrm{A}^{\prime}$ which was constructed from the "Atlantis" observations in the Florida Current off Cape Canaveral.

\footnotetext{
${ }^{33}$ This water, carrying negative salinity anomalies (Fig. 57), is diluted through horizontal turbulence with the Sargasso water along the right hand edge of the current. Also part of this deficit of salt is carried into the Sargasso Sea via the southern branch of the Gulf Stream System.
} 
The outflow from the Mediterranean is, of course, exerting an opposite effect on the course of the mean T-S curve for the Sargasso Sea. From this source there comes to the northern edge of the Northern Equatorial Current a good supply of relatively saline water. In mid-ocean, the characteristics of this water can be represented by the curve $\mathrm{M}^{\prime} \mathrm{M}^{\prime}$ constructed from the "Atlantis" observations at stations I I62 and I I63 (Fig. 55). Along the southern boundary of the Sargasso Sea the turbulence resulting from the deep wind current mixes the remnants of the Sub-Antarctic intermediate layer with the layer influenced by the outflow from the Mediterranean, thus producing a supply of water of intermediate character which is carried by the wind current to the southwestern Sargasso Sea, where much of it is absorbed in to the Gulf Stream System.

Besides these more active regions of mixing, turbulence is everywhere continually blending together the various primary types of water which are manufactured in the Sargasso Sea, or which are brought thither by currents. The results, for the greater part of the region, is a smooth curve connecting the characteristics of the deep water with those of the surface layer. The dominant part which the Sub-Antarctic intermediate water plays in the shape of this curve is explained both by the relatively large supply of this water entering the North Atlantic and by the current system at a mid-depths set up by the wind in low latitudes. The contrary influence, the Mediterranean water, results from a smaller outflow, which to some extent is prevented by the wind system from spreading westward except in a much diluted state. Moreover, as has been shown by Wüst (1935) part of the Mediterranean influence becomes drawn into the general southward movement which supplies salt to the deeper layers (I 500-2500 meters) of the South Atlantic. A good part of the salt thus lost from the North Atlantic moves south from the under side of the axis of the layer of greatest Mediterranean influence. As Jacobsen (I929) has shown, in the eastern half of the ocean there is a considerable volume of this water which is a direct mixture of Mediterranean (M) water and bottom (B) water.

The scheme outlined in the preceding pages is contrary to the former widespread belief that the Sargasso Sea is a center of sinking. Such direct vertical movements (except in high latitudes) are not supported by the available observations. It seems more probable that the vertical transfer in the Sargasso Sea only takes place extremely slowly through internal turbulence, by which process the surface water is transferred downward on the whole less effectively than the deep water is stirred upward.

This point of view is supported by the following reasoning. The depth scale along the mean T-S curve (Fig. 58) shows that at about 800 meters (the heart of the main thermocline) the percentages of deep water and surface water are approximately equal. In other words, only down to this relatively slight depth does there exist a greater proportion of surface water, while deeper down the characteristics of bottom water quickly begin to predominate, so that at $\mathrm{I} 400$ meters the mixture shows approximately $90 \%$ of the character of bottom water and only I0\% of surface water. Until we can make more exact estimates of the amounts of Sub-Antarctic intermediate water and of Mediterranean water which take part in the Sargasso Sea in the mixture at 700-1 500 meters these estimates are, of course, only roughly approximate. Nevertheless, it is evident that the downward stirring of surface characteristics affects strongly a much less extensive depth zone than the upward mixing of bottom water.

Further support is given to this reasoning when we consider that in the center of the Sargasso Sea the factors causing internal turbulence are at a minimum. Since the area is relatively free from currents, the most effective vertical mixing should occur in the 
deeper layers where the stability is only slight. Except for a short period in winter, the waters of the Sargasso Sea always have considerable stability above a depth of about I 200 meters which must hinder the downward mixing of surface water.

If the above theory be in the main correct, there are two paths by which the upward mixing deep water of various origins leaves the Sargasso Sea. On the one hand, the northern branch of the North Atlantic Current is continually carrying off to the north a considerable volume containing, even at relatively shallow depths (Fig. 3I), a good percentage of water of deep characteristics. On the other hand, as Wüst (I935) has shown, there is also a slow southward seepage into the South Atlantic which is continually removing water from depths just below the main thermocline. This southward flow, carrying water with temperatures of about $4.5^{\circ}$ and salinity of about $35 \%$ (Fig. 32 and 33), contains a high percentage of deep water, mixed only with a small amount of the Mediterranean outflow and an even smaller quantity of water stirred downward from the superficial layers. Thus on the whole both of these outward movements from the Sargasso Sea act as mechanisms whereby the deep water is drawn into the horizontal circulation. While the northern branch of the North Atlantic Current is a fairly direct mechanism for carrying water into the superficial layers, the southward seepage of water into the South Atlantic only approaches the surface on reaching high southern latitudes (Wüst I935).

\section{SUMMARY AND CONCLUSIONS}

I. The "Atlantis" observations (I93I-I934) provide the first adequate and satisfactory data for a study of the broad features of the distribution of temperature and salinity in the western half of the North Atlantic Ocean.

2. Two areas relatively free from current have been examined, namely the slope water and the Sargasso Sea.

3. The permanent currents in the region under consideration fall into two systems: the Northern Equatorial System and the Gulf Stream System. The latter separates the slope water from the Sagrasso water.

4. In both of these regions long period, vertical oscillations have been shown to take place in the depths occupied by the thermocline layer. Such changes accompany variations in the transport of the Gulf Stream System, At the same time, there probably exist also short period changes, possibly tidal in origin.

5. The Northern Equatorial System is directly caused by the trade winds and hence is widespread and, except near the surface, has relatively small velocities. The westerly movement of the water causes a gradual slope upward towards the equator of the water layers constituting the thermocline. Approximately two-fifths of this westerly flow enters the Caribbean and, after being slightly modified by mixing, emerges through the funnellike opening of the Straits of Florida to form the beginning of the Gulf Stream System. A second and probably minor subdivision, known as the Antilles Current, follows the line of the West Indies northwestward and also contributes to the Gulf Stream System. A third and major subdivision, namely the northern part of the trade wind current, moves slowly westward outside (northeast) of the Antilles Current to join the Gulf Stream System south of Cape Hatteras. Finally, there is also absorbed south of Cape Hatteras a considerable volume of water coming from the northeast, supplied in part by the most southern branch of the Gulf Stream, which recurves just east of the Grand Banks. 
6. The Gulf Stream System, in contrast to the pure wind currents of low latitudes, is relatively narrow and swift, being characterized by the steep slope of the isotherms and isohalines across its parth. On the basis of changes in structure, demonstrated by the "Atlantis" sections, this system may be subdivided longitudinally as follows: the Florida Current, the Gulf Stream and the North Atlantic Current.

7. Although the Gulf Stream System is chiefly initiated by the westerly moving wind currents of low latitudes, it seems to be to a large extent unaffected by the prevailing winds of higher latitudes. The narrowing and intensifying of the flow as it parallels the American coast cannot yet be adequately explained. Nor is it understood just what factor causes a branching of the current east of the Grand Banks, from which point on the name North Atlantic Current is appropriate. The paths which these branches follow seem to be largely determined by the topography of the bottom.

8. The northern branch of the North Atlantic Current, which is probably the most vigorous, is relatively shallow and carries water far to the north, away from the general circulatory system surounding the Sargasso Sea. Its path is probably variable, and this fact explains the periodic "transgressions of Atlantic water" described by LeDanois (I935), for the northern branch of the North Atlantic Current in general marks the limit near the surface of water more saline than $35 \%$. The middle branch of the current remains deep as it nears the region off the coast of Europe where the energy is to a large extent dissipated in great eddies. A third subdivision, less clearly defined, appears to curve around sharply to the right and to return more directly to the southwestern Sargasso Sea.

9. Although at mid-depths in the Sargasso Sea temperature and salinity only change extremely gradually in a horizontal direction, the surface layer, at least in winter, shows several sharp zones of salinity transition which separate bodies of water having contrasting densities. While the surface waters of this region were found to be homogeneous down to a sufficient depth so that Ekeman's theoretical studies cannot be criticized on the basis of vertical stratification, the sea is not homogeneous in a horizontal direction. The transition zones between the areas of different density remain sharp, either because of the inability of the adjoining bodies of water to mix readily, or because of shallow currents which are set up in response to the dynamic forces across the boundaries, and which to some extent block the lateral transfer which the wind would otherwise produce.

IO. The loss of water to the north from the great Atlantic eddy is largely compensated for in the Sargasso Sea by the continual absorption from beneath through turbulence of deep water which is predominantly northern in origin. At a shallower depth some northern water (Sub-Arctic) is also being continually absorbed into the northern branch of the North Atlantic Current and thus is returned more directly to the north.

II. The longitudinal transfer across the equator must likewise balance. From the standpoint of the North Atlantic, the intake occurs both above the depth of I 200 meters and near the bottom The southward movement then must occupy the mid-depths.

I2. It has been shown that on the whole the waters of the Sargasso Sea are remarkably constant in temperature-salinity correlation. Therefore the salinity anomaly method is a particularly sensitive one for tracing the slow lateral seepages of water at mid-depths. A study of all available data for the central North Atlantic indicates that there are two great movements of this type which exert widespread influences. The layer centering at 1200 meters and containing a slight admixture of Mediterranean water has been traced as far west as Bermuda and in mid-ocean as far south as the trade wind belt. Here it 
meets and mixes with the remnants of the relatively fresh Sub-Antarctic intermediate layer. The latter, as it penetrates northward from the equator, tends to spread northwestward and a relatively strong concentration of it has been observed in the Florida Current.

I3. While everywhere in the surface layer climatic factors play an all important rôle in controlling the temperatures and salinity of the water, below a depth of about 300 meters in the Sargasso Sea the waters are only modified through internal mixing. In this way, water is slowly absorbed from the Sub-Antarctic intermediate layer in the south and from the layer of Mediterranean influences in the east. The Sargasso Sea loses water in two main directions. In the first place, it contributes in the southwest at all depths to the Gulf Stream System and part of this water escapes to the north. Secondly, it contributes in the southeast water from the deeper layers (1 500-2500 meters) which, along with a mixture of diluted Mediterranean water and bottom water, passes slowly in to the South Atlantic. In no other way can the relatively high salinities at these depths south of the equator be explained.

I4. The relatively slow lateral movements found at mid-depths in the central North Atlantic, though important in the interchange between this ocean and the neighboring seas, do not as greatly influence the temperature-salinity correlation of the mid-layers as does the upward mixing of deep water and the downward stirring of the surface water. The blending through turbulence of the characteristics of these two contrasting layers to a large extent accounts for the temperature-salinity ratio of the thermocline. A consideration of the typical T-S curve of the Sargasso Sea suggests that in this area surface water only exerts a strong influence in a relatively shallow depth zone, and that since little such water is carried away to the north, the region is not such an effective center of sinking as has been generally supposed.

Bigelow, Henry B.

\section{BIBLIOGRAPHY}

1915. Exploration of the coast water between Nova Scotia and Chesapeake Bay, July and August 19I3, by the U. S. Fisheries Schooner Grampus. Bull. Mus. Comp. Zool., Vol. 59, pp. 149-359, 2 pls.

I9I7. Explorations of the U. S. Coast and Geodetic Survey Steamer Bache in the western Atlantic, January-March I9I4. Oceanography. App. V, Rept. U. S. Commissioner of Fisheries, I9I 5 (I9I7), 62 pp., I chart.

1922. Exploration of the coastal water off the northeastern United States in 1916 by the U.S. Fisheries Schooner Grampus. Bull. Mus. Comp. Zool., Vol. 65, pp. 87-1 88 .

1927. Physical Oceanography of the Gulf of Maine. Bull. U. S. Bureau of Fisheries, Vol. 40, Part II, pp. 51 I-1027, 207 figs.

1933. Studies of the waters on the continental shelf, Cape Cod to Chesapeake Bay. I. The Cycle of Temperature. Papers in Phys. Oceanography and Meteorology, Vol. II, No. 4, I35 pp., 66 figs.

Bigelow, Henry B. and Sears, Mary

1935. Studies of the waters on the continental shelf, Cape Cod to Chesapeake Bay. II. Salinity. Papers in Phys. Oceanography and Meteorology, Vol. IV, No. I, 94 pp., 55 figs.

CONSEIL PERMANENT INTERNATIONAL POUR L'EXPLORATION DE LA MER.

1933a. Appendice au Bulletin Hydrographique pour l'annee 193I, 6 pp.

1933b. Bulletin Hydrographique pour l'annee 1932, I I 2 pp., 5 charts.

1934. Bulletin Hydrographique pour l'annee 1933, II 3 pp., 6 charts.

Church, Phil E.

1932a. Surface temperatures of the Gulf Stream and its bordering waters. Geographical Review, Vol. XXII, No. 2. April, pp. 286-293, 7 figs.

1932b. Progress in the investigation of surface-temperatures of the western North Atlantic. Trans. Am. Geophys. Union, Thirteenth Annual Meeting, pp. 244-249, 2 figs.

Defant, AlBERT

1928. Die systematische Erforschung des Weltmeeres. Sonderband zur Hundertjahrfeier der Ges. f. Erdkunde, pp. 459-505, 31 figs., Berlin.

1929. Dynamische Ozeanographie (Einführung in die Geophysik III). 222 pp., 87 figs., Berlin.

1935. Der äquatoriale Gegenstrom. Sitzungsberichten der Preussichen Akademie der Wissenschaften, Phys.-Math. Klasse, 1935. XXVIII, pp. I-25 $(450-472)$, I 2 figs.

1936. Schichtung und Zirkulation des Atlantischen Ozeans. III Lieferung. Die Troposphäre. Wissenschaftliche Ergebnisse der Deutschen Atlantischen Expedition auf dem forschungs- und vermessungsschiff "Meteor' I 925-1927, Band VI, Teil I, pp. 289-4I I, Figs. 49-76, Pls. XXXVI-LIV. 
Dietrich, G.

1936. Aufbau und Bewegung von Golfstrom und Agulhasstrom, eine vergleichende Betrachung. Die Naturwissenschaften, 24 Jahrg. Heft I 5, Pp. 225-230, i figs.

EKMAN, V. WALFRID

1928. A Survey of some Theoretical Investigations on Ocean-Currents. Journal du Conseil. Cons. Perm. Internat. pour l'Exploration de la Mèr, Vol. III, No. 3, pp. 295-327, x 3 figs.

Harwood, T. Monroe and Brooks, Charles F.

1933. Monthly sequence of sea-surface temperature on the New York-San Juan steamship route. Trans. Am. Geophys. Union. Fourteenth Annual Meeting, pp. I73-1 80, 2 figs.

Helland-Hansen, BJörn

19I 8. Nogen hydrografiske metoder. Forhandlinger ved de skandinaviske naturforskerer I6 de mote i. Kristiania IO-I 5 juli I 916 , Oslo, I9I8.

1930. Report of the scientific results of the "Michael Sars" North Atlantic deep-sea expedition I9IO. Vol. I. Physical Oceanography and Meteorology. II 5 PP., 47 figs., Bergen.

Helland-Hansen, Björn, and Fridtjof NanSEN

1926. The eastern North Atlantic. Geofysiske Publikasjoner Vol. IV, No. 2: utgitt av det Norske Videnskaps-Akademie i Oslo, 76 pp., 71 pls., 19 text figs., Oslo.

Huntsman, A. G.

1924. Oceanography. Handbook of Canada. British Association for the Advancement of Science, Toronto meeting, August I 924 , pp. $274-290$, figs. $32-36$. Toronto.

International Ice Observation and Ice Petrol Service in the North Atlantic Ocean. I9I 3-I936. U. S. Coast Guard Bulletins, Nos. I-I9, Washington.

ISELIN, C. O'D.

1930. Recent work on the dynamic oceanography of the North Atlantic. Trans. Am. Geophys. Union, Tenth Annual Meeting, pp. 82-89, 9 figs.

1933. The development of our conception of the Gulf Stream. Trans. Am. Geophys. Union, Fourteenth Annual Meet ing, pp. 226-231, 3 figs.

I934. Temperature-salinity correlation within the Florida Current. Trans. Am. Geophys. Union, Fifteenth Annual Meeting, pp. 208-209.

JACOBSEN, J.P.

1927. Eine graphische Methode zur Bestimmung des Vermischungskoeffizienten im Meere. Gerlands Beiträge Geophysik. Bd. XVI, Heft 4, pp. 4O4-4I2

1929. Contribution to the hydrography of the North Atlantic. Danish "Dana" Expedition I920-22. Oceanographical

reports No. 3,98 pp., 63 figs.
Koninklijh Nederiandsch Meteorologisch Institudt.

1918. Publ. No. I IO, Oceanographische en Meteoroligische Waarnemingen in den Atlantischen Ocean,1870-1914. Atlas, 4 vols., Amsterdam.

KRÜмmel, OTto

189I. Die nordatlantische Sargassosee. Petermann's Mitteilungen, Bd. 37, I29 pp., I chart.

Le Danois, ED.

I934. Les transgressions océanique. Off. Sci. Tech. Pêches Maritimes, Revue des Travaux, Tome VII, Fasc. 4, No. 28, pp. $369-462,50$ figs., Paris.

Merz, A. AND Wüst, G.

I922. Die atlantische Vertikalzirkulation. Zeitschr. Ges. f. Erdkde. zu Berlin. Nr. I/2, pp. I-35, figs. I-9.

NiELSEN, J. N.

I9I 2. Hydrography of the Mediterranean and adjacent waters. Report on the Danish Oceanographical Expeditions 1908-1910, Vol. I, No. 2, pp. 77-r9r, 19 figs., XI plates.

1925. Golfstrommen. Saertryk af Geografisk Tidskrift, Bind 28, Heft I, March, I I pp., 5 figs., Copenhagen.

PARr, A. E.

I933. A geographic-ecological analysis of the seasonal changes in temperature conditions in shallow water along the Atlantic coast of the United States. Bull. Bingham Oceanographic Coll., Vol. IV, pp. I-90, 28 figs.

1935. Report on hydrographic observations in the Gulf of Mexico and the adjacent straits made during the Yale Oceanographic Expedition on the "Mable Taylor" in I932. Bull. Bingham Oceanographic Coll., Vol. V, Art. I,

Perlewtiz, P. 3 pp., 33 figs.

I908. Ozeanographisch Versuche und Beobachtungen an Bord S.M.S. "Möwe" und S.M.S. "Zieten" im Sommer 1907. Ann. d. Hydrographie und Maritimen Meteorologie, XXXVI Jahrg. (1908), Heft I, pp. I-5.

Rakestraw, Norris W.

1933. Studies on the Biology and Chemistry of the Gulf of Maine. I. Chemistry of the Waters of the Gulf of Maine Rossby, C.-G. in August, I932. Biol. Bull., Vol. LXIV, pp. I $49^{-1} 58,4$ figs.

1936. Dynamics of steady ocean currents in the light of experimental fluid mechanics. Papers in Phys. Oceanography RUPPIN, E. and Meteorology, Vol. V, No. I, 43 Pp., 26 figs., II charts.

1906. Umkippthermometer als Tiefenmesser. Wissenschaftliche Meeresuntersuchungen N.F. Band IX, Nr. 5, Abt. Kiel I906, pp. I82-183.

SANDSTRöm, J. W.

1919. The hydrodynamics of Canadian Atlantic waters. Canadian Fisheries Expedition, 19r4-15 (1919), Department of the Naval Service, pp. 22I-343, 59 figs., Pls. I-XV, Ottawa. 
Schumacher, Arnold

1923. Neue Hilfstafeln für die Umkippthermometer nach Richter und Beiträge zur thermometrischen Tiefenmessung. Ann. d. Hydrographie und Maritimen Meteorologie, LI Jahrg. (I923), Heft XII, pp. 273-280, Tab. I2-I3.

1935. Neuere Arbeiten über den Golfstrom im westlichen Atlantischen Ozean. Ann. d. Hydrographie und Maritimen Meteorologie, LXIII Jahrg. (I 935 ), Heft II, pp. 53-58, 5 figs.

SVERDRUP, H. U.

I932. Arbeider i luft-og havforskning. Chr. Michelsons Institut, Beretninger II, 5, 20 pp., 3 figs. Bergen.

Winge, $O$.

I923. The Saragasso Sea, its boundaries and vegetation. Report on the Danish Oceanographical Expeditions 1908I gIo, Vol. III (Miscellaneous Papers) No. 2, 34 pp., I7 figs. and charts.

WÜST, GeORG

I924. Florida- und Antillenstrom, eine hydrodynamische untersuchung. Veröff. d. Inst. f. Meereskunde. N.F., Reihe A, Heft I2, pp. 5-49, 6 figs., I plate.

1929. Schichtung und Tiefenzirkulation des Pazifischen Ozeans. Veröff. d. Inst. f. Meereskunde, N.F., A, Heft 20, pp. 5-63, I4 figs., IV plates.

I930. Der Golfstrom, Zeitsch. Ges. f. Erdkde. zu Berlin. Nr. I/2, pp. 42-59, Figs. I 5-2I.

1932. Oceanographische Methoden und Instrumente. Abschnitt B. Thermometrische Tiefenmessung. Wissenschaft. liche Ergebnisse der Deutschen Atlan tischen Expedition auf dem forschungs- und vermessungsschiff "Meteor" I $925-27$, Band IV, Erster Teil, pp. 60-177, Figs. I0-18, Tab. 2I-42.

1933. Schichtung und Zirkulation des Atlantischen Ozeans. I Lieferung. Das Bodenwasser und die Gliederung der Atlantischen Tiefsee. Wissenschaftliche Ergebnisse der Deutschen Atlantischen Expedition auf dem forschungsund vermessungsschiff "Meteor" I 925-1927, Band VI, Teil II, Pp. I-Io6, Figs. I-I6, Pls. I-VIII.

1934. Das Golfstromproblem, "Tiefseebuch" (Bd. III der Sammlung "Das Meer"). pp. I25-I42, Figs. 62-68, Pls. XIII-XVI, E. S. Mittler und Sohn, Berlin.

1935. Schichtung und Zirkulation des Atlantischen Ozeans. II Lieferung. Die Stratosphäre. Wissenschaftliche Ergebnisse der Deutshcen Atlantischen Expedition auf dem forschungs- und vermessungsschiff "Meteor" 1925-1927, Band VI, Teil I, pp. I09-288, Figs. I 7-48, Pls. IX-XXXV. 